Portland State University

PDXScholar

1989

\title{
Social construction of sexual equality in distilled beverage advertising
}

Kathleen Dianne LeCoe-Cannucci

Portland State University

Follow this and additional works at: https://pdxscholar.library.pdx.edu/open_access_etds

Part of the Feminist, Gender, and Sexuality Studies Commons, Gender and Sexuality Commons, and the Public Relations and Advertising Commons

Let us know how access to this document benefits you.

\section{Recommended Citation}

LeCoe-Cannucci, Kathleen Dianne, "Social construction of sexual equality in distilled beverage advertising" (1989). Dissertations and Theses. Paper 4058.

https://doi.org/10.15760/etd.5942

This Thesis is brought to you for free and open access. It has been accepted for inclusion in Dissertations and Theses by an authorized administrator of PDXScholar. Please contact us if we can make this document more accessible: pdxscholar@pdx.edu. 
AN ABSTRACT OF THE THESIS OF Kathleen Dianne LeCoe-Cannucci for the Master of Science in Sociology presented July 6, 1989.

Title: Social Construction of Sexual Equality in Distilled Beverage Advertising.

APPROVED BY THE MEMBERS OF THE THESIS COMMTTEE:

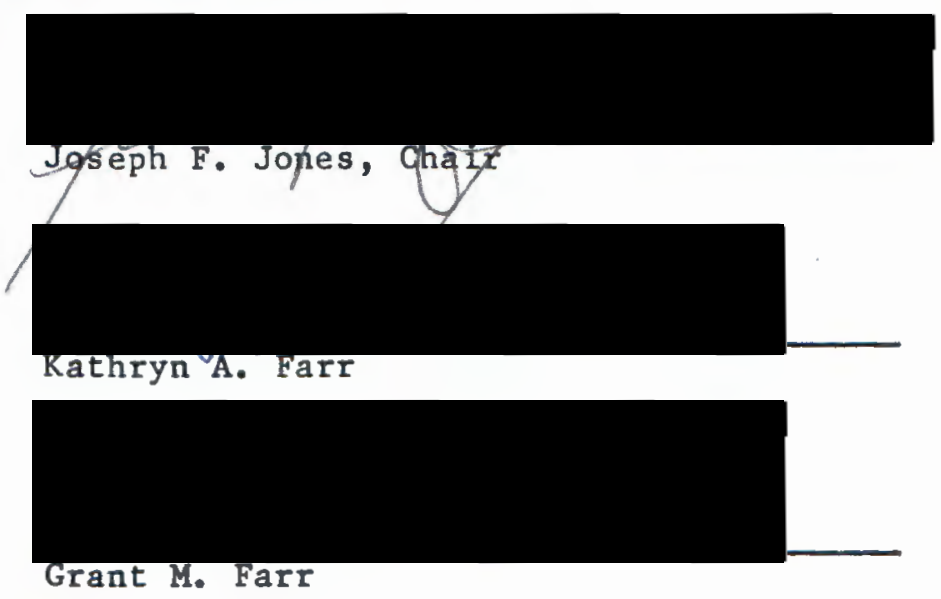

One aspect of the role of advertising in the process of maintaining and reinforcing or challenging the socially constructed worlds of maleness and femaleness, and especially the portrayal of the "woman's place," was explored in this study.

Distilled beverage advertisements were chosen as a focus because women have been included in such advertisements only in relatively recent times. An examination of this advertising was conducted to 
ascertain if it represented a new format or context for transmitting the message of greater sexual equality as a construction in a realm of advertising and behavior traditionally associated with the masculine image.

Two questions guided the design and execution of the research. First: Does the inclusion of women in distilled beverage advertising reflect that they now can be regarded as more co-equal consumers, or is their inclusion under the guise of sexual equality a mask for the exploitation of women through a continuation of the traditional presentation of them as sex objects for the solicitation of the intended market, men? A second question addressed is: What impact does the relaxation of laws, rules and regulations restricting the usage of women in distilled beverage advertising in fact have upon the inclusion and portrayal of women in such advertising?

To address these questions, as developed in the form of hypotheses, content analysis was employed in the examination of a non-random sample of distilled beverage advertisements drawn from three different audience appeal magazines: Playboy, Cosmopolitan, and Newsweek. The time period of this sample spanned the years 1958 (when the ban which excluded women in such advertising was lifted) to 1985.

Analysis of the data did not support the position that the inclusion of women in such advertising could be regarded as a vanguard for social change in the socially constructed reality of the worlds of maleness and femaleness. Rather, the findings indicated quite clearly that the "woman's place" in such advertising was in the traditionally exploitive role of sex object. 
Further, little support was found that the laws, rules and regulations addressing the place of women in such advertising appeared to have any impact on the portrayal of women over time. of course, this analysis was only of one type of beverage alcohol advertising--distilled beverage. As such, a recomendation for further research in this area was suggested. 
SOCIAL CONSTRUCTION OF SEXUAL EQUALITY IN

DISTILLED BEVERAGE ADVERTISING

by

RATHLEEN DIANNE LECOE-CANNUCCI

A thesis submitted in partial fulfillment of the requirements for the degree of

\author{
MASTER OF SCIENCE \\ in \\ SOCIOLOGY
}

Portland State University 


\section{TO THE OFFICE OF GRADUATE STUDIES}

The members of the Committee approve the thesis of Kathleen Dianne LeCoe-Cannucci presented July 6, 1989.

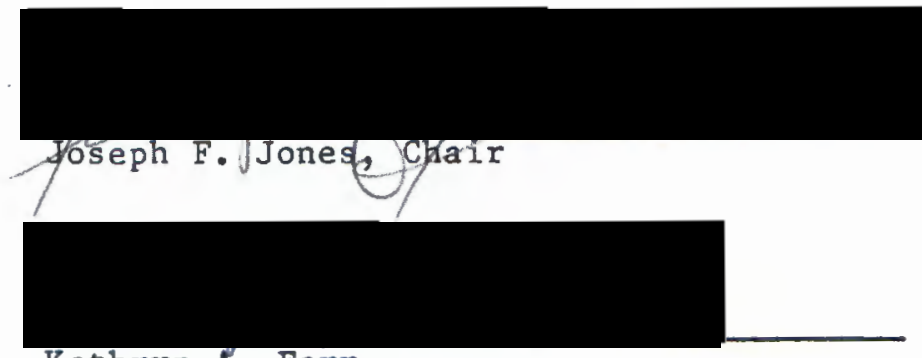

Kathryn A. Farr

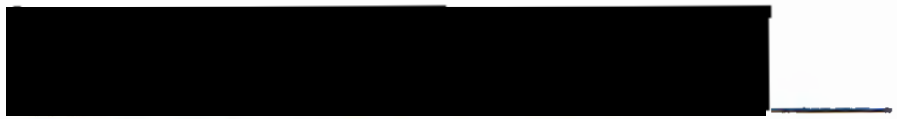

Grant M. Farr

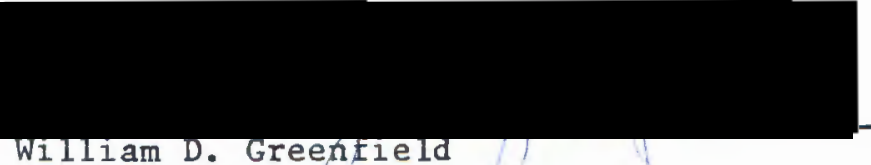

William D. Greentield

APPROVED :
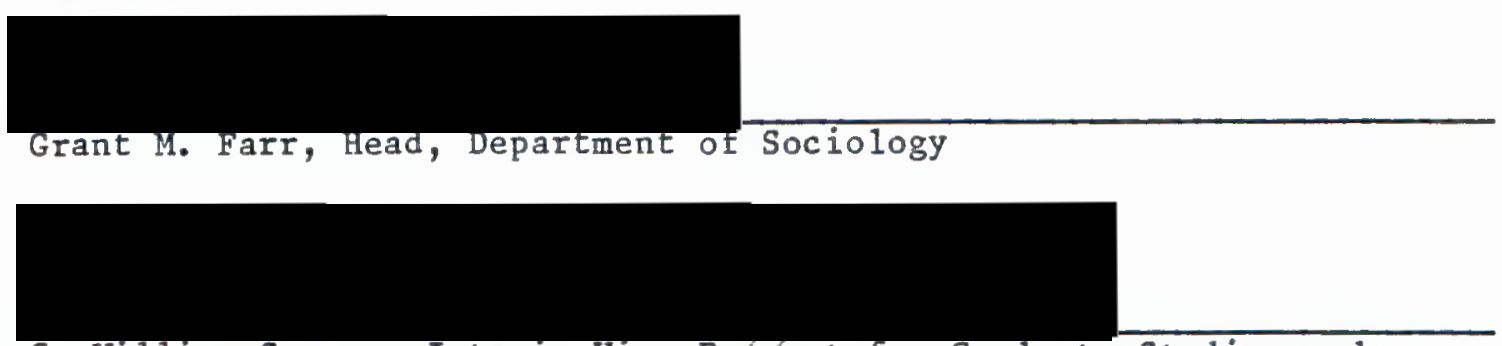

C. William Savery, Interim Vice Provost for Graduate studies and Research 


\section{ACKNOWLEDGEMENTS}

Nothing is accomplished without the interaction of caring, supportive, and committed individuals. This was certainly the case in the completion of this thesis.

First and foremost, I wish to express my sincere gratitude to the members of my thesis committee, Dr. Joseph Jones, Dr. Kathryn Farr, Dr. Grant Farr, and Dr. William Greenfield for their dedicated comitment to getting this thesis done. Dr. Joseph Jones as chairperson is especially thanked for his considerable patience, support and assistance with every aspect of this endeavor including his commitment to reteach me the English language. Special thanks is also extended to Dr. Kathryn Farr for her willingness to go beyond the call of duty in helping to support me in meeting some very important deadines. Without this help, I know this thesis would not have been completed. My gratitude is also extended to Dr. Lee Haggerty who although not on my committee responded as if nothing was more important than helping me not on ly complete the methodological procedures needed for this thesis, but to understand these procedures. Such dedication oftentimes goes unnoticed; I wish Dr. Haggerty to know it did not.

To Lynn Worman, friend and confidant, I express my special appreciation for not only willingly opening up her home to me in order 
to get the space needed to complete this thesis, but for always being there with a helping hand, a gentle nudge and a shoulder I could lean on when I needed it most.

Finally, I wish to give special acknowledgement to two individuals who gave me the drive and perseverance to complete this project even when there were times I wanted to throw my hands up and scream "enough"--my daughters, Jamie Michelle and Angela Jaie. To you two, I wish to say two things: First, I love you very much, especially for all you sacrificed for the completion of this project, and second, mom is finally done with her thesis. 
TABLE OF CONTENTS

PAGE

ACKNOWLEDGEMENTS ....................... iii

LIST OF TABLES • . . . . . . . . . . . . . . . . . . . viii

CHAPTER

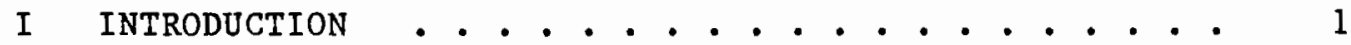

I I THEORETICAL FRAMEWORK . . . . . . . . . . . 6

Historical Production of Gender Roles:

"Externalization" . . . . . . . . . . . .

Prehistoric Period

Biblica 1 Period

Freudian Period

The "Objectivation" of Gender Roles . . . . . . . 16

The Production of People: "Internalization" . . . 25

III DESCRIPTION OF THE PROBLEM . . . . . . . . . . 30

Advertising as Communication . . . . . . . 33

The "Woman's Place" in Advertising . . . . . . 38

The Representation of the Employed Woman Versus the Housewife in Advertising

The Representation of Woman as Sex object in Advertising

Woman's Inequality and Advertising . . . . . . .

The American History of Alcohol Use and the

"Woman's Place". . . . . . . . . . . .

The Colonial Era

The Victorian Era

The Modern Era 
The "Woman's Place" and Alcohol Advertising . . . 64 METHODOLOGY . . . . . . . . . . . . . 72

Population . . . . . . . . . . . . . 72

Source of the Sample . . . . . . . . . 73

Development of the Coding Sheet . . . . . . . 75

Themes and Appeals

Portrayals of Human Models

Techniques of Presentation

Target Market

Intercoder Reliability

Data Collection Procedures . . . . . . . . 86

Data Preparation and Analysis . . . . . . . 87

Data Preparation

Data Analysis

Limitations . . . . . . . . . . . . . 91

V FINDINGS . . . . . . . . . . . . . . . . . 93

Description of the Total Sample and Human Models

Sample . . . . . . . . . . . . . 93

Techniques of Presentation

Themes and Appeals

Era and Target Market

Description of the Human Models Sample . . . . 106

Relevant Characteristics of Human Models

Human Model Groups With and Without Sexual

Connotations . . . . . . . . . . . 116

Techniques of Presentation

Relevant Characteristics

Era

Target Market

Themes and Appeals: Separate

Themes and Appeals: Recoded

Evaluation of the Hypothesis . . . . . . . 152 
vii

PAGE

VI SUMMARY AND DISCUSSIONS . . . . . . . . 156

REFERENCES . . . . . . . . . . . . . . . . . . . 163

APPENDICES

A IN-DEPTH CODING SHEET . . . . . . . . . . . . 177

B ABBREVIATED FORM OF CODING SHEET . . . . . . . . . . 184

C COMPUTER CODING OUTLINE . . . . . . . . . . . . 186 


\section{LIST OF TABLES}

I Frequencies of Themes Per Advertisement . . . . . . .

II "Techniques of Presentations" Variables for the Total

Sample and Human Models Sample in Number and

Percent . . . . . . . . . . . . . .

II "Techniques of Presentation" For Human Models: In

Number and Percent . . . . . . . . . . . .

IV Total Sample and Human Model(s) Sample: "Themes and

Appea ls" Variables: Separate, in Number and

Percent . . . . . . . . . . . . . . .

V Total Sample and Human Model(s) Sample: "Themes" and

Appeals" Variables: Recoded, in Number and Percent

VI Distilled Beverage Advertisements for Era and "Target

Market" and "Target Market" by Era for the Tota1

Sample and Human Models Sample in Number and Percent 103

VII "Relevant Characteristics"--Presentation--of Human

Models, in Number and Percent . . . . . . . 108

VIII "Relevant Characteristics"--Dress--of Human Mode1s,

in Number and Percent ........... 109

IX "Relevant Characteristics"--Focus of Attention--of

Human Models, in Number and Percent . . . . . . 110 
PAGE

X "Relevant Characteristics"--Relational Postures and

Physical Proximity--of Human Models, in Number

and Percent ... . . . . . . . . . . . .

XI Gender Depiction in Ads (Including Couples), in Number and Percent . . . . . . . . . . . . 114

XII Human Model Ads With and Without Sexual Connotation by

Gender (Including Couples), in Number and Percent .

XIII "Techniques of Presentation" for Female Only

Advertisements With and Without Sexual Connotations

in Number and Percent . . . . . . . . . . .

XIV "Techniques of Presentation" for Male Only Advertise-

ments With and Without Sexual Connotations in

Number and Percent . . . . . . . . . . .

XV "Techniques of Presentation" for Mixed Company

Advertisements With and Without Sexual Connotations

in Number and Percent .... . . . . . . . .

XVI "Techniques of Presentation" for Couples Only

Advertisements With and Without Sexual Connotations in Number and Percent . . . . . . . . . . .

XVII "Relevant Characteristics" for Female Only Advertisements With and Without Sexual Connotations: Presentation, Physical Proximity, Focus of Attention, Relational Postures, and Dress..... 
XVIII "Relevant Characteristics" for Male Only Advertisements With and Without Sexual Connotations: Presentation, Physical Proximity, Focus of Attention, Relational Postures, and Dress .... 132

XIX "Relevant Characteristics" for Mixed Company Advertisements With and Without Sexual Connotations: Presentation, Physical Proximity, Focus of Attention, Relational Postures, and Dress..... 134

XX "Relevant Characteristics" for Couples Only Advertisements With and Without Sexual Connotations: Presentation, Physical Proximity, Focus of Attention, Relational Postures, and Dress .....

XXI "Era" in Number and Percent for all Groups Advertisements With and Without Sexual Connotations . . .

XXII Target Market in Number and Percent for all Groups

With and Without Sexual Connotations ......

XXIII Themes and Appeals: Separate, in Female Only and Male Only Advertisements with and without Sexual Connotations, in Number and Percent .......

XXIV Themes and Appeals: Separate, in Mixed Company and Couples Only Advertisements with and Without Sexual Connotations, in Number and Percent .... 
XXV Themes and Appea1s: Recoded, in Female Only and Male

Only Advertisements With and Without Sexual

Connotations and Number of Themes Per Ad, in

Number and Percent . . . . . . . . . . .

XXVI Theme and Appea1s: Recoded in Mixed Company and

Couples Only Advertisements With and Without Sexual

Connotations and Number of Themes Per Ad, in

Number and Percent . . . . . . . . . . .

XXVII Themes and Appeals Portrayed for Each Gender Type in

Percentages . . . . . . . . . . . . . . 
CHAPTER I

\section{INTRODUCTION}

Without fear of contradiction it may be asserted that in numerous ways the activities and images of women have undergone major changes within the past few decades. In the worlds of work, sports and education, to list only a few, women are currently engaging in behaviors which would have been unheard of only a short time ago. However, it is the case that more nearly equal participation does not necessarily imply more equal acceptance nor more equal treatment. As will become apparent, women have become a larger share of the market for distilled beverages, and, in relatively recent times, women have been included in magazine advertising for distilled beverages. Such advertising is, in and of itself, controversial in the public view; as Marsteller and Karnchanapee (1980: 1) point out, beverage alcohol is obviously "different in character from soap or cereal."

One aspect of distilled beverage advertising "that has been carefully controlled for many years is the use of women to promote sales of [such] beverages" (Marsteller and Karnchanapee, 1980:1). This was so because the reality of the proper place constructed for women, especially in the pre-Prohibition era, was simply "ladies don't drink." 
Thus when National Prohibition was repealed in 1933, specific policies adopted by members of the distilling industry were added to the various federal and state laws in a concentrated effort to avoid any revivification of the temperance movements that put them out of business (Marsteller and Karnchanapee, 1980: 1; a1so see Lender and Martin, 1982).

One specific policy enacted in 1936 by the Distilled Spirits Institute, an industry trade group now named the Distilled Spirits Council of the United States (DISCUS), was an advertising code which banned, among other things, the portrayal of women in the advertising of distilled beverages. This Code of Good Practice was the evidence that distillers were very much concerned with public acceptance (United States Congress, Senate Committee on Labor and Public Welfare, Subcommittee on Alcoholism and Narcotics, 1976: 213).

This concern was apparently quite justified in terms of accepted views of the traditional woman's place and of accepted views of women as consumers of alcoholic products, views which continued for some time after the repeal of Prohibition. However, World War II brought about major economic changes, especially the increased number of women in the work force and the concomitant importance of women as active consumers of a range of economic goods. One consequence of this and other changes was a shift in what were seen as appropriate roles for women generally, and specifically the emergence of new patterns of drinking behavior among women, and of new sets of attitudes toward such drinking (see Whitehead and Ferrence, 1976; Wilsnack, 
1976; Ratliff and Burkhart, 1984), although concern still exists regarding the woman's place (see Belfer et al., 1971; Wilsnack, 1976; McLachlan et a1., 1979).

Partially as a result of these changes, DISCUS relaxed the ban on the use of women in distilled beverage advertising on November 20 , 1958, but with a note that such advertising only be allowed if done in a "dignified" manner and in "good taste." This is how the Code of Good Practice is stated today (Marsteller and Karnchanapee, 1980: 1, 4).

But as research has suggested (see inter alia: Busby, 1975; Tuchman, 1979; Butcher et a1., 1981), women have only been featured in the advertising process in one of two capacities: "as most sollicited (sic) consumers and as instruments of persuasion" and in these capacities only by virtue of her two-dimensional role: "her role as housewife/mother/wife and her function as a decorative and sexual object" (Ceulemans, 1979: 3).

Which is the "real" role of women in distilled beverage advertising is the essential focus of this study. More specifically, "Is the portrayal of women in distilled beverage advertising more a reflection that now women can be regarded as co-equal consumers of a product traditionally associated with the masculine role or is such a portrayal more a reflection of the use of women to promote sales of liquor through sexually exploitative advertisements for the real intended market, men?" 
In relation to the notion of how one comes to define what is real in this world, Peter Berger and Thomas Luckmann have argued that "reality is socially constructed" (1967: 1).

In other words, people create that which is defined as real. Thus, included in this study is the theoretical question of just what kind of reality is being reinforced and maintained or challenged with the recent inclusion of women in distilled beverage advertising.

To summarize: The purpose of this study is to explore, focusing specifically on an examination of distilled beverage advertisements, how the social construction of reality of the worlds of "maleness" and "femaleness" are either reinforced and maintained or challenged as the only real way to be.

This investigation is introduced in Chapter II by drawing upon the theoretical framework provided by Berger and Luckmann as to how the worlds of maleness and femaleness have been socially constructed.

Provided in Chapter III is a review of literature dealing with women's drinking behavior historically, the role of advertising in the construction and maintenance of reality, and the utilization of women in advertisements for distilled beverages. Based upon this literature, the hypotheses to be evaluated are derived and stated.

The methodology of this study is presented in Chapter IV where the operationalization of concepts, the derivation of a research instrument, and specification of a sample frame of distilled beverage advertisements are explained. Additiona11y, certain study limitations are $\mathrm{listed.}$ 
Reported in Chapter $\nabla$ are the specific findings including the descriptions of the overall sample and subsample of specific human model groups. Also included in the final section of this chapter is the evaluation of the hypothesis.

Chapter VI completes the study with a summary of the main findings and suggestions for further research. 
CHAPTER II

\section{THEORETICAL FRAMEWORK}

Some social facts are truisms. Little boys don't grow up to be pretty; maybe good looking, rugged looking, or even distinguished looking, but surely not pretty. Likewise, little girls don't grow up to be virile; maybe sexy, demure, or even nymphomanical, but surely not virile. Without fear of contradiction it can be asserted that being a woman is very different from being a man. This reality is simply taken for granted. Put another way, being male, or being female, involves inhabiting a social world as much or more as it involves possessing specific biological characteristics.

This study examines one aspect of the creation of the "worlds" of "maleness" or "femaleness," focusing specifically on an examination of distilled beverage advertisements. To be examined are how these worlds are maintained and reinforced or challenged as the only real way to be, and how this "reality" reflects views of gender equality. But, as Kenneth Plummer (1975: 10) points out, ". . the way to begin any sociological inquiry is to start with the formulation of a theoretical perspective."

One theoretical perspective that specifically addresses the process of how coming to know what is "real" or what is taken for granted as "knowledge" is that contained in Peter L. Berger and Thomas Luckmann's The Social Construction of Reality (1967). 
Berger and Luckmann's (1967: 3) basic contention is that:

Al1 human "knowledge," or whatever passes for "knowledge" in a society, regardless of the ultimate validity or invalidity (by whatever criteria) of such "knowledge," . . is developed, transmitted and maintained in social situations .. . in such a way that a taken-for-granted "reality" congeals for the man in the street.

In other words, "reality is socially constructed" (Berger and Luckmann, 1967: 1); a product of a reciprocal relationship between typifications of individuals (both existing prior to individuals and negotiated by individuals in their everyday interactions) and the social environments in which they live (1967: 3, 16, 21, 23).

Before considering the creation of the "worlds" of "maleness" and "femaleness," a distinction needs to be made between sex and gender, for as has been pointed out (see, e.g., Stoller, 1968; Millett, 1970; Chafetz, 1974; Walum, 1977; Lipman-Blumen, 1984), there exists a great deal of confusion in both academic and general public discussions concerning these two terms. Laurel walum succinctly makes the distinction between sex and gender. She states (Walum, 1977: 5):

Sex refers to the biological aspects of a person such as the chromosomal, hormonal, anatomical, and physiological structure. It is an ascribed status in that a person is assigned to one sex or the other at birth. Gender refers to psychological, social, and cultural components. Unlike sex, it is an achieved status. People learn what behaviors and attitudes they should have according to their label-male or female (original emphasis).

In other words, the worlds of maleness and femaleness are social constructions of reality. Given this, there remains the question of how these worlds have been created and the degree to which they reflect equality or inequality. 
According to Berger and Luckmann (1967: 47), human beings have no "species-specific" environment, one that is structured by instinctual organization. Rather, "men together produce a human environment, with the totality of its socio-cultural and psychological formations" (1967: 51; original emphasis and gender). That is, in a particular natural environment and a specific cultural and social order, human beings develop ways of becoming and being human in as numerous ways as there exist cultures, in that "the human organism lacks the necessary biological means to provide stability for human conduct" (1967: 51 ).

Further, Berger and Luckmann (1967: 61) argue that the human origin of social realities is a three-fold dialectical process which they define as moments corresponding "to an essential characterization of the social world." Specifically, "externalization" is the "moment" where human beings, through their interaction and habitualization of actions, actively produce their world; defining such things as the economic arrangements, the technological arrangements, and just the everyday arrangements such as who will do what, when, and where (1967: 52-53). The second moment, "objectivation," is "the process by which the externalized products of human activity attain the character of objectivity"; in essence, where the social world (the product) "acts back upon the producer," as if it has a "reality" of its own (1967: 60-61). "Internalization," the third moment, is the process by which "the objectivated social world is retrojected into consciousness in the course of socialization," thereby making human beings products in and of themselves (1967: 61). Basically, Berger and Luckmann's 
contention is: "Society is a human product. Society is an objective reality. Man is a social product" (1967: 61; original emphasis and gender).

George Ritzer perhaps best outlines the direction that research following Berger and Luckmann's argument (1980: 250-51) should take:

First, we should study the way in which people historically produce society and its social structures and social institutions. Second, as a result of this process, we should be concerned with the way in which society becomes an objective reality. Finally, we should examine the way in which society, once it has achieved objective facticity, produces people through socialization and other ways.

HISTORICAL PRODUCTION OF GENDER ROLES: "EXTERNALIZATION"

Jean Lipman-Blumen (1984) addresses the first step in the social construction of the worlds of maleness and femaleness when she makes the point that much of the differential between gender roles is assumed to be rooted in sex roles. As she explains, roles assigned to each gender seem to stem from cultural elaborations of biological sex roles where "the threads of sex and gender roles are so intricately interwoven that most observers believe the current patterns have always existed" (1984: 2-3).

Obviously, bearing children is biologically possible only within the female sex role. That the female assignment of nurturing and rearing is not biologically inevitable is seen from the fact that some men, as well as women who have never given birth, have reared children. Theoretically, then, childrearing could be part of either gender role. Still, in most societies childrearing is assigned to females and becomes central to the female gender role, with the result that childrearing is treated as if it were a biological imperative for female (Lipman-Blumen, 1984: 2; original emphasis). 
Even today, the woman's behaviors (e.g., sitting up all night with a sick child, making birthday cakes), or values and attitudes ("This is the way it should be; I'm responsible for my child's welfare") are thought to be "natural," a biological given.

Yet, these images of the appropriate roles of women, and likewise of men, taken as if they were natural can be traced to developments in three historical periods: prehistoric, biblical, and Freudian.

\section{Prehistoric Period}

According to Berger and Luckmann (1967: 53), "A11 human activity is subject to habitualization," a repeated action that frequently becomes cast into a pattern and which is "apprehended by its performer as that pattern." This is so, they point out (1976: 53), because "habitualization carries with it the important psychological gain that choices are narrowed," that "tensions" are relieved from "undirected drives."

It appears, according to Chafetz (1974) and Lipman-Blumen (1984), that while speculations about gender role images in ancient civilizations are complex and conflicting, there does seem to be some evidence that in the earliest societies females had a great deal of prestige and, perhaps, power that stemed from their "natural" female life forces--specifically in their abilities to menstruate without succumbing to blood loss, to produce children (males and females) without any apparent male contribution, to produce life-sustaining milk for these children, and to still exhibit a sexuality that seemed endless (Lipman-Blumen, 1984: 70). 
Using Berger and Luckmann's argument, it seems that at least to some extent, that because it was on $1 y$ females, and not males, who could repeatedly be the "life-bearers," typifications about "femaleness" and "maleness" developed depicting females and not males as "metaphysically supreme."

To further understand how typifications, such as these, came to be, the work of Alfred Schutz (1962: 149) provides some guidance:

All typifications of common-sense thinking are themselves integral elements of the concrete historical sociocultural [worldview] within which they prevail as taken for granted and as socially approved. Their structure determines among other things the social distribution of knowledge and its relativity and relevance to the concrete social environment of a concrete group in a concrete historical situation.

Put simply, given the time and the "knowledge" available, it is of little wonder that women were viewed with awe and reverence in respect to their "femaleness."

Yet, as Lipman-Blumen (1984: 70) points out, there did seem to exist a hostility and fear as well as awe in relation to these "natural" forces; thus, "residues of ancient civilization depict women not only as life-bearers and goddesses, but also as witches, spell casters, contamination breeders, and death carriers."

Nonetheless, the social reality of female metaphysical supremacy, according to Lipman-Blumen (1984: 70$)$, seems to have continued until the recognition of the male contribution to conception developed. Then things seemed to change drastically. This shift, according to Lipman-Blumen (1984: 70-71) involved among other things, changes in magic worship such that whereas previously the female genitalia had been an important focus, the phallus became the center of 
attention. Similarly, animals which were the quarry of men supplanted the crop cultivation of women which had been featured in Paleolithic mythology. Concommitantly, the social importance of male shamans superseded the previous power of female gods. An additional transmogrification in classical Greek mythology substituted a reverence for the female's procreative and sexual prowess with an emphasis upon the danger of the woman's sexuality implied by the power of seduction and destruction of the male's strength: personal, political and social. In essence, a new reality was posited: that of a patriarchal order which proposed a male metaphysical supremacy rather than a female one. But if female metaphysical supremacy was reality, how could this nearly complete reversal come about?

Berger and Luckmann (1967: 103) offer an answer to this question when they point out that "all social reality is precarious. Al1 societies are constructions in the face of chaos" (original emphasis). This is so, they argue, because of "the very fact that all social phenomena are constructions produced historically through human activity" and therefore, can be "incipiently problematic." The degree to which they are problematic is the only question (1967: 106; original emphasis). Further, since a "problematic construction" can come about in several ways, e.g., in the transmission of the social reality from one generation to another, in different versions of reality that challenge the status quo, and/or in confronting other societies which may have very different histories, no society can be "totally taken for granted" (1967: 70-71). 
As previously discussed, Lipman-Blumen (1984: 70-71) interprets the shift in "realities" to be a consequence of the recognition of the male's contribution to conception, in other words, a different version of reality that challenged the status quo. Berger and Luckmann also offer an explanation for this particular shift by explaining how societies when confronting other societies which have very different histories can create a new reality. In their words (1967: 108):

It is easy to imagine how the advent of the patriarchal Greeks must have upset the universe of the matriarchal societies then existing along the eastern Mediterranean. The Greek universe must have had considerable appeal for the henpecked males of these societies, and we know that the Great Mother made quite an impression on the Greeks themselves (original emphasis).

Either way, the new "reality" of a patriarchal order seems to have been in place approximately $2500 \mathrm{BC}$. And while the actual transformation from matriarchal mythologies to patriarchal interpretations of mythology occurred in different places at different times, "by the biblical period, followers of the matriarchal religions were regarded as dangerous pagans" (Lipman-Blumen, 1984: 70-2).

\section{Biblical Period}

The biblical period can perhaps be best characterized as a time where patriarchy was not only further entrenched as the "real" order of the universe, but done so "with a special sacred legitimacy" (Lipman-Blumen, 1984: 72; also see Chaftez, 1974: 96-8).

Several examples drawn from the 01d Testament demonstrate how the gender relationship between women and men was cast in a new light, with women being portrayed in a more negative way. 
First, Eve is depicted as the architect of Adam's and thus all of humanity's downfall in that she caused the banishment from the Garden of Eden, and hence was destined to bring forth children in pain and suffering and slated to submit to Adam's dominance in all important realms. Implicit here is the message that a woman's desire for knowledge is dangerous. Second, the fate of Lot's wife when she disobeyed her husband and looked back at Sodom is instructive of the value of female subordination and obedience. Third, the story of Sarah and Hagar illustrates the assumed necessity of women deriving their power and authority from men. Fourth is the Samson and Delilah account of the dangers of defilement inherent in sexual encounters with women, and fifth, the faithfulness and fidelity of Ruth to Naomi is reflective of the obedience which women ought to show toward men, even to deceased husbands (Lipman-B lumen, 1984: 72-3).

Likewise, examples drawn from the New Testament where, for instance, in Ephesians 5:22-24 wives are told to "submit" themselves to their husbands, "as unto the Lord"; where the Trinity (the Father, Son and Holy Ghost) are male power figures; where the Virgin Mary, the central female figure, is portrayed as totally asexual and the other strong female figure is a repentant prostitute. "The resounding message is the necessity of an unquestioned patriarchal order between sexes; an order where male and female gender role images are unequivocally differentiated" (Lipman-Blumen, 1984: 73-4).

Even today within the Jewish religion, a orthodox male Jew is expected to say the following prayer every morning (Robertson, 1987: 321): 
Blessed art thou, oh Lord our God, King of the Universe, that I was not born a gentile. Blessed art thou, oh Lord our God, King of the Universe, that I was not born a slave. Blessed art thou, oh Lord our God, King of the Universe, that I was not born a woman.

Freudian Period

While the Judeo-Christian religion is only one minority religion, it has for centuries been a powerful tool in defining genderappropriate role images in the Western world, and continues to do so. But beginning in the early twentieth century, as Janet Saltzman Chafetz (1974) points out, it has been "science [which] has become our national theology" (1974: 99; original emphasis). With this new "scientific thought" came Freudian and neo-Freudian notions of the worlds of "maleness" and "femaleness"; where once again, the phrase is used: "Biology is destiny" (Chafetz, 1984: 102; original emphasis).

Briefly summarizing the Freudian position, Chafetz states (1984: 102):

While Freud himself may have been at least somewhat more sensitive than many of his later followers to the crucial impact of society, via the inputs of parents, on psychosexual development, it is clear in many of his writings that he thought that females are by nature designed to rear as we 11 as to bear children and not to compete in the world of work; that they are passive and masochistic, and to be otherwise is "neurotic." Conversely, he viewed the male as an active agent, creative in all areas of endeavor save childbirth and rearing and equipped with a we11-developed conscience (superego). Females emerge in his writings as defective males missing the most crucial of all appendages, the penis. Males appear as perpetually frightened lest they lose that presumably glorious tool.

Cloaked in the aura of science, this view was most persuasive. Currently there appear to be "normal" gender roles for men and women, and likewise, behavior contrary to these expectations are 
considered "deviant" or "sick." "She's sick to give up her kids to her ex-husband," "It's not normal for Sally to think of her career when she has little ones to raise," "She should move if her husband has a better job offer," etc., being but a few examples.

Those who challenge such role definitions (given their "value-free, scientific truth") may well be defined by the proponents of this position (and sometimes by themselves as we11) as also being "sick," making this approach a "truly potent social control mechanism" (Chafetz, 1974: 102-4).

In fact, the significance of these historically produced gender role images lies in their power to produce an "objective" reality about the "real" nature of gender relations.

\section{THE "OBJECTIVATION" OF GENDER ROLES}

"The process by which the externalized products of human activity attain the character of objectivity is objectivation" (Berger and Luckmann, 1967: 60); that is, where the products of the social world created by human activity are not only available to the producers of such products, but also where the meanings of such products are available to others as elements of a common world (1967: 34). In fact, as Berger and Luckmann (1967: 61) point out, it is only with the internalization of the "reality" of such products by a new generation that one can properly speak of having a "social world"; "only then does the fundamental social dialectic appear in its totality." 
Of course, as they go on to point out (1967:61-62,64), because reality is historically produced and comes to a new generation as a tradition rather than as a biographical memory, it requires legitimation or ways by which it can be explained and justified if it is to carry any conviction to the new generation. In essence, a "protective cover" of both cognitive and normative interpretation; a "logic," is necessary so individuals will come to "know" that their world is a consistent whole.

In the view of Berger and Luckmann, the production of signs and sign systems is seen as solving this problem (1967: 35-6). Specifically, they argue (1967: 64):

Language provides the fundamental superimposition of logic on the objectivated social world. The edifice of legitimations is built upon language and uses language as its principal instrumentality.

This is so because language, defined as a system of vocal signs, is considered by Berger and Luckmann (1967:36-7) to be "the most important sign system of human society." 1 Their assertion is that language, which is encountered as a facticity external to one's self, can typify experiences, transcend the "here and now," "making present a variety of objects that are spatially, temporally and socially absent," and be coercive in its effect to force people into its patterns (1967: 35-9).

${ }^{1}$ Laurel Walum (1977: 21) points out there is some evidence to suggest that non-verbal communication is more salient for the transmission of meanings. (See: Argyle et al., 1970; Cull and Hardy, 1973.) Further, Paul C. Higgins (1980: 24) argues in his book Outsiders in a Hearing World that language, in and of itself, is not the only means for the transmission of meanings whereby one becomes a fully competent and thinking individual. 
Basica1ly, Berger and Luckmann (1967: 41) argue that language, and its symbolic representations, is the means by which classification schemes are built up to differentiate objects, and one important differentiation is that of gender.

Drawing on an outline proposed by Laurel Richardson Walum $(1977), 2$ six general propositions can be made about the differentiation of the "worlds" of "maleness" and "femaleness":

"First, in terms of grammatic and semantic structure, women do not have a fully autonomous, independent existence: they are part of man" (1977: 15; emphasis supplied).

That is, the English language does not employ masculine and feminine forms, as is true of some languages. Rather, the masculine form is presumed to be inclusive of both sexes especially when used as an indefinite pronoun. But this grammatically correct usage conveys assumptions about reality which quite clearly indicate the male as the dominant force.

2 For a thorough listing of the research cited by Walum and on language and sex in general, see Nancy Henley and Barrie Thorne, She Said/He Said: An Annotated Bibliography of Sex Differences in Language, Speech, and Nonverbal Communication (1975, Pittsburgh: KNOW, Inc.). This bibliography is also available in Barrie Thorne and Nancy Henley (Eds.), Language and Sex: Difference and Dominance (1975, Rowley, Mass.: Newberry House). Of particular interest is the work of Murial R. Shultz, "The Semantic Derogation of Women," in Barrie Thorne and Nancy Henley (Eds.), op. cit. (1975: 64-75). Also see Nancy Henley and Barrie Thorne, "womanspeak and manspeak: sex differences and sexism in communication, verbal and nonverbal," in Alice Sargent, Beyond Sex Roles (1975, West Publishing Co., pp. 201-18) and Donald Mackay, "Prescriptive Grammar and the Pronoun Problem," in Barrie Thorne, Cheris Kramarae, and Nancy Henley (Eds.), Language, Gender, and Society (1983, Rowley, Mass.: Newberry House, PP. $38-53)$. 
"Second, in actual practice, our pronoun usage perpetuates different personality attributes and career aspirations for men and women" (1977: 16; emphasis supplied).

Occupational differentiation is reflected in the use of the feminine for such occupations as nurses and secretaries and the masculine for tasks such as those of the doctor, the electrician or engineers. This difference also appears in reference to nonhuman matters, with those things which are controlled by men, for example ships, calling for the feminine pronoun, and those seen as possessing a powerful self-contained force calling for the masculine, for example, God or Satan.

"Third, linguistic practice defines females as imnature, incompetent, and incapable and males as mature, complete and competent" (1977: 16; emphasis supplied).

To give but one example, the words "boy" and "girl" referring to the young of the species. In general, after the attainment of maturity the male is not often referred to as "boy" (but note that they occasionally do "have a night out with the boys"), except in conjunction with a not very highly valued occupation such as car attendant, or in a pejorative sense connoting immaturity and powerlessness. And yet females of all ages are frequently informally referred to as "girls" both by themselves and by others with no overt offense necessarily intended or taken.

"Fourth, in practice women are defined in terms of their sexual desirability (to men); men are defined in terms of their sexual prowess (over women)" (1977: 18; emphasis supplied). 
The use of slang words is illustrative, with the male terms connoting mastery and female terms connoting sexual desirability and passivity as contrasted by the statements "He's a real hunk" versus "She's a cute bit of fluff."

"Fifth, women are defined in terms of their relationships to men; men are defined in terms of their relationship to the world at large" (1977: 19; emphasis supplied).

Conventional usage is reflective of this. Upon introducing oneself, a man is apt to say something on the order of "I'm Sam Shurduloo, professor of sociology," while the woman is likely to say "I'm Sarah, Sam's wife." It remains fairly unusual to hear the male introducing himself with the phrase "I'm Sam, Sarah's husband."

"Sixth, there is an historical pattern such that originally neutral words for women acquire obscene and/or debased connotations; and this pattern of derogation does not hold for neutral words referring to men" (1977: 19-20; emphasis supplied).

One example will suffice for many. "Mistress" like "Mister" has been available as a term of address since about 1500 , but on ly the former has taken on as one of its meanings a person who habitually engages in sexual intercourse with one other than one's spouse. In summary then, the structure of the English language is reflective of, and helps to communicate the view that women are dependent upon men in a great many arenas and derive identity from successfully occupying a social position subservient to men.

Put in Berger and Luckmann's terms, with the accumulation of these "linguistic objectifications" a "social stock of knowledge" is 
constituted (1967: 41) which provides the logic to the differential "worlds" of "maleness" and "femaleness" posited in a patriarchal order. Further, since this logic, in and of itself, also becomes part of the socially available stock of knowledge and is taken for granted as such, in essence it is "socially objectivated as knowledge, that is, as a body of generally valid truths about reality." It then has the power to "program" the channels in which externalization produces an objective world (1967: 64, 66; original emphasis).

In other words, since this "knowledge" contains reciprocal typifications (habitualized actions of two or more individuals that interlock) defining the appropriate roles to be played in a patriarchal society for the "worlds" of "maleness" and "femaleness," and is taken for granted as "knowledge," "Ipso facto, it controls and predicts a 11 such conduct; what is taken for granted as knowledge in the society comes to be coextensive with the knowable..." (Berger and Luckmann, $1967: 65-6)$.

Of course, as they go on to point out, in that this knowledge requires some sort of social apparatus for it's transmission, problems could still exist on the level of logical coherence; where there may be a lack of agreement on the institutional order, and/or on the leve 1 of socialization; where there may be difficulties in the internalization of the institutional meanings (1967: 70-1). And as previously discussed, this is exactly what happened when the "reality" of female "metaphysical supremacy" was replaced with a patriarchal order that posited male "metaphysical supremacy." 
But it is important to note that when this shift in realities took place, it was within the mythologies of the prehistoric period. As Berger and Luckmann (1967: 110-11) point out, in discussing the conceptual machineries needed for reality maintenance, "mythology as a conceptual machinery is closest to the naive level of the symbolic universe," in other words, where "knowledge is not far removed from that is generally known." As such, many inconsistencies can continue to exist side by side without any theoretical integration. Given this heterogeneity, challenges to the existing order(s) would be facilitated.

As Berger and Luckmann see it, to eliminate inconsistencies and maintain "reality" in theoretically integrated terms (thus solving the problems of transmission) requires the use of "specialists," those persons whose bodies of knowledge are increasingly "removed from the common knowledge of the society at large" and "who become administrators of the sectors of the stock of knowledge that have been socially assigned to them" (1967: 78, 111-12).

And, as mentioned previously, it has been the "specialists," especially in "theological thought" and "scientific thought," areas in which there exist a greater degree of theoretical systematization than is true of mythology (Berger and Luckmann, 1967: 111-12), who have greatly contributed to the legitimation, maintenance, and transmission of the social reality of a patriarchal order that posits very different "worlds" for males and females. In fact, for many such an order appears as the result of divine will, cosmic laws, and/or facts of nature, rather than a creation of the human world. This 
"apprehension of the products of human activity as if they were something else than human products..." is what Berger and Luckmann define as "reification" (1967: 89; original emphasis).

For Berger and Luckmann, this is "an extreme step in the process of objectivation" in that "man is capable paradoxically of producing a reality that denies him" (1967: 89; original gender). Yet, since "reification exists in the consciousness of the man in the street" (1967: 90), what everybody "knows" is that being a woman is indeed much different from being a man.

And as Berger and Luckmann go on to point out (1967: 91), because roles may be reified in the same manner as the institutionalized order, "the sector of self-consciousness that has been objectified in the role is then also apprehended as an inevitable fate, for which the individual may disclaim responsibility; the paradigmatic formula for this kind of reification is the statement "I have no choice in the matter. I have to act this way because of my position -."-as father, husband, male or as mother, wife, female.

The importance of this is that the "subjective distance" that individuals may establish between themselves and their role-playing is greatly narrowed; sometimes to the vanishing point, and as such, identity itself (both one's own and that of others) may appear as nothing more than a total identification of the individual with his/ her socially assigned typifications: in other words, as "nothing but" that type (Berger and Luckmann, 1967: 91; original emphasis).

Further, "the sum total of these typifications and the recurrent patterns of interaction established by means of them" are what Berger 
and Luckmann (1967: 33) define as "social structure," which serves to link the emergence of face-to-face interactions and the highly anonymous abstractions with images that are objectified. Thus, for example, what is developed, objectified, and which appears to take on a "reality" of its own is a general impression that "maleness" is a "positive thing" and "femaleness" is either "negative or passive." In fact, a basic dualism is displayed toward the ferale, who is simultaneously held to be "sexually passive, uninterested" (the Virgin Mary or the Madonna image) and "seductive, flirtatious" (the wicked Eve tempting poor innocent Adam or the whore image). This contrast of the "good" versus the "bad" females has no parallels for males (Chafetz, 1974: 39, 108; also see Millett, 1970; Broverman et al., 1972; Walum, 1977 ; Ward and Balswick, 1978; Lipman-Blumen, 1984; and LeMoncheck, 1985).

To the degree that social structure as viewed by Berger and Luckmann (1967: 33) is "an essential element of the reality of everyday life," what "everybody knows" points to some serious power differences between men and women (Lipman-Blumen, 1984: 6). Of course, as Kate Millett (1970: 46) argues, this is understandable because:

Under patriarchy the female did not herself develop the symbols by which she is described. The image of women as we know it is an image created by men and fashioned to suit their needs.

Further, as Berger and Luckmann (1967: 109) argue, when there exists two conflicting definitions of "reality" the one "made to stick" in the society ". - will depend more on the power than on the theoretical ingenuity of the respective legitimators. He who has the 
bigger stick has the better chance of imposing his definitions of reality" (1967: 109; original gender).

Thus, it appears that the "objective reality" of gender role relations is not only one of very different "worlds," but one based on inequality. Accepting these "facts," how is it that society produces people to reinforce this "objective reality"?

\section{THE PRODUCTION OF PEOPLE: "INTERNALIZATION"}

According to Berger and Luckmann (1967: 129):

-. in the life of every individual . . there is a temporal sequence in the course of which he is inducted into participation in the societal dialectic. The beginning point of this process is internalization; the immediate apprehension or interpretation of an objective event as expressing meaning (original emphasis and gender).

This is brought about through "socialization," defined by Berger and Luckmann (1967: 130) as "the comprehensive and consistent induction of an individual into the objective world of a society or a sector of it."

Distinguishing between primary socialization, "the first socialization an individual undergoes in childhood," and secondary socialization, "any subsequent process that inducts an already socialized individual into new sectors of the objective world of his society," Berger and Luckmann (1967: 130-31) argue that it is primary socialization which is usually the most important. This is so because, through primary socialization, a specific social world is "filtered" to the individual in which he or she not only takes on, or internalizes, the roles and attitudes of significant others (usually 
the parents), but in the same process takes on their world, internalizing the roles and attitudes of society in general (1967: 131-33). The significance of internalizing this objective reality in the course of primary socialization is that once crystallized in the indvidual's consciousness, it "can readily be translated into subjective reality, and vice versa" (1967: 133). In other words, this social world, because it is internalized in circumstances where there is a great deal of emotional attachment to the significant others, becomes for the individual the world; it is "reality" pure and simple (Berger and Luckmann, 1967: 131, 134).

of course, given that what is internalized in primary socialization is affected by the "stock of knowledge" to be transmitted (1967: 137), it becomes obvious in regard to gender role relations that two very different "worlds" need to be posited, one for "maleness" and one for "femaleness," and by two very different types of significant others, males and females. This could present a problem for successful socialization in having socially different types of significant others mediating different "realities" to the individual (1967: 167). But as Berger and Luckmann (1967: 167-68) point out, since "maleness" and "femaleness" are socially recognized as just different versions of an "objective reality," both men and women, as significant others, function to mediate these discrepant versions to the child in a way whereby he or she will come to "know" and "identify" with the appropriate one. Therefore, the threat of unsuccessful socialization is not raised. In fact, "the reality. . gains in massivity in the 
course of its transmission" (1967: 61). "To put it crudely, if one says, 'This is how things are done,' often enough one believes it oneself" (1967: 60).

As reflected in the observation that one of the first questions asked when a child is born is "Is it a boy or a girl," it is the case that gender role socialization begins very early in life. For example, research has suggested that within the child's first twentyfour hours of 1 ife, both mothers and fathers perceive their newborn sons and daughters quite differently: "characterizing baby boys as more alert, stronger, larger featured, more coordinated, and firmer" while describing girl babies as "less attentive, weaker, finer featured, less coordinated, softer, smaller, more fragile, and prettier" (Rubin et a1., 1974: 512-19).

In fact, most research on the socialization of males and females confirms that they are most definitely raised to live in two very different worlds. (See inter alia: Bandura et al., 1969; Serbin et al., 1973 ; Maccoby and Jacklin, 1974; Whiting and Pope, 1974; and Weitzman, 1979).

Because participating in this process of primary socialization, specifically by the identification with significant others, is how the individual forms an identity appropriated only "along with" the world considered to be reality (Berger and Luckmann, 1967: 132; original emphasis), it can also be argued that individuals concurrently learn very early whether they are male or female and the difference in being one or the other. 
As many, including Robert Stoller (1968: 58) and Richard Green and John Money (1969: 24), have concluded, what is defined as one's "core gender identity" (an awareness of "maleness" versus "femaleness") is thought to be established as early as eighteen months of age and is considered to be irreversible after the first few years of a child's life.

Kate Millett succinctly makes this point when she states (1970: 30):

In cases of genital malformation and consequent erroneous gender assignment at birth . . . the discovery was made that it is easier to change the sex of an adolescent male, whose biological identity turns out to be contrary to his gender assignment and conditioning--through surgery--than to undo the educational consequences of years, which have succeeded in making the subject temperamentally feminine in gesture, sense of self, personality and interests.

In other words, what one is, is what one learns to be, a "knowledge" so firmly entrenched in the individual's consciousness that one "knows" it could not be otherwise.

But if "socialization is never total and never finished" and the "internalization of society, identity, and reality is not a matter of once and for all," as Berger and Luckmann (1967: 137) contend, could it not be possible for subsequent processes of socialization to construct new "realities"?

The focus of this study is on an examination of distilled beverage advertisements. The purpose of concentrating on such advertising stems from the fact that while alcohol advertising in general has been regulated by various laws and regulations since the 
repeal of prohibition, ${ }^{3}$ it has only been recently (1958) that the distillers themselves lifted the ban on the use of women in such advertising. As Phyllis Marsteller and Karen Karnchanapee point out $(1980: 2):$

The brewers and vintners have included women in their advertisements for many years, perhaps (because).. . beer and wine have traditionally been viewed as "drinks" of moderation."

Given the recency of inclusion of women in distilled beverage advertisements, an argument could be made that such advertising represents a new format or context for secondary socialization. As such, it becomes "possible to examine some of the motives and marketing techniques" of distilled beverage advertisements that include women (Marsteller and Karnchanapee, 1980:2) as a way of assessing the contemporary pattern of creation and maintenance of the worlds of maleness and femaleness within a narrowly focussed field. Thus, the question posed is: Does distilled beverage advertising construct a "reality" different from the one presented in the previous pages, wherein women are portrayed as co-equal consumers, or is such advertising just another means of maintaining and reinforcing the "objective reality" of the "worlds" of "maleness" and "femaleness"?

3 "The Federal Alcohol Administration Act (passed in 1935 and administered by the Bureau of Alcohol, Tobacco and Firearms), actions of the Federal Trade Commission, numerous state laws, policies of industry representatives (principally the Distilled Spirits Council of the United States, the United States Brewers Association and the Wine Institute) and policies of many broadcasters and publishers affect the advertising of alcoholic beverages" (Marsteller and Karnchanapee, 1980: 1). 
CHAPTER III

DESCRIPTION OF THE PROBLEM

Advertising, at least the type which Leech (1966: 25) describes as "commercial consumer advertising" (taking note there is advertising defined as non-commercial, such as public service ads), is defined by Harris and Sheldon (1962: 40) as a public notice "designed to spread information with a view to promoting the sales of marketable goods and services." As such, it has a relatively short history.

In fact, "the great breakthrough for advertising only came in the late nineteenth century" (Vestergaard and Schroder, 1985: 4):

Technology and mass-production techniques were not sufficiently developed for more firms to be able to turn out products of roughly the same quality and at roughly the same price. . literacy had spread to ever larger segments of the population.. . the first newspaper to rely on advertising for a significant part of its revenue . . began publication in this period (1896) . . . and finally... advertising became a profession of its own with the establishment of the first advertising agencies.

In essence, the social conditions which make advertising possible in the first place did not exist until just before the turn of the century (Vestergaard and Schroder, 1985: 4). Yet, today advertising is a very much taken-for-granted phenomenon, observed in everyday activities such as freeway driving, newspaper or magazine reading, supermarket shopping, or television watching. Indeed, television, as a commercial medium, and the post-war economic boom of the $1950^{\prime} \mathrm{s}$ may have triggered, and in turn been 
accelerated by, an increase in advertising activity as it is known today (Vestergaard and Schroder, 1985: 4-5). In fact, as Reekie (1974: 7-8) points out, these two factors may well have been the causes behind the increasing public interest in the disapproval of the methods of advertising that began in the late fifties and early sixties. For example, Vance Packard (1957: 11) warned consumers in his book, The Hidden Persuaders, of:

\footnotetext{
-. . the way many of us are being influenced and manipulated--far more than we realize--in the patterns of our everyday lives. Large scale efforts are being made, often with impressive success, to channel our unthinking habits, our purchasing decisions and our thought processes by the use of insights gleaned from psychiatry and the social sciences. Typically, these efforts take place beneath our level of awareness.

Wilson Bryan Key reinforced Packard's notion of the manipulative
} and hidden influence of advertising in his discussions (1972 and 1976) of the subliminal perception technique used in certain advertisements. Basically, he (1976:2) argues that:

-. [this] secret technology modifies behavior invisibly, channels basic value systems and manages human motives in the interest of special power structures . . subliminal stimuli assault the psyches of everyone in North America throughout each day of their (sic) lives.

While it may be difficult to "prove" such powers of advertising, criticism such as this continue (Defleur and Ball-Rokeach, 1982). According to Vestergaard and Schroder (1985: 5-8), "in our consumption of goods we satisfy both material and social needs," yet in a capitalist society, where commodities are produced only for money, it is possible for advertisers to produce commodities which go beyond satisfying the individual's needs of "use value" to 
downright exploiting "people's needs for group membership, selfidentification, and so on." In their words (1985: 8):

- . since the seller's only interest in his commodity is selling it, he will be satisfied as long as the commodity appears to be of use value (original emphasis and gender).

This, according to W.F. Haug (1971), has led to an

"aestheticization of commodities," pleasing by means of sense impressions.

In other words, the advertiser gives his/her product an image (a verbal and/or visible representation suggestive of some thing, idea, or concept) (Leiss et al., 1986: 238) "intended to function as an extra asset for the product in the market where it has be be somehow differentiated from competing products which are (near-) identical in terms of material use value." This is done, according to Vestergaard and Schroder (1985: 153, 155), to make the commodity appeal to the consciously or subsconsciously held values of the consumer, in hope they will purchase it. Through this process, according to Haug (1971: 65), the area of factual information is left and the area of persuasion is entered.

Of course, as Leiss et a1. points out, some writers, such as Staffan Linder (1970), have argued that "persuasion is not only good for society as a whole but that, in fact, consumers want to be persuaded" (1986: 40; original emphasis; also see Sandage and Fryburger, 1960; Levitt, 1970; Asker and Meyers, 1975; Rotzol1 et a1., 1976; and Oliver, 1981). Vestergaard and Schroder (1985: 9) nonetheless argue that: 
- . this aestheticization of the advertising message means that adverts can profitably be analysed by means of techniques normally applied to verbal and visual art.

\section{ADVERTISING AS COMMUNICATION}

Defining communication as "a social process, within a context, in which signs are produced and transmitted, perceived, and treated as messages from which meaning can be inferred" (Worth and Gross, 1974: 30 ), it can be argued that the media (in this case, via advertising) are a central part of the communication processes of modern societies (DeFleur and Ba11-Rokeach, 1982: 22). But questions may be posed. What is the message? How is it communicated?

According to Vestergaard and Schroder (1985: 14-15), "in the study of communication the object of the study (what goes on between the participants in the communication process) is referred to as a text." Defined as such, three observations can be taken for granted (1985: 15): (1) the text exists in a particular communication situation, (2) the text is a structured unit--it has texture and (3) the text communicates meaning.

A method for examining textual material that emerged from linguistics and from literary and cultural analysis is semiology (or semiotics) (Leiss et a1., 1986: 150).

Defining "semiology" as "the science of signs" (DeSaussure, 1966) and arguing that "signs are things that have a meaning, that communicate messages to people" (Leiss et a1., 1986: 152), "semiologists have concentrated on relationships among the parts of a 
message or communication system, for, they contend, it is only through the interaction of component parts that meaning is formed" (Leiss et a1., 1986: 150).

Specifically, Leiss et al. (1986: 152) argue that a sign within a system of meaning may be separated into two components: (1) "the signifier" (the material vehicle meaning or its "concrete" dimension) and (2) the "signified" (which "is" actually the meaning or its "abstract" side). What the creators of the messages try to do is turn signifiers (goods) into meaningful signs in the hope that this will prompt consumers to respond by purchasing the products (Leiss et al., 1986: $152-53)$.

Even more specifically, Leiss et al. (1986: 153) argue:

The semiological aproach suggests that the meaning of an ad does not float on the surface just waiting to be internalized by the viewer, but is built up out of the ways that different signs are organized and related to each other, both within the ad and through external references to wider belief systems.

Such an approach, they (1986: 151) argue, is especially appropriate for studying contemporary advertising given that "the growing preponderance of visuals in ads have increased the ambiguity of meaning embedded message structures."

Earlier advertising usually state(s) its message quite explicitly through the medium of written text (even if the most outrageous claims were made in the process), but starting in the mid-1920s visual representation became more common, and the relationship between text and visual image became complementary--that is, the text explained the visual. In the postwar period, and especially since the early 1960s, the functions of text moved away from explaining the visual and towards a more cryptic form, where text appeared as a kind of "key" to the visual. "Decoding" what is happening in these more complicated message structures requires the use of a method, such as semiology, sensitive to these nuances (Leiss et al., 1986: 151). 
Using an example drawn from Judith Williamson's book, Decoding Advertisements (1978) where "the face of a woman (the French fashion model/actress Catherine Deneuve) is shown with a picture of the product (a bottle of Chanel No. 5) in the corner of the image," Leiss et al. (1986: 153) state:

To the question, what is the meaning of this ad? we might answer: It tells us that Chane 1 No. 5 is chic, sophisticated, and elegant; that by wearing it we would be adding something to our character that is the epitome of "Frenchness," specifically, glamor and flawless beauty.

Breaking this down in semiological terms, we have the signifier-the actual bottle of perfume; the signified-French chic, glamor, beauty, and sophistication (represented by Catherine Deneuve); their unity in the sign--"Chanel No. 5" is French chic, glamor, beauty, and sophistication (original emphasis).

Such a conclusion was drawn in the process of using three specific steps, steps that require the reader or viewer to do the "work." As Leiss et al. (1986) point out:

"First, the meaning of one sign is transferred to another" (1986: 153; emphasis supplied).

Although no line of argument links the two, their juxtaposition within the structure of the ad facilitates the transfer to be made. "Second, this transfer of significance is not completed within the ad: We must make the connection ourselves" (1986: 155; emphasis supplied).

In essence, the reader/viewer becomes an active participant in the creation of the meaning because no where does it explicitly state "Chane1 No. 5" is like "Catherine Deneuve." 
"Third, in order for the transfer to take place, the first object must already have meaning to be transferred--it must already be significant to the audience" (1986: 155; emphasis supplied).

In other words, one must already "know" what Catherine Deneuve "stands for" in order that there be a significance to be transferred (Leiss et a1., 1986: 153-55).

"We exchange because we know" (Williamson, 1978: 100; original emphasis).

Paralleling the conceptualization of Berger and Luckmann's "social stock of knowledge" discussed in Chapter II, Williamson asserts that that which is "known," or the system of meanings from which materials are drawn in order to effect such a transfer, constitutes a "referent system," that is:

. . bodies of knowledge . . which are used or referred to "because" they "already" exist in society, and continue to exist in society "because" they are used and referred to (Williamson, 1978: 99-100).

Therefore, if advertisers want to sell their products (which is, after all, their goal), they "pretty much have to use what already exists in the imaginations of the target audience if the audience is to 'decode' the meaning adequately--that is, to make the transfer of meaning" (Leiss et a1., 1986: 156).

Yet, this implies that advertising not only generates meaning through a process of "denotation," but one of "connotation" as well (Leiss et al., 1986: 156). As Williamson (1978: 99) points out: - . denotation is the work of signification performed 'with' a sign as it were: It is the process whereby a signifier 'means, --denotes - -a specific signified... and connotation is a process where the signifier is itself the 
denoting sign: the sign in its totality points to something else. That something else.. - a referent system (origina 1 emphasis).

In other words, "the 'referent system' is always a connotation because what is denoted is the product" (Williamson, 1978: 100).

Of course, as Leiss et a1. (1986: 159) point out, "connotation is a feature of all communication, not an invention of advertising." (Also see Worth and Gross, 1974; DeFleur and Ball-Rokeach, 1982; Shapiro, 1984; Vestergaard and Schroder, 1985; and Heilbronn, 1987). Yet, since advertising does rely on connotative meaning, "if there is no common understanding, there can be no communication" (Leiss, et a1., 1986: 159).

One "referent system" or body of knowledge that exists in every society and which conveys messages about people is gender images. As Leiss et a1. (1986: 166) argue:

Gender . . . is one of the most important forms of codified behavior in all societies, and every culture has accepted "routine" forms for communicating gender identity. A culture's social norms indicate how men and women are suppose to look, act, and relate to each other in a wide variety of social situations; the resultant ritualized behavior "anchors" expectations, rewards, and punishments and stabilizes social intercourse.

Given that historically produced gender role images contain an "objective reality" of two very different, and very unequal worlds of "maleness" and "femaleness" and given that advertising is ubiquitous in the modern world, the linkage between these phenomena, that is the construction of "gender meaning" (Leiss et al., 1986:166), remains an issue to be explored. More specifically, if it is "known" that the "woman's place" is subordinate to that of the man's, the question of 
the role of advertising in reinforcing and maintaining or of subverting and weakening this "reality" may be posed.

\section{THE "WOMAN'S PLACE" IN ADVERTISING}

According to Gaye Tuchman (1978: 4-5, 23), little research existed on the question of the "woman's place" in the mass media, and in advertising specifically, prior to the advent of the modern women's movement. Generally, the mid-1960s, with the founding of the National Organization for Women (NOW), is identified as the historical beginning of this movement.

This was so, she argues (1978: 4), because "until then, psychology, sociology, economics, and history were written by men, about men, and for men; no one considered the way women experienced the world." of course, this was understandable given the historically produced gender role images, sometimes referred to as "stereotypes"; the set portrayals of gender-appropriate appearance, interests, skil1s, behaviors, and self-perceptions (Tuchman, 1978: 5), pertaining to the world of "femaleness," as previously discussed, resulted from a constructed "reality" where the woman's place was only considered in relationship to the male under a patriarchal order and taken for granted as such. Therefore, no one seemed to care about the media's role in the process of generation and maintenance of such a "reality" (Tuchman, 1978: 5).

But with the publication of Betty Friedan's Book, The Feminine Mystique (1963), which was an analysis of sexism based in part on an analysis of the portrayal of gender roles in women's magazines 
(Tuchman, 1978: 23), and given that today's mass media is viewed as having "replaced yesterday's cathedral and parish churches as teachers of the young and of the masses" (Lasswe11, 1948), concern has grown in respect to the part the media plays in the transmission of "sexist ideology." The concern has grown especially in light of the evidence that the social expectations and social conditions for women appear to be changing quite rapidly; one such area, for example, is their participation in the labor force:

In 1920 , twenty-four percent of the nation's adult women worked for pay outside the home and most of them were unmarried. Fifty years later, in 1976, over half of all American women between the ages of eighteen and sixty-four were in the labor force, most of them married and many of them with children who were of preschool age (Tuchman, 1978: 3-4).

One important consequence is that concern has grown in respect to the media's part in preparing individuals--females in particular-"for a world that no longer exists" (Tuchman, 1978: 4,6).

of particular interest to more recent and feminist-oriented researchers has been the part the media has played in presenting "traditional" images of women in advertising. This concern grew given that such a close relationship exists between advertising, which is economically dependent on consumers for its support, and the growing economic role of women as major consumers (Ceulemans, 1979: 7). As such, advertising, in and of itself, has become "a prime target for attack and scrutiny" (Deckard, 1975: 380).

Unlike other types of media content, where critics oppose the severe under-representation of females (see inter alia: Long and Simon, 1974; Sternglanz and Serbin, 1974; Miller, 1975), Ceulemans 
(1979: 7) points out that critics of female images in advertising are much more concerned with the qualitative representation, or the recurring "sexist charges," than the quantity of women appearing in the ads. Specifically, the "sexist charges" have focused on three aspects of the female image: "as employed woman, as housewife, [and] as sex-object" (Ceulemans, 1979: 7; also see Report, National Advertising Review Board (NARB), 1975).

The Representation of the Employed Woman Versus the Housewife in Advertising

Early research on images of women in advertising confirmed the "proper place of the woman was in the home" portrayal as the dominant one. As Linda J. Busby (1975: 117) summarizes a study by Courtney and Lockeretz (1971) entitled "A Woman's Place: An Analysis of the Roles Portrayed by Women in Magazine Advertisements":

o Women were rarely shown in out-of-home working roles.

- Not a single woman was shown as a professional or highlevel business person.

- Women rarely ventured far from home by themselves or with other women.

o Women were shown as dependent on men's protection.

- Men were shown regarding women as sex objects or as domestic adjuncts.

- Females were most often shown in ads for cleaning products, food products, beauty products, drugs, clothing, and home appliances.

- Males were most often shown in ads for cars, travel, alcoholic beverages, cigarettes, banks, industrial products, entertainment media, and industrial companies. 
Another study, one by Dominick and Rauch (1972) of television advertising, was also summarized by Busby (1975: 109) and reported very similar findings:

- Women were seven times more likely to to appear in ads for personal hygiene products than not to appear.

- Seventy-five percent of all ads using females were for products found in the kitchen or in the bathroom.

- Thirty-eight percent of all the females in these television ads were shown inside the home, compared to 14 percent of the males.

- Men were significantly more likely to be shown outdoors. . or in business settings.. . than were women.

- Twice as many women were shown with children as were men.

- Seventy-one percent of the women in the ads were judged to be between twenty and thirty-five years of age; for men only 43 percent were in this category.

- Men over fifty years of age outnumbered women over fifty by a factor of two.

- Fifty-six percent of the women in the ads were judged to be housewives.

- Forty-three different occupations were coded for men, eighteen for women.

- Of 946 ads with voice-overs, only 6 percent used a female voice; a male voice was heard on 87 percent.

However, some of the more recent studies indicate that a change in the "proper place" of women might be taking place. For instance, in a study of magazine advertisements that appeared over a span of twenty years, Sexton and Haberman (1974) reported some increase from 1951 to 1971 in the number of women who were shown working and a substantial decrease in ads portraying women as housewives or mothers. 
Venkatesan and Losco (1975) similarly reported that there was a decrease of women in the housewife role from 1963 to 1971 in magazine ads. A 1976 study (Cully and Bennett) which addressed both print and television advertising confirmed that the gap between the sexes, with respect to occupational representation, had narrowed significantly from 1970 to 1974 .

In essence, at least in terms of quantity, with an increased number of women portrayed as working and a decreased number of women portrayed as housewives, it appears the portrayal of women has moved toward parity. In the words of Wagner and Banos (1973: 214), who did a follow-up analysis of the "Woman's Place," ". . there has been a substantial improvement in emphasizing women's expanding role as a working member of society in a relatively short period of time" (emphasis supplied). The debate, however, is far from settled. First, as Ceulemans (1979: 12) points out, while some studies indicate an increase in the proportion of working women in advertisements in the past ten to fifteen years (see earlier discussion; also see Henstra and Pinckaers, 1976; Loree, 1977), other studies observed no such development (Millum, 1975; Ceulemans, 1977; Van De Maele, 1978).

Second, even in the advertisements that included the "working woman," most portrayed women in "traditional" female occupations. As Ceulemans (1979: 8) points out when drawing attention to a study by Cully and Bennett (1976),". . roles that are not depicted are as indicative as those that are. No women were shown as lawyers, 
doctors, judges, or scientist." (Also see Sexton and Haberman, 1974; Henstra and Pinckaers, 1976; Ceulemans, 1977; Loree, 1977).

Third, even when a decrease in the quantity of women portrayed as housewives is substantiated, the quality of such presentations, as Ceulemans (1979: 14) points out, leaves much to be desired from the standpoint of equality; either the advertisements continue to emphasize male authority and female dependency or they present downright "unflattering" portrayals of women within the domestic roles. For example, Courtney and Lockeretz (1971) reported that even in decision making for the household (the woman's place), women only appeared as being capable of handling relatively inexpensive purchases such as food, cleaning products, etc.; for the more expensive purchases, men were brought into the ads as if sought for advice. In a comparative study of the tasks and activities of product representatives in advertisements, Courtney and Wipple (1974) found that only females performed the domestic tasks related to the product; men just gave advice and instructions, but never used the product. In fact, it appears that when men weren't giving advice and instructions, their only relationship to the domestic products was as beneficiaries; 54 percent of the food ads and 81 percent of the cleaning product ads portrayed men as "receivers." Studies by Dominick and Rauch (1972) and O'Donnel1 and O'Donnel1 (1978) confirm the male/female relationship of authority/dependency by drawing attention to the predominant use ( 87 percent and 93 percent respectively) of males in "voice-overs," voices used to summarize the qualities of the products in TV commercials. (Also see Screen Actors Guild, 1974; Miles, 1975; Verna, 1975; Cu11y 
and Bennett, 1976). And who can forget the "ring around the collar" commercial that portrays the woman as failing her domestic duty by not using the "right" detergent and ignores the man who doesn't use the "right" soap to wash his dirty neck. Indeed, as Ceulemans (1979: 9) points out:

The housewife appears as a person obsessed with cleanliness and embarrassed or guilty about dirt. She is frequently shown as either envious of other women's achievements or boastful about her own cooking or cleaning accomplishments.

Finally, and probably most indicative of the lack of a "substantial improvement" in the portrayal of women in advertisements is the strategy of advertisers to combine the "working" woman with the "traditional" woman and thereby create a "new" woman. As Leiss et a1. (1986: 169; also see Janus, 1977; Gerbner, 1978; Williamson, 1978; Tuchman, 1979; Vestergaard and Schroder, 1985) point out, although advertisers draw materials from everyday life, they select them carefully.

By choosing some things and by reintegrating them into the meaning system of advertising, ads create new meanings; thus advertising enters into the routines of everyday 1 ife and produces meanings and categories that are not found elsewhere.

What is stressed in these types of ads, as Ceulemans (1979: 12) points out, is "efficiency in terms of performance and time... in order to reduce guilt feelings women might (and should!) experience when pursuing a (strictly female) career." Loree (1977) makes this point as we 11 when arguing that this change of strategy merely implies that advertising is willing to tolerate women's professional aspirations, provided they do not interfere with their domestic obligations. Yet, as Nona Glazer (1980) points out, the use of this strategy may not 
only reinforce old sources of oppression for women, but actually create some new problems. In her words (1980: 90):

The portrayals of employed women . . are an enforcement of privatized domestic work, in which the individual woman is responsibile for housework and child care. There is no recognition that the problems facing women are socially generated, that women are being asked to do two jobs simu1taneously. There is no questioning about the justice of the demand. There is no recognition that low family income and child support allowances pressure women to take paid jobs; that the organization of the workplace fails to consider that women workers have family responsibilities; that the organization of services, shops, recreational facilities, schools, etc., assume that most women are full-time housewives, not paid workers. Rather than any suggestion that there is a social source to women's problems, the double day is shown as a personal problem. Women, in turn, are shown as solving that problem by personal means. . . The re-emerged women's movement attempted to show how the personal is political. The portrayals of women.. have reversed the tie: the political has become personal.

In essence, the message to a woman is that if you can't "bring home the bacon, fry it up in a pan, and not let him forget he's a man" (in other words, according to Glazer, become a "sponge woman," 1980: 90), you have now personally failed as the "new" woman according to advertising.

In response to the critics, as Linda Busby (1975: 110) points out, many advertisers argue that the viewers are the ones that will not accept any major alterations in traditional gender role portrayals, and that programmers and advertisers cannot afford to use expensive media time to promulgate social changes that might be offensive to the "average viewer." In citing a letter to the New York Times magazine, June 18, 1972, the point is well made (Busby, 1975: 110): 
Advertisers attempt to sell goods and services to real people who exist today in the U.S., not people as NOW wishes they would become. The vast majority of American women-especially housewives over $30--$ do not actively participate in the Women's Liberation movement. In fact, most seem content with their role as wife, mother, and housekeeper. And that, of course, is exactly the female image portrayed on TV. No advertiser would stay in business very long if he did not aim his commercials at people as they actually are today. If and when the majority--or sizable minority--of women actively support Women's Liberation, advertisers will revise their campaigns accordingly. Until then, they will appeal to real people, not to ideals.

If there is no social recognition that women are more than "ful1-time housewives" and/or that the "new" woman is in a position that demands a great deal, perhaps the "real" is the representation of women as sex objects.

The Representation of Woman as Sex Object in Advertising

"Behold the compleat woman constructed by American advertising: Ultra Brite toothpaste 'gives your mouth sex appeal'; Colgate mouthwash is 'the mouthwash for lovers'; 'Tonight offer her a daiquiri made with Ronrico, Puerto Rico's tasteful rum. Then watch her slip into something light and comfortable'" (Komisar, 1971: 208-9, 211).

There is no shortage of evidence to support the fact that one of the "real" roles of women in advertising is to sell products to both men and women on the basis of their sexual appeal to men (see inter alia: Rocard and Gutman, 1968; Dispensa, 1975; Poe, 1976; Goffman, 1976; Loree, 1977; Weibel, 1977; Warren, 1978; Butcher et al., 1981 ; LeMoncheck, 1984). Indeed, as Lucy Komisar (1971: 210-11) argues, women have traditionally been "exploited out-rightly for the titillation and amusement, sometimes even the sadistic fascination, of men." 
Helen Butcher et al. (1981: 317) make much the same point when they draw attention to a National Airlines ad in The Guardian, where a smiling woman's face is beaming down on the reader and the caption reads:

I'm going to fly you to Miami like you've never been flown before. I'm Leslie. Next time you want to see what you've been missing, fly my wide-bodied, non-stop jet from London to sunny Miami.

Or take, for another example, women featured in the trade and specialist magazine advertisements "seductively draped across machinery." Are they simply there to "provide a nice framework in which to display the product" (Root, 1984: 61-62)? According to Root $(1984: 62):$

- . their [women's] bodies are there to represent potential power, status and potency to the reader, in much the same way that the bodies or pieces of bodies in pornography do. If female bodies carried none of these connotations (and, of course, it is not "natural" that they do) the advertisement would have no meaning whatsoever. It would be as absurd as the satirical "advertisements" which show men reclining half-undressed on car bonnets, or with packets of peanuts pushed down their swimming trunks.

John Berger makes much the same point in his book, Ways of Seeing, when he states:

Transform the woman into a man. Either in your mind's eye or by drawing on the reproduction. Then notice the violence which that transformation does. Not to the image, but to the assumptions of a likely viewer (1979: 64).

of course, this is so, as Butcher et a1. (1981: 317-18) argue, because such views have come to be taken for granted. "They are part of our everyday lives. The appear 'natural'; โthey】 are the images we are socialised (sic) into categorising (sic) women in terms of." Therefore, as it is, and has traditionally been, "We are forced to 
accept the concept of women as pleasurable and ever-available bodies every time we leaf through a magazine" (Root, 1984: 62).

Further, as she goes on to explain, while it may appear in some ways quite mystifying, not only is the viewer forced to accept the sexual exploitation of females in ads that are intended for males, but the viewer is also forced to accept the more common practice of sexual exploitation of the female in ads "which encourage women to look at other female bodies; practically all women's magazines are full of glossy and provocative advertising photographs of women's bodies, faces, and parts of bodies" (Root, 1984: 65; original emphasis). How can this be? What is the basis for acceptance of the ads intended for males that represent "power, status, and potency" to them, and even where women are being "encouraged to fantasize about the control and sexual consumption of other women" (Root, 1984:65)? How has women's sexuality come to be used in this way? One suggestion is offered by John Berger (1979: 45-46):

A man's presence is dependent upon the promise of power which he embodies. [Itj suggests what he is capable of doing to you or for you.

By contrast, a woman's presence expresses her own attitude to herself, and defines what can and cannot be done to her.. - there is nothing she can do which does not contribute to her presence.

To be born a woman has been to be born, within an allotted and confined space, into the keeping of men. The social presence of women has developed as a result of their ingenuity in living under such tutelage within such a limited space. But this has been at the cost of a woman's self being split in two. A woman must continually watch herself. She is almost continually accompanied by her own image of herself. Whilst she is walking across a room, or whilst she is weeping at the death of her father, she can scarcely avoid envisaging herself walking or weeping. From earliest 
childhood she has been taught and persuaded to survey herself continually . . because how she appears to others, and ultimately how she appears to men, is of crucial importance for what is normally thought of as the success of her life.

Although it may be argued that such a position is outdated in this time of Women's Liberation, clearly that message has not reached everyone. For example, Lucy Komisar (1971: 212-13) notes some male reactions to the charges of sexism in advertising:

"We didn't think that was degrading". . .

"Its just an expression--everyone took it in good fun"...

"Women are irrelevant--except of course, my mother" . .

"A11 women are masochists."

Frankie Cadwell, an advertising agency president, offers probably the best explanation for the continued sexism in advertising: "It sells, doesn't it" (quoted in Romisar, 1971: 231)?

Lending support for this suggestion, DeFleur and Ball-Rokeach

\section{(1982: 178-80) state:}

Since the most central media goal is economic profit, sex and violence or any other attention-getting and attentionmaintaining content is functional in the sense that even though it may be of low taste, it maximizes the size of the audience exposed to advertisements. When all is said and done... it is still true that low taste content sells-big . . . it will be abandoned by the media only with great reluctance, if at all (emphasis supplied).

Yet there is some evidence that the portrayal of woman as sex object is on the decline (see inter alia: Gravesteyn, 1975; Cully and Bennett, 1976; Henstra and Pinckaers, 1976; Thaxton and Jaret, 1985). For instance, Venkatesan and Losco (1975) found that over a thirteenyear period from 1959 to 1971 there was an overall drop in the category "woman as sexual object" even when other stereotypical categories 
such as "woman as dependent on man" remained relatively stable throughout all thirteen years. This decrease was also accompanied by an increase in the category "woman as physically beautiful" in women's magazines (this was the most frequently portrayed category, 61 percent). In actuality, "woman as sexual object" remained quite pronounced in men's ( 53 percent of the portrayed females) and general audience ( 65 percent) magazines.

This emphasis on "female physical beauty/physigue," according to some authors (see inter alia: Sexton and Haberman, 1974; Millum, 1975; Ceulemans, 1977; Van Da Maele, 1978; Warren, 1978), seems to have increased a great deal in recent decades.

Loree (1977) interprets this particular development, in much the same way as the increased working woman/decreased housewife portrayal, as reflecting advertising's response to criticism of sexism by presenting a commercialized version of the liberated woman.

As Judith Williamson (1978: 170) argues, "the movement of 'Women's Lib' has provided advertisements with a vast amount of material which actually enhances their sexual stance." Specifically, she states:

There is a television ad for an aftershave "Censored" where a woman is beating a man at chess. But then he puts on the aftershave and she is so wildly attracted to him that she leaps up, knocking over the chess board where she had him check-mated, and jumps on him like a wild animal. Now, far from the effect being to make us realize how inadequate the man is if he cannot stand being beaten at chess by a woman, her "cool" and intelligence and obviously "1iberated" image are in fact made to devalue themselves: because the point is that even a cool, "dominating" woman, an intellectual threat to a man, even she will become little more than an animal, and a captivated one, on smelling "censored" cologne for men. It is obviously more of an achievement to win over 
a "liberated" woman than one who was submissive all along. Many ads are based on this sort of line: "she's liberated but..." (Williamson, 1978: 170-71).

In other words, in ads where a "hint of female aggression is added to 'spice the image," the only "real" message that comes through is that the potential buyer now has "an even greater feeling of power" (Root, 1984: 63). As Ceulemans (1979: 14) states:

Under the guise of sexual liberation, advertising has turned to manipulating one aspect of the new woman, i.e., her sexuality, to exploit the traditional image of woman as sex-symbol. Other dimensions of woman's personality and the numerous ways in which she participates in all spheres of contemporary life are as absent from advertising images as ever.

\section{WOMAN'S INEQUALITY AND ADVERTISING}

In reviewing the overall findings Ceulmans concludes:

The fact that the concept of the woman's role.. . has remained virtually unchanged over the past decades indicates that advertising is indeed not to be perceived as a vanguard of social development (1979: 13-14).

Rather, as Ceulemans (1979: 13) argues, the woman continues to be featured in the process of advertising in just two capacities: "as most sollicited (sic) consumers and as instruments of persuasion," and only by virtue of her two-dimensional role: "her role as housewife/ mother/wife and her function as a decorative and sexual object."

Of course, as Gaye Tuchman (1979: 533) points out, this may be due to the fact that the media, especially advertising, may be symbolically capturing the "real" position of women in American society-"their continued real lack of power." 
George Gerbner (1978: 46-47) explains the media's recent role in the depiction of women as an espousal of the politics of cultural resistance, where "the main function of culture (the system of messages that cultivates the images fitting the established structure of social relations) is to cultivate resistance to change." This can be done, as he goes on to explain (1978: 48), by "discrediting, isolating, or undercutting" the changes that have taken place in the status of women: where "women libbers" appear as "hostile, aggressive, and unappreciative of men"; where women are encouraged "not to let anyone tamper with their sacred right to rule over 'their place," and where "sexual liberation may be used as a ploy for sexual exploitation."

Vestergaard and Schroder (1985: 164-65) make this point as well when discussing the "recuperating effects" of advertising to the criticism of the woman's role.

First, they draw attention to a well-known series of cigarette ads--"you've come a long way baby." According to them (1985: 164):

By equating Women's Lib with demands like the right to smoke, it works to trivialize an important historical movement, projecting what was a minor side-effect as a major achievement of women's struggle for liberation.

Second, they draw attention to an ad for Elizabeth Arden Cabriole fragrances which they argue uses a more reproachful, annoyed tone of voice; the headline asking "Why can't a woman be like a woman?" As they describe this ad (1985: 165):

The first paragraph of the body copy shows that this question is probably asked by a man, which may turn it into a warning: men think that Women's Lib has gone far enough; 
a beautiful woman is not necessarily an attractive woman, at least not if "she thinks like a man, she acts like a man. Why can't she be more of a woman?"

of course, in order to ask such a question, as they go on to point out, "the source behind [it] must think he has access to the true meaning of femininity: Why can't a person who is biologically a woman conform to the accepted social norms of female behavior?" $(1985: 165)$.

Yet, some, such as Jean Umiker-Sebeok (1981: 249), believe that shifting women into ads typically associated with traditionally masculine products and activities, if the women "accept the advertising industry's identification roles with the objects," may "help to upgrade the image of females." In Umiker- Sebeok's words (1981: 248):

Advertisements for liquor and cigarettes-typically the products associated with the most macho male images - have already begun to feature more powerful gender displays where a young woman may be shown, for example, proudly holding up a drink made with "her" brand of rum . . . her reward for personal achievement in work or play.

However, mere presence as evidence of equality is arguable. As Tuchman (1979: 532) argues, and as discussed previously, "presence also enables the reiteration of stereotypes."

Because the focus of this study is to ascertain what a woman's "place" is in such advertising, the larger context of this is the "woman's place" in the history of alcohol use in the United States. A brief overview of that history will set the stage for the more limited consideration of the portrayal of women in distilled beverage advertising, a "place," as Marsteller and Karnchanapee (1980: 1) point out, which has been "carefully controlled for many years." 
THE AMERICAN HISTORY OF ALCOHOL USE AND THE "WOMAN'S PLACE"

Ideally, the "woman's place" in respect to alcohol use is capsulized in the phrase, "ladies don't drink." Yet, as Edith Hornik (1977: 19) points out, "this attitude is unrealistic." In fact, as she goes on to point out, women and alcohol have been entwined throughout recorded history (1977: 19).

Nonetheless, even today, in some circles, the notion that drinking alcohol is exclusively (and should be!) a male phenomenon is still quite prevalent. Indeed, as William Chafe (1979: 15) points out, "one of the remarkable themes of women's history has been the constancy of prescriptive attitudes toward woman's "place" over three and a half centuries." But even he goes on to point out (1979: 19, 21) that although the cultural norms have remained relatively stable through time, the same cannot be said about the behaviors of women when they find themselves facing different social and economic circumstances.

Yet, to understand how women's use of alcohol changed in America, because indeed it did, it is necessary to understand the social and economic conditions which altered the expectations of how women should conform to the values of the "woman's place." Specifically, it is necessary, as Marc Lender and James Martin (1982) outline in their book, Drinking in America, to look at three periods in American history: seventeenth and eighteenth century--"The Colonial Era"; nineteenth and twentieth century--"The Victorian Era"; and 1920 to present--"The Modern Era." 
The Colonial Era

When the Mayflower landed on the shores of Plymouth Rock, there was little opportunity for a leisure class existence or a polarization of labor between the sexes. Everyone had to become involved in the mainstream economic activities of the community if the New World was to get on its feet; crops had to be planted and harvested, animals tended, clothes made, gardens cared for, and food prepared (Chafe, 1979: 17). And of course, as Lender and Martin (1982:4) point out, "beer had to be brewed."

In fact, it appears that in colonial America, alcohol use and production "constituted a central facet of colonial life" (Lender and Martin, 1982: 8). For example:

o Not only was brewing beer incorporated into most colonial wive's household routines, but many colonists operated backyard stills called "limbecs" by the late 17 th century.

- Beer and cider were the usual beverages at mealtime; men, women, and even children shared the dinner beer.

- Some New England towns held "ordinaries"--weekly community gatherings with compulsory attendance where citizenry prayed, ate, drank, and caught up on local affairs; absentees were assessed a fine to be paid in liquor.

o Weddings, baptisms, holiday celebrations, ministerial ordinations, militia musters, and even funerals were normally wet: for example, in 1678, at the funeral of Mary Norton, wife of one of Puritan Boston's most celebrated clergymen, those who came to pay their last respects downed over 50 gallons of expensive wine.

- Even the Anglican and the Puritan church used communion wine (Lender and Martin, 1982: 4, 8-10).

In essence, it appears that while the "ideal image" of the "woman's place" in relationship to alcohol might be "ladies don't drink," the actual behavior of many colonial women permitted a much greater 
variety and freedom of activity (Chafe, 1979: 17; also see Howland and Howland, 1982; Lender and Martin, 1982). Of course, as Allen Winkler (1968: 433-34) points out, "men usually drank more than the women," and a drunken woman was still considered a "harlot" and of "no particular credit to their sex" demonstrating the "ideal" was not forgotten.

Nonetheless, in a period of time where women ran groceries, practiced medicine, served as midwives, teachers, nurses, and printer, and made an overall contribution to the economic stability of the country (Chafe, 1979: 19), drinking alcohol seemed a minor change in the "ideal" norms of the "woman's place." Indeed, the fact that in 1690 some 40 percent of all the taverns in Boston were run by women attests to the fact that the prescriptive norms about women appeared to exist more as part of society's rituals than as a major force dictating their daily lives (Chafe, 1979: 19).

Nineteenth century America, though, brought very different social and economic conditions, and with these, very different social expectations about the "woman's place."

\section{The Victorian Era}

Actually, nineteenth century America brought an abundance of change to the New World. Not insignificant was the increased use of alcohol in the post-revolutionary era. Frederick Marryat, novelist and naval officer, probably best sums up the American drinking patterns at this time (quoted in Winkler, 1968: 419):

They say that the English cannot settle anything without a dinner. I an sure the Americans can fix nothing without a 
drink. If you meet you drink; if you part you drink; if you make an acquaintance you drink. They quarrel in their drink, and they make it up with a drink.

This increased consumption (among other things), according to Winkler (1968: 413), led many to believe that America was facing a rea 1 "drinking problem" (also see Howland and Howland, 1982; Lender and Martin, 1982), a "problem" which required "moral reform" as a solution (Gusfield, 1955 and 1963; also see Winkler, 1968; Howland and How land, 1982; Lender and Martin, 1982).

Not lost in this "moral reform" was the concept of the "woman's place." In fact, as Chafe (1979: 16) points out, the continued veneration of the "ideal" woman in colonial America, where advice manuals still:

-. . instructed women to be modest, meek, obedient, and pious--qualities nearly identical with the piety, purity, submissiveness, and domesticity which the historian Barbara Welter has identified as principal components of the "cult of domesticity," actually provided the foundation for a different set of expectations for 19 th century women.

One expectation that differed was women's relationship to alcohol use. Specifically, by providing the message that God frowned on drinking, frequently religious messages made temperance a fundamental doctrine of Christianity (Winkler, 1968: 439); women, as the "ideal" protector of the home and nurturer of children, had the compelling duty not only to refrain from drinking themselves, but to save their sacred trusts from external threat (Bordin, 1981: 8). In other words, it became their "place" to protect the morality of their homes by setting a good example, thus the norm "ladies don't drink." 
Further, to be sure that no "external threat" (such as saloons) posed a "problem" to their homes and families, many "ladies" (the majority middle and upper-middle class) set about to be "the chief preceptors of national virtue" (Lender and Martin, 1982: 106). Thus, they formed the basis of the Women's Christian Temperance Union (WCTU).

While much can be said about the actions of the WCTU "... in paving the way for Prohibition" (Gusfield, 1955: 22; also see Gusfield, 1963 ; Hornik, 1977 ; Bordin, 1981 ; Howland and Howland, 1982), probably the most important consequence of the WCTU's involvement in the temperance movement, as Lender and Martin (1982: 106) point out, is that through the example of their own purity of behavior, nineteenth century women were forced onto the "proverbial pedesta1."

The significance of this lies in the fact that even when society was faced with estimations suggesting that between one out of ten to one out of three women were "problem drinkers," many Americans refused to see such women as "real women": "the ideal woman was virtuous and pure; alcoholics were degraded. Women defended the home; alcoholics imperiled it" (Lender and Martin, 1982: 117-18). In other words, by the time Prohibition came into existence (1920), the adage "ladies don't drink" was well entrenched as a norm for the "woman's place." The Modern Era

On January 17, 1920, the Eighteenth Amendment officially became law; "the forces against alcohol had won--politica11y" (Howland and How land, $1982: 50)$. 
But unfortunately for these "winners," the "drys," this was also the period of time that "the moral concept reached its height of popularity" (Howland and Howland, 1982: 50). Since the "moral concept," defining drunkness as "nothing but a wanton immorality, a willful sin" committed by a "moral degenerate" (a position reinforced in the popular literature of the period, 4 was the basis of the preprohibition era, this change would have dramatic effects. Yet, Prohibition was in effect, and many "drys" appeared quite satisfied and therefore did little to maintain their victory (Howland and Howland, 1982: 52).

This was understandable given that the first few years of Prohibition were quite successful; alcohol consumption sharply decreased, prostitution decreased, women no longer came to beg for advance on their husband's wages, industrial accidents went down, and wife and child abuse dropped sharply (Gordon, 1943; Whitehead and Ferrance, 1976; Howland and Howland, 1982; Lender and Martin, 1982). Even WCTU membership increased during this period, from 344,892 in 1982 to 372,355 in 1931 (Gusfield, 1955: 222). And of course, on August 18, the same year as this victory, the Nineteenth Amendment, granting the vote to women, was passed. Women were in the position to

4See Pfautz, Harold, "The Image of Alcohol in Popular Fiction: 1900-1904 and 1946-1950," Quarterly Journal of Studies on Alcohol, 23, 1, 1962: 131-46; Linsky, Arnold, "Theories of Behavior and the Image of the Alcoholic in Popular Magazines 1900-1966," Public Opinion Quarter1y, 34, Winter 1970-71:573-81; and Lender, Mark, and Karen Karnchanapee, "Temperance Tales," Journal of Studies on Alcohol, 38 (7), 1988: 1347-70. 
become the "housekeepers" of the nation (Chafe, 1979: 29), guaranteeing that there would be no return of "the traffic." At least, that is how it appeared.

But, as Howland and Howland (1982: 52) point out, what appeared initially as a colossal success turned rapidly into a stunning failure; "the moral concept was endangered." As Lender and Martin (1982: 166) point out, it appears that even women were changing their attitudes toward alcohol. Indeed, as they explain, instead of the "vote" driving "yet another nail into the coffin" of the liquor traffic, it actually appeared to be "chipping away at the cult of domesticity." Specifically, the increased free time and the diversification of lifestyles among women in this period created a situation where the mores of a sober republic "seemed increasingly dated in the eyes of many women, even if they did not drink" (Lender and Martin, 1982: 166). Such attitudes, as Lender and Martin go on to point out (1982: 166-67), were soon expressed in concrete form. Many women actually joined organized pro-liquor groups intent on repealing the Eighteenth Amendment. One such group was the Women's Organization for the National Prohibition Reform founded in May 1929 by a wealthy New York socialite with excellent political connections--Pauline Sabin. The interesting aspect of this group is the position it took in regard to the return of the liquor traffic; specifically, "home protection" (a concept developed by the WCTU to fight for Prohibition) was turned around to argue that it was Prohibition that was actually worse "for the protection of the American home" than legal liquor (Lender and Martin, 1982:166-67). 
While this could not be substantiated, and in fact, was "repudiated again and again" (Gordon, 1943: 131-32), Prohibition was nonetheless repealed in February 1933.

Yet, in relation to the "woman's place," the repeal did not bring with it a total acceptance that now women could drink. In fact, statements such as the one in an April 1936 issue of Harpers Magazine, that described women who drank as behaving in ways that were "embarrassingly loose and even sluttish" (quoted in Gordon, 1943: 225), indicated that the qualities that were still receiving the most praise at this time were those traditionally associated with being a "lady," not an assertive individual ready to face the world (Chafe, 1979: 69) or make an independent decision to drink (also see Gusfield, 1955).

Of course, as Chafe (1979: 118) points out, the "fundamental error" at this time was to exaggerate the ability of a political reform, in this case, the repeal of the Eighteenth Amendment, to transform an entire structure of roles and activities based on gender. Therefore, while it is certainly true that there were changing attitudes on beverage alcohol's place in society, to move to a total acceptance of women drinking was a bit much at this point.

It was not until World War II brought some major economic changes to the country, especially in relation to the "woman's place," where "female work patterns were virtually transformed in the years after 1940" (Chafe, 1979: 19; also see earlier discussion, especially Tuchman, 1978), that change started taking place regarding women's "ideal" place as homemaker. 
Further, it was not until the 1960's brought with it the advent of the modern women's movement, as previously discussed, that most people even became aware of the changing "place" of women.

Yet, with both these changes, among others (for instance, declining birth rates), there appears to have been and continues to be a "continuing decline" in the norms associated with the "ideal" of the "woman's place" (Chafe, 1979: 120-21).

One area in which this "continuing decline" in norms associated with the "woman's place" seems to be evident is with the norm "ladies don't drink." As Sharon Wilsnack (1976: 55) points out, not only has the proportion of women who drink risen steadily since World War II, but it has increased more rapidly than it has for men. Confirming this pattern, Whitehead and Ferrence (1976: 166) state:

In 1940 in the United States 64 percent of men and 38 percent of women aged 21 and over used alcoholic beverages. Proportions for United States citizens in 1965: 77 percent of men and 60 percent of women.

(Also see U.S. Department of Health, Education, and Welfare, 1971.) There is some evidence that this increase is largely due to younger women increasing their use of beverage alcohol (see inter alia: Cahalan et al., 1969; Hope, 1972; Milman and Su, 1973; Hanson, 1974; U.S. Department of Health, Education, and Welfare, 1974; Demone and Wechsler, 1976). As reported to the U.S. Congress by the National Institute on Alcohol Abuse and Alcoholism (NIAAA): "The fact that nearly all younger women drink stands in stark contrast to the dominant pattern of abstention among older women, and is undoubtedly a 20th-century phenomenon" (1978: 20). 
Not only are the drinking patterns changing, but there seems to be some evidence that attitudes about women drinking seem to be changing too. For example, Ratliff and Burkhart (1984) conducted a study on college students' motivations for and effects of drinking, and concluded that not only was drinking as socially acceptable for women as for men by the majority of the students, but even heavy drinking was as acceptable (1984: 31$)$.

However, these changes in patterns and attitudes of women drinking has led some researchers to conclude that women who drink, especially to excess, must be suffering from greater pathologies (see inter alia: Winokur and Clayton, 1968; Belfer et al., 1971; Beckman, 1975; Wilsnack, 1976; McLachlan, 1977; McLachlan et a1., 1979). Of course, not all researchers agree. In fact, as Ratliff and Burkhart (1984; also see Lisansky, 1958) argue, maybe the "greater pathologies" associated with heavy drinking among women than men have more to do with the "ideal" of the "woman's place" not being forgotten, rather than true "maladjustments." In their words (1986:26):

The fact that excessive drinking has traditionally been considered masculine behavior and more socially taboo for women has doubtless affected the different expressions and perceptions of pathology among heavy-drinking men and women. Professionals operating under the assumption that only greater pathology could elicit drunkenness among women may have perceived women alcoholics as sicker than men who were demonstrating similar traits. What appears to be greater pathology in women . . could be the result of the greater social disapproval . . rather than an indication of their greater maladjustment and disturbance.

Nevertheless, recognizing that alcohol use in general and especially use by women is a controversial subject, it does appear that women are becoming more equal consumers of beverage alcohol. As such, 
it might appear reasonable that advertisers, whose goal, after all, is to sell their product, would identify women as a "target market," and direct advertising toward them as co-equal consumers. It is the case, however, that this remains an empirical question, specifically: Just what is the "woman's place" in alcohol advertising?

\section{THE "WOMAN'S PLACE" AND ALCOHOL ADVERTISING}

With the repeal of Prohibition in 1933 , not only was the legal production and sales of alcohol re-established, but so was the alcohol advertising industry. Given that the alcohol industry, and the various state laws, stressed "temperance" (without defining the term) the advertising of alcohol took a determinedly "soft sel1" approach, ". . avoiding any themes that remotely suggested immoderation" or that would "prompt another reform drive" (Lender and Martin, 1982: $170,173)$.

Sam D. Chilcote, Jr., Executive Vice President of the Distilled Spirits Council of the United States, Inc. (DISCUS), probably best summarizes these points (1976: 211-12):

Industry executives at all levels were conscious of the fact that certain segments of the American public had highly emotional, rather than realistic attitudes toward any use of distilled spirits. In the minds of those people it was not a question of abuse but simply a question of use.

In an effort to maintain the good order that existed in their own houses, and to earn the favorable attitude of the general public, the distillers moved swiftly toward selfregulation.

Thus, in 1936, the Distilled Spirits Institute (founded in 1934), now known as DISCUS, put into effect a Code of Good Practice as 
practical evidence of the distillers concern for the public good. Among other recommendations, such as banning distilled spirit advertising on radio (later, 1948, to include television), Sunday papers, and religious publications, the use of women in such advertising was also banned. Indeed, as the current code is stated today (United States Congress, Senate Committee on Labor and Public Welfare, Subcomittee on Alcoholism and Narcotics, 1976: 213):

No advertisement of distilled spirits shall contain an illustration of a woman unless such illustration is dignified, modest, and in good taste and no such advertisement shall depict a woman in provocative dress or situation.

In addition, many state laws have also addressed the use of women in distilled spirit advertising (see inter alia: Summary of State Laws and Regulations Relating to Distilled Spirit, DISCUS, 22nd Edition, 1977). For example, current Oregon State law prohibits such things as the use of testimonials or the exploitation of the female form in newspaper or magazine distilled beverage advertisements (1977: 12).

Nonetheless, according to Marsteller and Karnchanapee (1980: 3), women did appear in advertisements of distilled spirits despite DISCUS' ban from 1936 to 1958. As they state (1980:3):

In the June 11, 1956, issue of Life, . . Bacardi Imports showed a gray haired, grandmotherly woman serving a Bacardi cocktail and flaming rum sausages.

[Likewise] - . a 1957 campaign sponsored by Rums of Puerto Rico [featured] the woman . . holding a glass of rum, a liberty DISCUS would not authorize until the end of 1963. 
Yet as they go on to point out, by drawing attention to several other examples, ads such as these only made the ban on the use of women in such advertising appear unrealistic (Marsteller and Karnchanapee, 1980: 4-5).

On November 20, 1958, twenty-five years after the repeal of Prohibition--DISCUS agreed; the ban was lifted. Of course, as Marsteller and Karnchanpee (1980:5) point out, not all the responses were positive. In the words of Gerald Keller (quoted in Marsteller and Karnchanapee, 1980:5):

Now that the restrictions have been relaxed on women appearing in liquor advertising, they should be eased into the position. They belong there just like any other prop to make the advertising situation look realistic. But, to come out and say, "Look, we've got women in our ads" or "We really always made our brand for women" is going to spell the kiss of death for any brand that adopts it.

As pointed out by Marsteller and Karnchanapee (1980: 5-7), the patterns that developed in the late 1950 s and early 1960 s relfected this concern and had much to do with fostering the "passive role" of women in such advertising at this time; women were passive props, naive, demure, and basically "teetotalers." It was not until the late 1960 s that women appeared in ads that demonstrated they "had taste, opinions about the beverages they drank, and the nerve to assert themselves at liquor stores" (1980: 7). Yet, as Marsteller and Karnchanapee (1980: 8) go on to point out, "the advertisements showing liberated shoppers usually emphasized their sexiness as well as their loyalty to a product." In fact, one dominant pattern emerging after women were permitted to appear in these ads "was the equation of women with beverages." For example, Catto Gold Label Scotch presented an ad 
where "a seductive woman in a mink jumpsuit says, 'I never say no to Catto"" (Marsteller and Karnchanapee, 1980:10). Implied was that if you buy this product, "I won't say no to you." This and similar ads equating alcohol beverages with sexual success prompted the DISCUS (1975) Board of Directors to adopt a resolution on September 8, 1975, stating, in part:

WHEREAS, recent isolated advertisements do not appear to be upholding the standards followed by the industry in the past regarding sex, sensualism, and suggestiveness, and ... WHEREAS, said Council has always felt that advertisements should not include copy or illustrations which are sexually titillating or which imply a link between drinking and sexual success; nor should any advertisement contain any demonstration of affection in such a way as to suggest sexual involvement between those portrayed; NOW, THEREFORE, BE IT RESOLVED by the Distilled Spirits Council of the United States, Inc., that it hereby expresses its disapproval of any and all advertisements which emphasize sex in such a way as to utilize sensualism and suggestiveness to encourage the purchase and/or consumption of any type or brand of distilled spirits... (quoted in Marsteller and Karnchanapee, 1980: 10).

But even with the adoption of this resolution in 1975 , Marsteller and Karnchanapee (1980: 10-11) argue that women continue to be exploited ". . as sex symbols seducing or being seduced by men, ${ }^{5}$. . as hostesses serving men, . . or, occasionally, as stubborn, opinionated women acting like men."

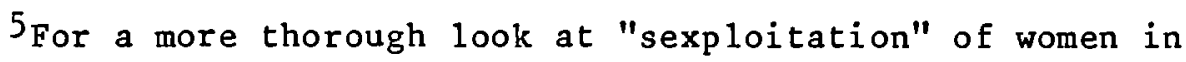
distilled beverage advertising see U.S. Congress, Senate Committee on Labor and Public Welfare, Subcommittee on Alcoholism and Narcotics, Media Images of Alcoho1: The Effects of Advertising and Other Media on Alcohol Abuse, Hearings, 94 th Congress, 2d session, 8 March $\frac{1976,}{\text {, }}$ especially testimony by: Robert Hammond (pp. 196-202), "Viewpoint" (pp. 203-9), Michael Looney (p. 315), and Wilson Bryan Key (pp. 173-81, author of Subliminal Seducation). Also see Breed, W. and Defoe, J.R., "Themes in Magazine Alcohol Advertisements: A Critique," Journa 1 of Drug Issues, 9, 1979: 511-22; Nationa1 Advertising Review Board (NARB), Advertising and Women: A Report on Advertising Portraying or Directed to Women, New York, NARB, 1975. 
In other words, according to Marsteller and Karnchanapee (1980), women continue to be featured in stereotypical roles synonymous with the "ideal" of the "woman's place," rather than as a "target market" for distilled beverage alcohol. Part of the explanation for this could lie in the fact that some people are still concerned about advertising's place in the increased consumption of alcohol by women in the last few decades. Thus in the view of Whitehead and Ferrence (1976: 178, 186), who argue that since women and children are "particularly vulnerable" to increased consumption, and that "mass marketing of alcoholic beverages must share some of the responsibility" for the rising consumption, all alcohol advertising should be banned. (A1so see Kohn and Smart, 1987.) While this may seem extreme, local and national concern has resulted in requests for much the same thing (see inter alia: Senate Hearings, 1976; The Oregonian, March 25 and 27 and May 19 and 20, 1984).

Given the considerable concern about such advertising, the fact that there is virtually no empirical evidence available concerning the types of appeals used or the specific content of alcohol messages (Pittman and Lambert, 1978) would seem especially surprising.

That is not to say that studies have not been done (see inter alia: Breed and Defoe, 1979, 1981 ; Marsteller and Karnchanapee, 1980 ; Atkin and Block, 1981), but as Strickland et a1. (1982: 660) point out, these studies, and particularly their results, are flawed by a number of analytic shortcomings:

(1) small or overly selective samples of advertisements;

(2) failure to standardize or in some cases, report categories used; 
(3) inadequate treatment of category reliabilities (in most cases, reliabilities are unreported);

(4) limitations in scope which prevent useful inter- and intramedia comparisons;

(5) reliance on anecdotal or illustrative evidence to support an interpretive framework; and

(6) unsupported causal attribution based solely on content find ings.

In an attempt to rectify the perceived flaws in these findings, Strickland et al. (1982) conducted a content study of alcohol advertising in magazines. A brief summary of their results include $(1982: 679-680)$ :

- The thematic analysis found the majority of themes used in magazine alcohol advertising to be product-related: quality, information and tradition or heritage were the most frequently occurring themes.

o Less than 40 percent of the ads contained human models; relatively infrequent were such controversial themes as sexual connotation, religious symbolism, hedonism, and self-indulgent reward.

- Male models were found in more ads than were female models; one-third and one-fourth respectively.

o Little support exists for the claims that supposedly vulnerable groups (blacks, women, youth) were targeted.

- In the magazines oriented to the women . . relatively low levels of alcohol advertising occurred.

While this is a very comprehensive study of an overall picture of alcohol advertising, what is particularly troublesome is that while the authors criticize Marsteller and Karnchanapee's study of the use of women in the advertising of distilled spirits as being "unscientific. . [with】 the absence of an attempt to perform any kind of systematic analysis of content" (1982: 658 ), they do not specifically 
apply any systematic analysis of the role of women in such advertising. As this review indicates, there is a relative dearth of empirical evidence available concerning the "woman's place" in alcohol, and more specifically in distilled beverage, advertising. In an attempt to at least partially fill this knowledge gap, this study focuses upon two major hypotheses derived from the literature review above.

First: The portrayal of women in distilled beverage advertising emphasizes the sexual persuader role over the consumer role.

Briefly summarized, the rationale underlying this hypothesis is that the appeal to women in advertising tends to take one of two forms, that of valued consumers or of manipulable persuaders as stated by ceulemans (1979: 13). The literature reviewed above indicates that while either of these might be possible, alcohol advertisers appear to have concentrated upon one aspect of the new woman, her sexuality, and have in essence continued to exploit the traditional view of women as sex objects.

Second: Laws, rules and regulations addressing the issue of women in distilled beverage advertising have had little impact over time in the portrayal of women in such advertising.

Again, a brief summary of the rationale of the hypothesis seems to be in order. Although the women's movement has had an impact upon the public proclamations of the spokespersons for the industry, in actual fact it is business as usual in the advertising presentation of the "woman's place" as subservient to the man, and hence little change will be observed over time in the utilization of women in distilled beverage advertising. 
In the following chapter, IV, the methodology will be presented including the development of the coding sheet used to assess the above hypotheses. Chapter IV will also include the study limitations. 
CHAPTER IV

METHODOLOGY

POPULATION

Considering that the major goal of this study is a determination of the portrayal of the social worlds of maleness and femaleness in distilled beverage advertisements and recognizing that not all such advertisements could be analyzed, three magazines representing a range of audience appeals were selected: Playboy, aimed primarily at men; Cosmopolitan, designed primarily for women; and a general audience magazine, Newsweek. 6

The population under examination is the distilled beverage advertisements which appeared in these magazines between 1958 (when the ban on the use of women in distilled beverage advertisements was lifted) and 1985. These magazines were selected because (1) they were found apriori (see Strickland et al., 1982) to be among the largest circulation magazines in the U.S.; indeed, each has a circulation of over two and a half million (Gale Directory of Publications, 1988:

${ }^{6}$ Newsweek was chosen as the "general audience" magazine because other magazines with a large circulation (e.g, People, TV Guide, Readers Digest, National Geographic, etc.) that might appear as more appropriate were found to contain few or no advertisements for alcohol (Strickland et al., "A Content Analysis of Beverage Alcohol

Advertising," Journa 1 of Studies of Alcohol, 43 (7), 1982: 655-82) or were initially published post 1970 making them invalid for this study. 
$383,943,988)$; (2) they either appeal to a specific target audience-men, women--or a general audience; (3) they were in publication for the time span of this study; (4) they were found apriori (see Strickland et a1., 1982, and Atkin et al., 1984) to contain the most distilled beverage ads within the subcategories of magazines this study is focusing on: men's, women's, and general audience; and (5) from preliminary investigation, they are the ones that make the greatest utilization of women in distilled beverage advertisements. ${ }^{7}$

\section{SOURCE OF THE SAMPLE}

The sampling strategy involved an attempt to maximize three analytic goals within a limited time frame: (1) to secure distilled beverage ads reaching the largest possible audience within the subcategories of magazines mentioned earlier; (2) to secure distilled beverage ads in issues of these magazines which contained the greatest number of human models in the twenty-eight year time span under investigation; and ( 3 ) to achieve a relatively representative overall sample of distilled beverage ads which feature human models. To meet the first goal, sampling took place using the three magazines determined to be the largest circulation magazines within the subcategories with the greatest number of distilled beverage advertisements. Preliminary investigation was directed toward the second goal.

7 The emphasis on woren in such advertisements is not to suggest that there is a complete lack of interest in the male's role within this type of advertising (as will be demonstrated in Chapter v). Yet, as mentioned before, since alcohol advertisements have always been associated with the most "macho male" images, the emphasis will be more on the "woman's place." 
Several issues over the twenty-eight years indicated little difference in content (with the exception of the special occasion/holiday theme and gift suggestions), but a great difference in the number of ads featuring human models between the December issues and those from the other months of the year with, in some cases, the December issues featuring three times as many such ads. As such, the December issue was selected for the monthly publications (Playboy and Cosmopolitan) and the third week of the month was randomly selected from the December issues of Newsweek, a weekly publication. In a11, 84 issues were identified for the study; 28 December issues of Playboy, 28 December issues of Cosmopolitan, and 28 third-week December issues of Newsweek, spanning the time frame from 1958 to 1985. Within these issues, 1,447 distilled beverage advertisements were found and identified; of these, 520 featured human models.

According to Strickland et a1. (1982: 647-75), men's magazines appear to be grouped in either a sex and nudity category or a sports and auto category. Likewise, women's magazines can be grouped in either the fashion and beauty category or the home and family category. Because this study drew the sample from men's sex and nudity category and women's fashion and beauty rather than the other categories, and due to the fact this was not simple random sampling, the research findings may have been biased. On the other hand, the fact that there was less concentration of distilled beverage advertising in these other categories, few or no ads in some cases (see strickland et a1., 1982: 674-75), one could argue that the sample is probably quite representative of the "message created" in magazine distilled beverage 
advertisements that feature human models. This influence or lack of influence is discussed more fully in Chapter $v$.

\section{DEVELOPMENT OF THE CODING SHEET}

The means by which one can answer "what" is the specific content of the "message created" in distilled beverage advertisements, as mentioned previously (see Chapter III; Worth and Gross, 1974; Williamson, 1978; Vestergaard and Schroder, 1985; Leiss et al., 1986), is to analyze such advertisements by techniques normally applied to verbal and visual art.

Such a technique, and one that is predominantly used in studies of advertising (see Chapter III, above, particularly Busby, 1985), is content analysis. (Because the focus of this study is on the qualitative representation of women in distilled beverage advertising, such a technique is quite applicable to the measurement of the "message created.")

For this study, a single in-depth coding sheet (see Appendix A), with an abbreviated form (see Appendix B), was used to obtain data from the sample of distilled beverage magazine advertisements. For the most part, this process was accomplished by using (with revisions) an existing instrument developed by Donald Strickland and associates (1982) for their study: "A Content Analysis of Beverage Alcohol Advertising: Magazine Advertisements." The rationale for use of this instrument was twofold.

First, since, as noted previously (see Pittman and Lambert, 1978), there has been virtually no empirical evidence available 
concerning the types of appeals used or the specific content of alcohol advertising messages, this instrument helped to define the parameters of an objective, systematic analysis of the messages contained in alcohol advertising. Specifically, this meant not only outlining the "structural characteristics" (i.e., the identification number of the ad, the magazine name, the year of the issue, the number of pages, the brand and type of beverage, the size of the ad, the color format, and whether or not the ad featured human models, a "characteristic" included in this study), but presenting the broad areas of content categories to be analyzed: "themes and appeals, portrayals of human models, and techniques of presentation" (Strickland et a1., 1982: 661-62).

Second, the degree of intercoder reliabilty assessing the results in Strickland et al.'s study appeared quite acceptable (an overall average of .78 ). More will be mentioned on this point when addressing the intercoder reliability of the present study.

\section{Themes and Appeals}

While Strickland et al.'s study included twenty-two thematic categories, with a mean intercoder reliabilty score of .62 (1982: 663), the substantive interests of the present study dictated the inclusion of only fourteen of these categories.

of the fourteen categories selected from Strickland et al.'s study, the mean intercoder reliability score, as reported by Strickland et a1. (1982: 664), was .60 with a range of .41 - .81. This score was computed, as Strickland et al. (1982: 663) point out, 
by "using Krippendorff's (1980) refinement of Scott's pi (1955)," thus "controlling for the degree of agreement expected by chance." Indeed, as they (1982: 666) go on to point out, if the intercoder reliability score had been computed using the average percentage coefficient (the usual measure in content analysis, when reported), the overall score would have been above .95 , a score "substantially higher than the summary reliabilities reported in previous studies of alcohol advertising." For this reason, thirteen of the fourteen themes drawn from the Strickland et al. study were not revised for this study. The fourteenth theme though, sexual connotations, was quite troublesome given the review of the existing literature related to this theme (see Chapter III), even though the intercoder reliability score was reported by Strickland et al. as being .71 .

As Strickland et al. defined this thematic category, "Sexual Connotations" were to include:

o References suggesting sexual encounter;

o This can include references in the text of the ad such as naughty, discreet, tempting, kisses but never tells, etc.;

o (Provocative) poses of models suggesting sexual availability or sexual encounters;

but were not to be coded "present" for such things as:

- Good looking or sexy models that are less than "provocative";

- Models that are simply "showing skin," but are less than provocative;

o (Where love and romance or close friends might be more appropriate themes.) 
"Sexy" yet less than "provocative," "simply showing skin" but less than "provocative," to whom (emphasis supplied)?

According to the research on the "representation of woman as sex object" (see Chapter III), the use of women in "sexy" poses, which often include "showing skin," is a strong indication that sexual connotations exist in such advertisements. 8

Judith Williamson (1978: 80) specifically points this out when arguing that whenever a woman is presented in an ad alone where her dress (or blouse) is unbuttoned "provocatively," in other words, where she is "showing skin," this indicates two things: (1) she may be "sexy" but "not in a passive way" and (2) this is done entirely for the gaze of a man who "is conspicuously absent." As such, the ad becomes a "sexed one." In her words, the man who is absent: . . . is nowhere and everywhere, a pervasive presence defining and determining everything, and in whose terms the woman must define herself. She is doomed to see herself through his eyes, describe herself in his language (1978: 80 ; original emphasis).

As such, women in unbuttoned blouses, low-cut dresses and other poses "showing skin," were included in the thematic category "sexual connotations" in the present study.

Further, because many times the language is used "to invoke certain areas of 'reality' besides carrying a direct message... [giving] it the capacity for uniting several meanings in one"

8 This point was specifically made about alcohol advertising by the Viewpoint, (June 1975) in describing the use of "semi-clothed blonds" in the Black Velvet ads as "sexploitation" at the Hearings before the Subcomittee on Alcoholism and Narcotics (1976: 206-7). 
(Williamson, 1978: 86; original emphasis), the caption of the advertisement was included in the present study to ascertain if sexual connotations existed in the ad. For instance, from a 1981 playboy ad for Black Velvet where a woman with no obvious relation to the product is presented in a black velvet gown and with the caption "feel the velvet," the reader not only is given the denoted message referring to the product, but because of the "referent system" pertaining to gender, is given the connotated message of just where to "feel the velvet." In this way, the product and the model are simultaneously brought together and actually create more than one meaning. Such usage of language, especially in the form of puns, as Williamson points out (1978: $86-87$ ), provides a "short cut between a product and a referent system" and is essential in understanding sexual connotations even in ads where the model is presented in "less than provocative" poses (also see Marsteller and Karnchanapee, 1980: 8-9).

While strickland et al. do draw attention to this point by the inclusion of "references in the text.. Such as naughty, discreet, tempting, kisses but never tells, etc.," included in the present study's instrument are: (1) puns such as "sip into something comfortable" and (2) references that equate the mode1(s) with the product. Thus, in the revised version used in this study, "Sexual Connotations" were coded "present" for:

o References suggesting sexual encounter;

- This can include references in the text of the ad such as naughty, discreet, tempting, kisses but never tells, etc.;

o (Provocative) poses of models suggesting sexual availability or sexual encounter; 
o Puns such as "sip into something comfortable," "Get into shorts," etc.;

- References not only to the product but to the model also; "I never say no to "';

- Provocative dress styles (low-cut dresses, unbuttoned blouses, etc.)

and not coded "present" for such things as:

o Where it appears love and romance is a more important ingredient in a relationship or close friendship;

- Get-togethers where no sexual connotations exist;

o Where mode1(s) are attractive yet not implying any sexual reference (see Appendix A III: 12).

As presented in this form, it is believed that a more in-depth qualitative indicator of sexual connotation was developed than would have been the case if the Strickland et al. format had been employed.

Finally, two new themes ("Host/Hostess"; see Appendix A III: $3,4)$ were constructed and included in the "themes and appeals" section of this study. These inclusions were based on the degree to which women were shown "as hostess serving men," as Marsteller and Karnchanapee (1980: 11) argue. Much of the format for these themes was drawn from the "language" of the other themes developed by Strickland et al. A complete list of the sixteen themes and their definitions can be found in Appendix A.

Portrayals of Human Mode 1s

Like that of strickland et al., this study included such dimensions as dress styles, physical proximity, focus of attention, and relational posture. Yet because Strickland et al. didn't exactly define these dimensions, much of the coding for these areas was based 
on a review of the related literature, specifically from Goffman's analysis of Gender Advertisements (1976) and Williamson's book, Decoding Advertisements (1978). Further, based on this literature, it was deemed appropriate to add a dimension describing whether or not models were presented in full figure or only partial presentation (i.e., heads on $1 y$, hands on $1 y$, etc.).

What this study did not include was strickland et al.'s emphasis on blacks, ages, and celebrity models. Again, this is not to suggest the unimportance of these topics but as noted previously, the focus of this study is on the "woman's place," no matter "who" they are.

\section{Techniques of Presentation}

Included in this study, like strickland et al.'s study, were the various settings depicted in the ad (e.g., tavern or restaurant, indoors, outdoors, fictional), the displays of the product (including the numbers of beverage containers and drinks portrayed), and the various promotional techniques used in the ad, such as recipe offers, suggestions of how much to drink, claims of product purity, naturalness, and caloric content.

But unlike Strickland et al., two other "techniques of presentation" were included in this study: (1) the "caption of the ad" to assess the phrases used to "grab" the audience and (2) the model's (when appropriate) sex and relationship to the product (e.g., the number of males and/or females holding drinks, drinking, or just being "decorative" with no functional relationship to the product). According to some (see Chapter III, particularly Williamson, 1978), 
these two inclusions under "techniques of presentation" can help to identify the purpose the model(s) serve by their inclusion in the ad.

\section{Target Market}

For this particular study, a fourth content category was included as a separate area to be analyzed: that of "target market." Strickland et al. did address this issue; as they point out (1982: $656,675,680)$, one of their main goals was to ascertain if "supposedly vulnerable groups (blacks, women, and youth)," were being disproportionately targeted in massive magazine advertising programs. Their conclusion was that there was "little support for the claims" (1982: 680 ; emphasis supplied).

What was troublesome was the method used by strickland and his associates to determine whether women were being "targeted," disproportionately or not. Specifically, they used a quantitative approach, counting the number of ads in the sampled issues and dividing the total number by the number of pages in a year's issues and rank-ordering by number of pages per alcohol ad. From this process, strickland et al. concluded that "relatively low levels of alcohol advertising"9 occurred in magazines oriented to women, thus the women were not being disproportionately targeted (1982: 680). While counting ads is certainly one way that "target market" can be calculated, it can be argued that even if the same number of ads

${ }^{9}$ It should be noted that Cosmopolitan was one of the few magazines to carry over 200 ads $(245)$ in the twelve issues they examined. Playboy (357), Psychology Today (250), and Penthouse (207) were the other such magazines. 
appeared in women's magazines as in men's or other magazines, this would not necessarily constitute women as the "target market."

Much of the rationale for this belief has been cited previously (see Chapter III), but to reiterate using Gaye Tuchman's words (1979: 536):

Radio, television, newspapers, and magazines all seek to deliver as many consumers as possible to advertisers. Like advertisers, they speak the language of "markets" for specific products. Which messages are formed depends on the market sought (emphasis supplied).

Thus, the key is not how many ads, but what message is being created for the "target market." Since, as George Gerbner argues (1972: 156), "every decision to communicate certain things is at the same time a decision to suppress other things," the inclusion of this fourth content category as a separate area to be analyzed was deemed a very important aspect of the analysis of the "woman's place" in distilled beverage advertisements. Indeed, if women are included in such ads to create the message that they have, in fact, become emerged "into first-class citizenship" (Cisin, 1982: 153), worthy of being "targeted" for a product historically associated with the "macho male" role, this would indicate a change or an active altering of the previous existing cultural context that "ladies don't drink." On the other hand, if the message is that women are not being "targeted" as consumers, their inclusion in distilled beverage advertising may be communicating qualitatively a "reiteration of stereotypes" (Tuchman, 1979: 535), specifically, women as sex objects to attract attention for the "real" target market: men. 
With the inclusion of this content category, a definition of "target market" is in order. Simply defined, a "market" is potential consumers for a product. As discussed earlier (see Chapter III), advertising did not come about until certain social conditions (e.g., mass-production techniques, literacy, and a medium to reach the public) existed.

But, advertising has come a long way. As Leiss et al. (1986: 156) explain, today one can speak more accurately of "market segmentation." This is the process by which "advertisers can draw upon the specialized knowledge of fragmented audiences, so that the same product can be sold in different ways to different groups" (Leiss et a1., $1986: 156)$

This specialization implies that advertising can now be "user-centered" rather than "product-centered" where "the core of advertising's purposes is not the message itself as a commicators of meaning, but rather its relationship to the audience (Leiss et al., 1986: 151 ; original emphasis).

As such, "target market" can be defined as the group that can "evoke associations with what is 'stored' in their memories and imaginations" with that which the advertisers encode in the message (Leiss, et al., 1986: 152).

\section{Intercoder Reliability}

In order to assess the reliability of these new inclusions and the revision of Strickland et al.'s thematic category "sexual connotation," an outside person unfamiliar with the study was asked to 
independently code a subsample of ads using the coding sheet as deve1oped for this study. Given the difficulty of a time limitation for the independent coder volunteering, only one issue of playboy was used to assess the reliability of the developed instrument. The reason for using Playboy rather than Cosmopolitan or Newsweek is that from preliminary investigation it was determined that playboy contained more distilled beverage advertisements. Because only one issue of playboy was being used, no intercoder reliability was computed for the "structural characteristics."

For this study the "percentage-of-agreement" computation was used to assess the overall mean intercoder reliability score. As Atkin and Block (1984: 94) point out, this computation "is the kind most widely used in the content-analysis literature (and) has the advantages of simplicity and ease of understanding. . . "

The overall mean intercoder reliability score resulting from this procedure was .70 for the techniques of presentation" (.95 when comparing the ratings made) $;^{10} .77$ for the "relevant characteristics of human models" (.98 when comparing the ratings made); .71 for the "themes and appeals" (.97 when comparing the ratings made); and .53 for the "target market" (.83 when comparing the ratings made) 11 for an overall average intercoder reliability of .66 (.93 when comparing the ratings made).

10Five ads were missing in the independent coder's file; time limitations prevented a follow-up on this.

11 Not only were the five ads missing, but two ads were missing this information, further reducing the number of ratings made in this section. 
Given that the overall intercoder reliability score would have yielded .95 in strickland et al.'s study, had they used the percentage-of-agreement computation (1982:665), and the fact that of the ratings made in the present study an average intercoder reliability score of .93 , with a range of $.83-1.00$, was computed, it could be argued that the intercoder reliability of the present study is quite comparable to Strickland et al. study.

Yet, limitations do exist in this study's intercoder reliability scores: (1) the total number ads rated in this manner was quite small (only fourteen); (2) these ratings only applied to the ads in the one issue of Playboy; (3) time limitations prevented follow-up of intercoder reliabilities; and (4) both coders in this process were female, and as has been pointed out by some (see Holakan and Stephan, 1981; Thaxton and Jaret, 1985), the sex of the observer can have an effect on the perceptions of "what" is being seen, especially in the portrayal of women.

While noting these limitations, the coding sheet, as developed, was deemed acceptable for the collection of data for this study.

\section{DATA COLLECTION PROCEDURES}

Prior to the initiation of data collection, an abbreviated form of the coding sheet was developed (see Appendix B). The rationale for this procedure was twofold: (1) the original coding sheet was quite cumbersome and (2) budgetary constraints dictated a more compressed version of the coding sheet. 
Once the abbreviated form of the coding sheet was developed, the collection of the data began at the Multnomah Public Library in Portland, Oregon, in April 1987 with the 1958 hard copy, December issue of Playboy. Over the course of the next few months, April, May, June, July, and August of 1987, all hard copy issues of playboy, Cosmopolitan, and Newsweek for the time span needed (1958 to 1985) were found and coded. Most of the issues of Playboy were coded at Multnomah County Library. Spokane Public Library in Spokane, Washington, carried the early years of Cosmopolitan (1958-1970). King County Public Library in Seattle, Washington, carried the remaining issues of both Cosmpolitan and Playboy. All the third week December issues of Newsweek were coded at Portland State University Library. The coding of one issue took an average of forty-five minutes. As each ad was coded, the abbreviated coding sheet was put in a manila folder marked with the magazine name and year of issue and then stored.

DATA PREPARATION AND ANALYSIS

\section{Data Preparation}

As indicated, content analysis is a quantitative method applicable to what has traditionally been called qualitative material. As such, this study employed a computer-aided analysis of the data.

To begin with, this process involved assigning a numerical code to each variable in the study. Each ad was assigned an identifying number which consisted of: (1) the place in sequence that the ad appeared in each issue (no issue contained more than 43 ads); (2) the 
code for the magazine ( 1 for Playboy, 2 for Cosmopolitan, and 3 for Newsweek), and (3) the year of the issue (58-85). Therefore, the first ad in Playboy, in the year 1958, was assigned the identifying number 01158; Cosmopolitan's first ad in 1958 was 02158 . In other words, all identifying numbers were exclusive of one another. Once this was accomplished, all were coded for relative characteristics pertaining to the ad (see Appendic $C$ for a complete outline of the computer coding process), including the assignment of a missing value when appropriate.

Yet, a few changes were included in this process. Because "cocktails" and "Vermouth" were written in on the abbreviated coding sheet quite often in the "other" section of the "type of beverage," these were coded as separate types of beverages. Likewise, in the "promotional techniques" section, "gift" was separated from "other" promotions. Other changes included adding a separate code for males and/or females presented "waist up" as a partial presentation of model(s), and for males and/or females "looking outside the ad, but not at the audience" as a separate focus of attention. Again these were written in quite often.

Further, many relational postures were excluded in the computer analysis as they were deemed non-applicable (few or no cases).

Following these changes, each ad was "filed" in the computer; a process which took all of September 1987 and most of October 1987. 


\section{Data Analysis}

In that the purpose of this study is exploratory, descriptive statistics were employed. Specifically, this involved first, the computation of frequency distributions for each of the variables, not only for a description of the total sample, but also to isolate the ads which featured human models.

Once the ads which featured human models were computed as a separate sample, frequency distributions were again computed for each variable.

Following this, and guided by one of the hypotheses, certain variables were recoded to ascertain the number of ads which featured only female models, only male models, and models in mixed company. An added elaboration was performed to ascertain the number of ads which featured couples on $1 y$.

The rationale for recoding these variables in this manner was to be able to perform bivariate analysis, "any presentation of data in which an attempt is made to relate two variables to one another" (Williamson et al., 1982: 386), to detect relationships and/or the lack of relationship between ads of different composition, thus offering some explanation for the findings.

Further, the years of issue were recoded to represent different eras of time. As previously mentioned (see Chapter III; specifically Marsteller and Karnchanpee, 1980), the rules and regulations applying to the "woman's place" in such advertising appeared to have an affect on the presentation of women. Thus 1958 (when the advertising ban was lifted) to 1963 (when the regulation not allowing women to be shown 
holding drinks was liberalized by DISCUS), was recoded as the "demure" era; 1964 to 1975 was recoded as the "sexy" era (as the ads appeared in this time to emphasize sex to sell the products), and 1976 to 1985 was recoded as the "modern" era.

Likewise, the themes were recoded following Strickland et al.'s (1982: 666-67) dichotomy of product-related and human models-related themes. Specifically, the product-related theme was recoded to include the quality, tradition or heritage, and information themes. Human models-related themes were recoded, per Strickland et al.'s coding, as (1) lifestyle theme (including achievement and success and general success), (2) psychological-oriented theme (including selfreward and individuality), (3) sociable (including (close) friendship, relaxation, camaraderie, and special occasions and holiday celebrations), and (4) sexy theme (including sexual connotations and love and romance). Additional recodings of human model themes included server (combining host and hostess themes), and sports (which was a recoding of the physical theme). After this recoding, no ad contained more than four themes. In fact, as shown in Table I, most ads ( 89.4 percent) contained only one or two of the themes as recoded.

\section{TABLE I}

FREQUENCIES OF THEMES PER ADVERTISEMENT

Number of Themes

\begin{tabular}{lcr} 
in Ad & Frequency & Percent \\
\cline { 1 - 1 } One & & \\
Two & 223 & 42.9 \\
Three & 43 & 46.7 \\
Four & $\frac{9}{520}$ & $\frac{1.7}{100.0}$ \\
Tota 1 & Missing Cases $=0$
\end{tabular}




\section{LIMITATIONS}

One limitation of this study is the reliance on a single coder during the coding process. While, as indicated, there was an independent intercoder reliability test on a subsample of the ads to assess the reliability of the content categories, this subsample was indeed quite small. And since, as Sexton and Haberman (1974: 42) point out, the fact is that "different individuals may and do classify a given ad differently even when they refer to the same set of definitions," this lack of independence between coders during the coding process probably inflated the reliability coefficients of some of the content categories (Strickland et a1., 1982:660). On the other hand, especially in the themes and appeals category, because much of the instrument was developed using Strickland et al.'s content categories, many with no changes, this limitation may not have seriously inflated the reliabilities.

Another limitation, and one also mentioned previously, is the non-random sampling. Yet again, as mentioned, in that the present study is exploratory in nature and that the sample was drawn from the magazines with the most exposure, one can argue that it is probably quite representative of the "message created."

A final "limitation" of this study, in comparison with Strickland et al.'s study, is the lack of removal of duplicate ads. In criticizing a study of beverage alcohol advertising done by Eveslage et al. (1978), Strickland et a1. (1982: 658) argue that the use of duplicate ads can lead to "the frequency of occurrence of some 
groups of themes," thereby inflating the percentages. While this may be true, because in this study ads were rarely duplicated (if at al1) in the same issue of one magazine, each of the magazines was selected for a specific "target market," and most importantly only one issue per year per magazine was selected, no duplicate ads were removed.

Furthermore, because a more important purpose of this study was to explore the "message created" over time, the duplicating of ads from year to year, indicating the same "message," was deemed a meaningful aspect of the analysis rather than a "limitation." For this reason, all 520 ads which featured human models were included in the analysis.

Chapter $V$, following, presents the findings of this analysis. 


\section{CHAPTER V}

\section{FINDINGS}

This chapter outlines the findings of the content analysis of the distilled beverage advertisements drawn from the sample of Playboy, Cosmopolitan, and Newsweek magazines. Descriptions of the total sample and the human models subsample (differentiated by female only, male only, mixed company, and couples only) containing and not containing sexual connotations are presented. The final section is an evaluation of the hypotheses.

\section{DESCRIPTION OF THE TOTAL SAMPLE AND HUMAN MODELS SAMPLE}

As mentioned, 1,447 distilled beverage advertisements were found and identified, constituting the total sample; of these, 520 featured human models--the human models sample

A overview of the characteristics of these two samples will set the stage for more detailed analysis.

\section{Techniques of Presentation}

Table II contains the "techniques of presentation," the "objectively definable items" (Strickland et al., 1982;667), in number and percent, for the total sample and human models sample. Magazine. In both samples, the majority of the ads were found in playboy, 49.3 percent in the total sample and 54.8 percent in the 
"TECHNIQUES OF PRESENTATIONS" VARIABLES FOR THE TOTAL SAMPLE AND HUMAN MODELS SAMPLE IN NUMBER AND PERCENT

Total Sample

Number Percent
Human Mode1 Sample Number Percent

Magazine

\begin{tabular}{lrr}
\hline Playboy & 714 & 49.3 \\
Cosmopolitan & 397 & 27.5 \\
Newsweek & 336 & 23.2 \\
\cline { 2 - 3 } Total & 1,447 & 100.0
\end{tabular}

285

$127 \quad 24.4$

Tota 1

Brand*

Seagrams

Johnnie Walker

Gordon's

$\mathrm{J} \& \mathrm{~B}$

Other

Total

$\begin{array}{rrlrr}109 & 7.6 & \text { Seagrams } & 44 & 8.5 \\ 46 & 3.2 & \text { Jack Daniels } & 28 & 5.4 \\ 44 & 3.0 & \text { Martini \& Rossi } & 21 & 4.0 \\ 44 & 3.0 & \text { Smirnoff } & 21 & 4.0 \\ 1,204 & 83.2 & \text { Canadian Club } & 16 & 3.1 \\ \overline{1,447} & \overline{100.0} & \text { Other } & \frac{390}{520} & \frac{75.0}{100.0}\end{array}$

Total Sample Number Percent
Human Model Sample Number Percent

Type

Vodka

Bourbon

Scotch

Canadian

Gin

Rum

Brandy

Tequila

Liqueur

Vermouth

Cocktails

other

Other whiskey

Total

70

145

326

138

125

120

89

53

27

276

33

24

$\frac{18}{1,444}$

Missing Cases
4.8

10.0

22.6

9.6

8.7

8.3

6.2

3.7

1.9

19.1

2.3

1.6

$\frac{1.2}{100.0}$

$\frac{108}{520} \quad \frac{20.8}{100.0}$ 
TABLE II (CONTINUED)

"TECHNIQUES OF PRESENTATIONS" VARIABLES FOR THE TOTAL SAMPLE AND HUMAN MODELS SAMPLE IN NUMBER AND PERCENT

$\frac{\text { Total Sample }}{\text { Number }}$

Size

Under $1 / 2$ page

$1 / 2$ to i full page

Full page

$>$ full to \& 2 pages

2 or more pgs.

Tota 1

Missing Cases

Color

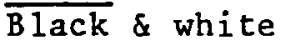

Color

Mixed

Total

Missing Cases

Human

Yes

No

Tota 1

Missing Cases

Environment

Tavern, restaurant

Indoors

Outdoors, party

Outdoors, beach

Fictiona 1

Total

Missing Cases

Promotions

Recipes

Purity

Naturalness

Caloric

Suggestions of how to

drink

Gift

Other Promotions

Total

\begin{tabular}{rr}
178 & 12.3 \\
150 & 10.4 \\
1,066 & 73.8 \\
9 & .6 \\
41 & 2.9 \\
\hline 1,444 & 100.0
\end{tabular}

(3)

\begin{tabular}{rr}
520 & 36.0 \\
925 & 64.0 \\
\hline 1,445 & 100.0
\end{tabular}

(2)

101

1.8

7.1

3

191

.2

13.3

$\frac{1,112}{1,433}$

(14)

$\frac{77.6}{100.0}$

149

33.6

2.4

19

4.3

0.0

\begin{tabular}{rr}
50 & 11.3 \\
166 & 37.4 \\
49 & 11.0 \\
\hline 444 & 100.0
\end{tabular}

\begin{tabular}{rr}
188 & 13.5 \\
1,135 & 81.8 \\
65 & 4.7 \\
\hline 1,388 & 100.0 \\
$(59)$ &
\end{tabular}

70

402

$\frac{25}{497}$

(23)

45

63

396

$\begin{array}{r}5 \\ 11 \\ \hline 520\end{array}$

uman Mode1 Sample Number Percent

520

100.0

$\overline{520}$

$\overline{100.0}$

24

87

4.6

120

$\frac{283}{517}$

(3)

51

35.7

6

3

4.2

2.1

0.0

22

15.4

$44 \quad 30.7$

$\frac{17}{143} \quad \frac{11.9}{100.0}$ 
human models sample. This finding was not unexpected given that in both preliminary investigations and from Strickland et al.'s study (1982: 672), Playboy was apriori determined to contain the most distilled beverage advertisements of the three magazines examined in the present study. Likewise, the fact that Cosmopolitan ranked second in both samples (27.4 percent for the total sample and 24.4 percent for the human models sample) was not unexpected. As mentioned previously (see Chapter IV; particularly Strickland, et al., 1982: 672), Cosmopolitan was one of the few magazines to carry over 200 ads per the year's issues. (Note that percentages hereafter will represent the total sample first, followed by the human models sample.)

Brand. Because sixty-eight different brands were observed (the sixty-ninth considered "other"), only the brands which were featured in 3 percent or more of the appearances were listed separately in this section. As indicated in Table II, the most often presented brand for both samples was Seagrams $(7.6$ percent and 8.5 percent). Type. Scotch (22.6 and 20.0 percent) and liqueurs (19.1 and 14.6 percent) ranked one and two for both samples. Size, Color, Environment. The majority of the ads in both samples were full-page $(73.8$ and 76.2 percent), full-color ( 81.8 and 80.9 percent), and in fictional, or studio, settings ( 77.6 and 54.8 percent). Unexpectedly, only a small number of ads (three for both samples) were depicted as a party or get-together outdoors (only .2 percent and .6 percent).

Promotions. Ads in both samples were very simliar in promotional techniques with recipe promotions (33.6 percent and 35.7 
percent) and gift promotions ( 37.4 percent and 30.7 percent) promotions ranking first and second, although vice versa for the two samples. This was not unexpected either, in that the ads were drawn from the December issues of the magazines. Thus, gift giving (for Christmas) and recipes (for holiday entertaining) were expected to be more concentrated.

No ad featured claims of low caloric content, which is also not surprising for distilled beverages, although such claims may well occur in the future.

Human Mode1s. As mentioned, of the total sample of 1,447 distilled beverage advertisements, only 520 featured human models. Thus, 36 percent featured human mode1s and 64 percent did not.

In the total sample $(1,447)$, men were pictured in 30.9 percent of the ads and women in 24.1 percent of the ads. This finding is very similar to Strickland et al.'s study (1982) in which men were found "pictured in 32.8 percent of the unique ads and women in 25.2 percent" (1982: 671).

Techniques of Presentation for Human Models. As Table III demonstrates, of the ads which featured human models (520), males were again featured more often than females $(86.0$ percent and 67.1 percent respectively).

A note should be made concerning the missing cases in this and other tables. These cases indicate either a coding error took place during the coding (for example, human models were not coded present or absent), or a coding error took place in the transfer to the computer 
TABLE III

"TECHNIQUES OF PRESENTATION" FOR HUMAN MODELS:

IN NUMBER AND PERCENT

Number

Percent

Males

Present

Not Present

Total

447

$\frac{73}{520}$

349

$\frac{171}{520}$

Tota 1

Males

Holding Drinks

Drinking

Decorative

Tota 1

Missing Cases

Females

Holding Drinks

Drinking

Decorative

Tota 1

Missing Cases
250

1

$\frac{240}{491}$

154

0

$\frac{223}{377}$

(4)
86.0

$\frac{14.0}{100.0}$

67.1

$\frac{32.9}{100.0}$

50.9

.2

$\frac{48.9}{100.0}$

40.8

0.0

$\frac{59.2}{100.0}$

(a 9 was coded instead of a 1 for instance). In some tables the number of missing cases is quite high; in others it is not existent.

Males were predominantly featured holding drinks ( 50.9 percent) followed by decorative (no functional relationship to the product) presentation ( 48.9 percent). Females, on the other hand, were predominantly featured in decorative presentation (59.2 percent). In less than one half of the presentations which featured females (40.8 percent) were the females shown holding drinks. Further, only one ad featured a model drinking (the drink was to the mouth), and this ad featured a male. While it is possible in one ad to have one or more 
males and/or females holding drinks and one or more males and/or females in decorative presentation, the resounding message is clear; females were much more likely to be presented in decorative poses while males were depicted holding drinks and thus having some relationship to the product.

Themes and Appeals

Presented in Table IV is the occurrence information for each of the sixteen themes and appeals used in the analysis for both the total sample and the human models sample. Much like the findings in the Strickland et al. study, in which product-related themes were more

\section{TABLE IV}

TOTAL SAMPLE AND HUMAN MODEL(S) SAMPLE: "THEMES AND APPEALS" VARIABLES: SEPARATE, IN NUMBER AND PERCENT

Themes and Appea 1s*

Achievement/Success

Self-Reward

Host

Hostess

Information

(Close) Friendship

Relaxation

Camaraderie

Love and Romance

Special Occasions

"General" Success

Sexual Connotations

Individuality

Physical Activity

Quality:*

Tradition or Heritage

* Not mutually exclusive.

$*$ *Product related.

Human Model Sample

Total Sample $(\mathrm{N}=1,447)$

Number Percent

6

11

23

26

833

47

9

24

69

636

115

162

49

16

354

138
.4

.8

1.6

1.8

57.6

3.2

.6

1.7

4.8

44.0

7.9

11.2

3.4

1.1

24.5

9.5 $(\mathrm{N}=520)$

Number Percent

3

7

12

15

284

28

6

24

57

160

49

156

30

15

130

34
.6

1.3

2.3

2.9

54.6

5.4

1.2

4.6

11.0

30.8

9.4

30.0

5.8

2.9

25.0

6.5 
frequent than any other themes (1982: 665), the present study also found product-related themes to have the highest concentration for both samples. Specifically, the information theme ranked number one for both samples ( 57.6 percent and 54.6 percent). The other productrelated themes were quality ( 24.5 percent and 25.0 percent) and tradition or heritage ( 9.5 percent and 6.5 percent). Following the combination of the product-related themes, the special occasion theme ranked second for both samples ( 44.0 percent and 30.8 percent). While this is unlike Strickland et al.'s study, where this theme only occurred in 10.8 percent of the unique ads (1982: 664), the findings in the present study were not unexpected because, as mentioned earlier, the ads were drawn from the December issues with Christmas as the special occasion. Therefore, the percentages and numbers for this particular theme were expected to be relatively high.

The real difference between the two samples was in the human models-related themes, the remaining twelve themes. Of course, this difference was not unexpected, for as Strickland et al. (1982: 679) pointed out, "few ads which did not picture human models presented human model-oriented themes." And this certainly appeared to be the case. For example, in the eleven ads which featured the self-reward theme, seven of them were in the human models sample; in the nine ads that featured the relaxation theme, two-thirds (six) were in the human models sample; and of particular relevance to this study, in the 162 ads which featured the sexual connotations theme, 156 were in the human models sample. In fact, what was troublesome when comparing the findings of the themes and appeals in the present study to the 
findings in the Strickland et al. study (1982), was that while they acknowledged that human model-oriented themes rarely occurred in ads where human models are not present, they reported their findings based on the total sample, rather than the ads which contained human models, and concluded "relatively infrequent were such controversial themes as sexual connotation..." (1982: 679). As Table IV demonstrates, there was quite a difference between the two samples. Whereas the sexual connotations theme was only "present" in 11.2 percent of the total sample, it was "present" in 30.0 percent of the human models sample. Likewise, rather than the 6.7 percent occurrence of sexual connotations in the unique ads, as Strickland et al, reported (1982: 664), the percent of sexual connotations "present" would have been higher (as high as 17.1 percent) if the human model ads had been isolated ( 43 ads divided by the 251 ads that featured one or more human models) (Strickland et al., 1982: 670).

Again, even when the themes were recoded, as mentioned in Chapter IV, in line with Strickland's combination of themes representing product-related themes versus a number of human-realted themes (Strickland et al., 1982: 666), there existed a notable difference between the total sample and the human models sample (see Table V). The percentage of product-related themes was higher in the total sample ( 91.6 percent) than in the human models sample ( 64.8 percent) and the percentage of sexuality themes (the combination of the sexual connotations theme and the love and romance theme) was much higher in the human models sample $(41.0$ percent) than in the total sample (16.0 percent). 
TABLE V

TOTAL SAMPLE AND HUMAN MODEL(S) SAMPLE: "THEMES" AND APPEALS" VARIABLES: RECODED, IN NUMBER AND PERCENT

\begin{tabular}{|c|c|c|c|c|}
\hline \multirow[b]{2}{*}{ Themes and Appea 1s } & \multicolumn{2}{|c|}{$\begin{array}{l}\text { Total Samp le } \\
(\mathrm{N}=1,447)\end{array}$} & \multicolumn{2}{|c|}{$\begin{array}{l}\text { Human Mode } 1 \text { Sample } \\
(\mathrm{N}=520)\end{array}$} \\
\hline & Number & Percent & Number & Percent \\
\hline Lifestyle & 121 & 8.3 & 52 & 10.0 \\
\hline Psychological & 15 & 4.2 & 37 & 7.1 \\
\hline Serving Others & 49 & 3.4 & 26 & 5.0 \\
\hline Sociability** & 716 & 49.5 & 200 & 38.5 \\
\hline Sports & 16 & 1.1 & 15 & 2.9 \\
\hline Sexuality & 231 & 16.0 & 213 & 41.0 \\
\hline Product Related & 1,325 & 91.6 & 337 & 64.8 \\
\hline
\end{tabular}

*Not mutually exclusive.

$* *$ Special occasion/holiday theme included.

The sociability theme, unexpectedly, was higher in the total sample (49.5 compared to 38.5 percent). The only rationale for this finding, in that sociability is usually considered a human modelsoriented theme (Strickland et a1., 1982: 667), was again the emphasis on the special occasion theme included in this recoded thematic category.

Era and Target Market

Era. As mentioned in Chapter IV, the years were recoded to represent different eras of time. The rationale for doing so was to determine if the "place" of women changed over time given the rules and regulations established to address the woman's place. Thus, as mentioned previously, 1958 (when the ban on the use of women in distilled beverage advertising was lifted) to 1963 (when the regulation not allowing women to be shown holding drinks was liberalized by 
DISCUS) was coded as the "demure era"; 1964 to 1975 (when DISCUS adopted the resolution to disapprove of any distilled beverage ad that emphasized sex to sell their products) was coded as the "sexy era" simply because of the criticisms that brought such a resolution about; and 1976 to 1985 was coded as the "modern era."

As demonstrated in Table VI, the majority of the advertisements for distilled beverages were presented in the modern era: 1976-1985,

TABLE VI

DISTILLED BEVERAGE ADVERTISEMENTS FOR ERA AND "TARGET MARKET" AND "TARGET MARKET" BY ERA FOR THE TOTAL SAMPLE AND HUMAN MODELS SAMPLE IN NUMBER AND PERCENT

Era

Demure 1958-63

Sexy $1964-75$

Modern 1976-85

Tota 1
Total Sample

$\frac{(\mathrm{N}=1,447)}{\underline{\text { Number }} \quad \underline{\text { Percent }}}$

Target Market

Males Only

Females Only

General Audience

Tota 1

\begin{tabular}{rr}
171 & 11.8 \\
554 & 38.3 \\
722 & 49.9 \\
\hline 1,447 & 100.0
\end{tabular}

13.1

190

18

$\frac{1,239}{1,447}$

1.2

$\frac{85 \cdot 7}{100 \cdot 0}$

28

89

14.7

46.9

$\frac{73}{190}$

$\frac{38.4}{100.0}$

Females Only

Demure Era

Sexy Era

Modern Era

Tota 1

General Audience

Demure Era

Sexy Era

Modern Era

Total

Human Model Sample

$\frac{(N=520)}{\underline{\text { Number }}}$

64

12.3

220

42.3

$\frac{236}{520}$

$\frac{45.4}{100.0}$

167

12

32.1

$\frac{341}{520}$

2.3

$\frac{65 \cdot 6}{100 \cdot 0}$

Target Market by Era

\section{Tota 1 \\ Demure Era \\ Sexy Era
Modern Era}

190

$2 \quad 11.1$

$10 \quad 55.6$

$\frac{6}{18} \quad \frac{33.3}{100.0}$

21

80

12.6

$\frac{66}{167}$

47.9

$\frac{39.5}{100.0}$ 
for both samples ( 49.9 percent and 45.4 percent), while very few advertisements were presented in the demure era: 1958-1963 (11.8 percent and 12.3 percent). A partial explanation for this finding was the coding of the eras. The demure era only represented six years; the modern era represented ten years.

Yet, if the number of years were the only factor which influenced the findings, the sexy era which spanned twelve years (1964-1975) should have presented the highest concentration of advertisements, which was not the case, at least not when one compares the overall percentages of the ads for both samples presented in this particular era.

Target Market. Presented also in Table VI are some overall comparisons regarding certain subgroups as targeted markets for the distilled beverage advertisements. As evident, the findings indicated that the general audience was the most targeted group for both samples, followed by males only, and finally by females only. Yet, differences did exist in the extent to which these groups were targeted, between the total sample and the human models sample. As indicated, the percentage for general audience as the targeted market dropped dramatically in the human models sample (85.6 percent compared to 65.6 percent) and the percentage for males only as the targeted market rose substantially in the human models sample (13.1 percent compared to 32.1 percent). In fact, most of the ads targeted for males only were contained in the human models sample (167 of the 190). Likewise, most of the ads targeted for females only were 
contained in the human models sample (12 of the 18), although the total percent targeted for women was quite small in both samples ( 1.2 percent and 2.3 percent).

Target Market by Era. A more detailed comparison of specific subgroups as targeted markets for the distilled beverage advertisements is also presented in Table VI. As is evident in this particular presentation, the previous findings do not hold constant for the concentration of ads in different eras targeted for the specific subgroups or from sample to sample.

Specifically, when the target markets were males only and females only in the total sample, most of the ads were concentrated in the sexy era ( 46.9 percent and 55.6 percent respectively) rather than the modern era. This was also true when the target market was males only in the human models sample ( 47.9 percent in the sexy era and only 39.5 percent in the modern era).

The overall increase in the number and percent of the ads presented in the modern era, as previously cited, appeared to arise from three sources: those targeted for the general audience in the total sample, those targeted for the general audience in the human models sample, and to some extent, and pertinent to this study, those targeted for females only in the human models sample.

As indicated by the percentages, women as a targeted market increased era by era, at least in the human models sample $(16.7$ percent in the demure era to 33.3 percent in the sexy era to 50.0 percent in the modern era). This finding would indicate some support that women were increasingly being targeted for distilled beverages over 
time. Yet again, it must be noted that the number of ads targeted for females only was indeed quite small, only two in the demure era, four in the sexy era, and six in the modern era for a total of twelve ads out of the 520 human models advertisements. In contrast, and as also mentioned earlier, males were the targeted market for 167 such ads, and the general audience was targeted for 341 ads.

Thus, much like Strickland et al.'s study, in which the authors concluded that women were not being disproportionately targeted (1982: 680 ), the present study found little support that women were being targeted as co-equal consumers of distilled beverages. In fact, the present study found little support that women were being targeted at all as a separate group.

\section{DESCRIPTION OF THE HUMAN MODELS SAMPLE}

Because the remaining variables in the analysis focus on the "relevant characteristics" of human models and because, as indicated earlier (see Chapters III and IV), the focus of this study is on the portrayal of the social worlds of maleness and femaleness, and more specifically on the "woman's place," in distilled beverage advertising, the remaining descriptions will pertain only to the human models sample.

Relevant Characteristics of Human Mode1s

Several "relevant characteristics" of the human models portrayed in the distilled beverage advertisements were included in this study for the purpose of a more thorough description of the "message created" in such advertising. 
Included in this section is the presentation of the models (e.g., full figure or partial, such as heads only, hands only, etc.), the dress style of the models (e.g., formal, swimsuits, professional, etc.), the focus of attention of the models (e.g., looking at the audience, looking at the product, etc.), the relational postures of male and female models (e.g., who was positioned higher in the ad, who was on the receiving end of a mock attack, etc.) and the physical proximity of the models (e.g., whether the models were featured alone in the ad or with others, and if with others, in what degree of involvement).

Presentation. As indicated in Table VII, the most common presentation for both males and females, with the percentage being higher for males, was the full figure presentation ( 24 percent and 19.9 percent respectively). The next most frequent depiction was of models depicted in the partial pose "from the waist up" ( 15.3 percent for males and 12.2 percent for females). Relatively infrequent were the partial poses, "torso only" (.3 percent for males and .1 percent for females) and "heads only," while the percentage for this pose was slightly higher ( 3.6 percent for males and 2.6 percent for females). A notable difference did exist though between males and females featured in the partial presentation "hands only" ( 7.5 percent for males and only 2.3 percent for females). One explanation for this difference between males and females presented in this pose could be, as previously mentioned, that males were depicted more often holding drinks. For, in fact, in most of the ads that featured the "hands only" presentation, the hands were holding drinks. 
"RELEVANT CHARACTERISTICS"--PRESENTATION--OF HUMAN MODELS, IN NUMBER AND PERCENT

Number Percent

Full Presentation

Males 211

Females

24.0

19.9

Partial Presentation

\begin{tabular}{lcr}
\hline Males Hands OnIy & 66 & 7.5 \\
Females & 20 & 2.3 \\
& & \\
Maleads Only & 32 & 3.6 \\
Females & 23 & 2.6 \\
& & \\
Malorso Only & 3 & .3 \\
Females & 1 & .1 \\
Waist Up & & \\
Males & 135 & 15.3 \\
Females & 108 & 12.2 \\
& & \\
Other Partial Presentation & 51 & 5.0 \\
Males & 56 & 6.4 \\
Females & & \\
Total & 881 & 100.0 \\
$\quad$ Missing Cases & $(41)$ &
\end{tabular}

Dress. The data in Table VIII suggest that for both males and females, the most likely presentation was in casual dress styles ( 24 percent for males and 20.3 percent for females). The least likely dress style was nightwear, such as pajamas ( .4 percent for males and 1 percent for females).

A very similar representation of males and females, although small in percentages, was in swimwear $(1.7$ and 1.9 percent respectively). 
TABLE VIII

"RELEVANT CHARACTERISTICS"--DRESS--OF HUMAN MODELS, IN NUMBER AND PERCENT

\section{Number $\quad$ Percent}

Forma 1 Dress

Males

63

9.0

Females

98

13.9

Professiona1 Dress

Males

62

8.8

Females

10

1.4

Casua 1 Dress

Males

24.0

Females

143

20.3

Swimsuits

Males

12

1.7

Females

13

1.9

Nightwear

Males

Females

3

7

.4

1.0

Other Dress

Males

12.1

Females

39

5.5

Tota 1

Missing Cases

704

(34)

100.0

But beyond these similarities, the depictions of males and females in dress styles were quite different. Females were presented first in formal dress ( 13.9 percent), second in other dress ( 5.5 percent), and finally a few (ten) in professional dress ( 1.4 percent). Males on the other hand, were presented first in other dress (mostly in uniforms) (12.1 percent), second, in formal dress ( 9 percent), and fina11y, and just about as often, in professional dress ( 8.8 percent). This finding clearly indicates that few women were presented in dress styles outside the ideal of the "woman's place." 
Focus of Attention. The focus of attention for the human models was very similar in many respects, although males demonstrated somewhat higher percentages "looking at other people" (19.8 percent compared to 14.9 percent for females) and "looking outside the ad, but not at the audience" ( 7.2 percent versus 3.8 percent for females). Females, on the other hand, were somewhat more likely to "look at the audience" ( 13.8 percent compared to 12.5 percent for males) and to "look at the product" ( 2.1 percent versus 1.4 percent), although this was the least likely focus of attention for both males and females (see Table IX).

TABLE IX

"RELEVANT CHARACTERISTICS"--FOCUS OF ATTENTION-OOF HUMAN MODELS, IN NUMBER AND PERCENT

Looking at the Audience Males

Females

\begin{tabular}{rrr} 
Number & & Percent \\
\cline { 1 - 1 } 99 & & 12.5 \\
109 & & 13.8 \\
& & \\
11 & & 1.4 \\
17 & 2.1 \\
& \\
157 & & 19.8 \\
118 & & 14.9 \\
& & \\
63 & & 8.0 \\
50 & & 6.3
\end{tabular}

Looking at the Product

Males

50

6.3

Looking Outside Ad But

Not at the Audience

Males

Females

Focus Somewhere E1se

Males

Females 
Relational Postures. When presented, there was a clear distinction between the representation of male and female models in relational postures, as Table $\mathrm{X}$ indicates. Probably the most

\section{TABLE X}

"RELEVANT CHARACTERISTICS"--RELATIONAL POSTURES AND PHYSICAL PROXIMITY-OF HUMAN MODELS, IN NUMBER AND PERCENT

Relationa1 Postures

Who is Positioned Higher in Ad

Males

Females

Total
Number

91

$\frac{14}{105}$

Who is Laying Down or in a Reclining Position Males

Females

Total

$\begin{array}{rr}1 & 4.8 \\ 20 & \frac{95.2}{100.0}\end{array}$

$\frac{28}{28}$

$\frac{100.0}{100.0}$

$\frac{26}{26}$

$\frac{100.0}{100.0}$

Whose Hands are Tracing the Object

Females

Total

Whose Hands are Grasping the Object

Males

Total

Who is on the Receiving End of the Mock Attack

Males

Females

Total

Whose Arm is Interlocked With Whom

Females in Males

Tota I

Whose Arm is Around Whom

Females Around Males

Males Around Females

Tota I

$\frac{2}{2}$

$\frac{100.0}{100.0}$

Physical Proximity

Low Involvement

Medium Involvement

High Involvement

Alone in Ad

Tota 1

Missing Cases
12

$\frac{15}{27}$

26

107

185

200

518

(2)
44.4

$\frac{55.6}{100.0}$

5.0

20.7

35.7

$\frac{38.6}{100.0}$ 
indicative of this distinction was the finding that in 100 percent of the ads in which there was a difference in how one handled an object, female hands always traced the object and male hands grasped the object.

Another predominant difference pertained to the position in which one was placed in the ad; males were positioned higher in the ad much more often than females ( 86.7 percent versus 13.3 percent) and females were much more likely to be presented lying down or in a reclining position ( 95.2 percent compared to 4.8 percent for males).

Female arms were always (100 percent) interlocked in male arms rather than the other way around, and male arms were slightly more often ( 55.6 percent compared to 44.4 percent) placed around the female shoulders, as if in a protective way.

While it may be argued that these findings do not mirror everyday life, they were not unexpected. As previously mentioned (see Chapter IV), much of the coding for the relational postures was drawn from Goffman's analysis of Gender Advertisements (1976). As he points out $(1976: 25)$ :

- - although the pictures shown (might not) be representative of gender behavior in real life..., one can probably make a significant negative statement about them, namely, that as pictures they are not perceived as peculiar and unnatural (original emphasis).

In fact, if male hands were tracing objects and female hands were grasping objects, if men were lying down and women were positioned higher, and if males were to interlock their arms in females', these pictures might appear peculiar and unnatural to many. 
Nonetheless, they do demonstrate the reiteration of stereotypes that define the proper "place" of women.

Physical Proximity. Also indicated in Table $\mathrm{X}$ is the degree of physical proximity, as measured by the perceived involvement, between the models when two or more models were present.

The largest percentage (38.6) of ads contained only one model. When more than one model was presented though, they were presented in states of high to medium involvement ( 35.7 percent and 20.7 percent respectively), suggesting a great deal of intimate interaction. Only 5 percent of the ads presented models in the state of low involvement.

This finding was in direct contradiction to the results reported in the Strickland et al. study. In their words (1982: 671): "Most - . were shown in close physical proximity but in states of low to medium involvement rarely suggesting intimate interaction."

The only rationale for the difference in findings between Strickland et al.'s study and the present study is the qualitative indicators used to measure involvement, much like the difference in the measurement of sexual connotations (see Chapter IV). In other words, there may have been a different definition of what constituted the difference of low, medium, and high involvement. Not knowing Strickland et al.'s criterion for this measurement, this is only an as umption.

As evident from these findings on the "relevant chacteristics" of human models, there were some key differences in the representation of male and female models, in presentation, in dress styles, in the focus of attention, and most indicatively, in the relational postures. 
For these reasons, and guided by the hypothesis that the portrayal of women in distilled beverages advertising emphasizes the sexual persuader role over the consumer role, a further computation was performed on the human models sample, as mentioned in Chapter IV. The purpose of this computation was to ascertain the number and percent of the distilled beverage advertisements which featured only female models, only male models, and models in mixed company (including a separate subsample of couples only). It was believed that a clearer picture of the representation of women and men could be obtained in this manner and relationship and/or lack of relationship regarding the roles of females and males in such advertising could be found.

Table XI presents the results of this computation. As indicated, only 73 ads ( 14.0 percent) featured females only, 171 ads (32.9 percent) featured males only, and 276 ads (53.1 percent) featured models in mixed company, of which 175 ads or 33.7 percent of the sample featured couples only.

\section{TABLE XI}

GENDER DEPICTION IN ADS (INCLUDING COUPLES), IN NUMBER AND PERCENT

$$
\text { Number }
$$

$$
\text { Females on } 1 y
$$

Males Only

Mixed Company (Couples)

Tota 1
73

171

$276(175)$

\section{Percent}

$$
14.0
$$$$
32.9
$$

$\frac{53.1}{100.0}(33.7)$

To ascertain the number and percent of ads which included the thematic category sexual connotations, once the human models sample 
was separated by gender, and thus, to address the hypothesis as mentioned, a frequency distribution for this variable was computed for each group. Table XII presents the results.

\section{TABLE XII}

HUMAN MODEL ADS WITH AND WITHOUT SEXUAL CONNOTATION BY GENDER (INCLUDING COUPLES), IN NUMBER AND PERCENT

Female Only Ads

With Sexual Connotations Without Sexual Connotations Total
Number

$$
53
$$

$\frac{20}{73}$

$\begin{array}{r}3 \\ 168 \\ \hline 171\end{array}$

$100(75)$

$\frac{176}{276}\left(\frac{100)}{(175)}\right.$
Percent

72.6

$\frac{27 \cdot 4}{100 \cdot 0}$

Male Only Ads

With Sexual Connotations

Without Sexual Connotations

Tota 1

Mixed Company (Couples)

With Sexual Connotations

Without Sexual Connotations

Tota 1

1.8

$\frac{98.2}{100.0}$

As is evident from this computation, sexual connotations were much more apparent in the female only ads $(72.6$ percent) than in the male only ads ( 1.8 percent), in the mixed company ads ( 36.2 percent), and even in the couples only ads (42.7 percent). Given that female only ads only constituted 14.0 of the human models sample (see Table XI) and 72.6 percent of them carried sexual connotations, it could be argued that the hypothesis addressing the "woman's place" was well supported.

But, to thoroughly address this hypothesis and to address the second hypothesis which states that the laws, rules and regulations addressing the issue of women in distilled beverage advertising have 
had little impact over time in the portrayal of women in such advertising, descriptions of the ads that contain and do not contain sexual connotations for all the groups (female only, male only, mixed company and couples) seem to be in order.

Therefore, a brief description of the characteristics of these groups with and without sexual connotations is presented.

HUMAN MODEL GROUPS WITH AND WITHOUT SEXUAL CONNOTATIONS

\section{Techniques of Presentation}

Tables XIII, XIV, XV, and XVI contain the techniques of presentation variables for the different groups, in number and percent.

Magazine. Playboy overall had the highest concentration of ads both with and without sexual connotations for the mixed company and couples only categories. Yet in both of these categories, the concentration increased in $\underline{\text { Playboy }}$ in those ads which carried the sexual connotations theme; 51.7 percent to 55 percent for the mixed company group and 48 percent to 60 percent for the couples only category.

Cosmopolitan had the highest concentration of female only ads when the ad did not have sexual connotations ( 45 percent). But when sexual connotations existed in the ad, more female only ads were concentrated in Playboy ( 54.7 percent) than in Cosmopolitan ( 24.5 percent).

Likewise, for the male only ads, the highest concentration was in Playboy when no sexual connotations existed (60.1 percent). But again, when sexual connotations were present, two of the three ( 66.7 percent) such ads were located in Cosmopolitan. 
Newsweek carried the least concentration of ads for all categories, with and without sexual connotations.

\section{TABLE XIII}

"TECHNIQUES OF PRESENTATION" FOR FEMALE ONLY ADVERTISEMENTS WITH AND WITHOUT SEXUAL CONNOTATIONS IN NUMBER AND PERCENT

Sexual Connotations Number Percent
Without Sexual Connotations Number Percent
Magazine

Playboy

Cosmopolitan

Newsweek

Tota 1
29

13

$\frac{11}{53}$
54.7

24.5

$\frac{20.8}{100.0}$
8

9

$\frac{3}{20}$
40.0

45.0

$\frac{15.0}{100.0}$

Brand*

Martini \&

Rossi

Black Velvet

13

5

24.5

9.4

Tequila

Sausa

Johnnie

Walker

Jose Cuervo

5

9.4

4

3

7.6

5.7

Other

Total

$\frac{23}{53}$

$\frac{43.4}{100.0}$

$\begin{array}{ll}\text { Other } & 5 \\ \text { Amaretto } & 4 \\ \text { Schenley } & 2 \\ \text { Seagrams } & 2 \\ \text { Tequila } & \end{array}$

Sausa 2

Other 10

$\overline{20}$
25.0

20.0

10.0

10.0

10.0

50.0

$\overline{100.0}$

Type of

Beverage

Vodka

Bourbon

Scotch

Canadian

Other

Whiskey

Gin

Rum

Brandy

Tequila

Liqueur

Vermouth

Cocktails

Other Total

$\begin{array}{rr}3 & 5.7 \\ 1 & 1.9 \\ 10 & 18.8 \\ 5 & 9.4\end{array}$

3

2

15.0

10.0

1

5.0

2

10.0

0.0

0.0

5.7

0.0

15.1

17.0

24.5

13

0.0

$\frac{1}{53}$

$\frac{1.9}{100.0}$

0.0

10.0

0.0

0.0

10.0

30.0

0.0

10.0

2

$\frac{0.0}{100.0}$

* Only the brands which are featured in 5 percent or more of the ads are listed separately. 
TABLE XIII (CONTINUED)

"TECHNIQUES OF PRESENTATION" FOR FEMALE ONLY ADVERTISEMENTS WITH AND WITHOUT SEXUAL CONNOTATIONS IN NUMBER AND PERCENT

Sexual Connotations Without Sexual Connotations Number Percent

Size of Ad

Under half page
Half to less

than full page

Full page

More than full, less than two

Two or more pages

Total

Color Format

Black \& White

Color

Mixed

Tota 1

Missing Cases

Environment

Tavern, restaurant

Indoors, party

Outdoors, party

Outdoors, beach

Fictiona 1/studio

Total

Relation to Product

\section{Holding drinks}

Drinking

Decorative

Tota 1

\section{1}

2
50

0

$\frac{0}{53}$

1

47

$\frac{3}{51}$

(3)

$$
1.9
$$

3.8

94.3

$\begin{array}{r}0.0 \\ 0.0 \\ \hline 100.0\end{array}$

2.0

92.1

$\frac{5.9}{100.0}$

0.0

$\frac{48}{53}$

20

0

$\frac{33}{53}$
7.5

0.0

1.9

4

0

1

90.6

37.7

0.0

$\frac{62.3}{100.0}$
1

0

19

$\begin{array}{r}0 \\ 0 \\ \hline 20\end{array}$

0

16

$\frac{1}{17}$

(3)
5.0

0.0

95.0

0.0

$\frac{0.0}{100.0}$

Promotiona 1

Techniques

Recipe offers

Claims product purity 0

3

42.9

0.0

claims of

$$
\text { naturalness }
$$

0

0.0

15

0

75.0

0.0

$\frac{5}{20}$

$\frac{25.0}{100.0}$

0.0

10.0

0.0

0.0

$\frac{18}{20}$

$\frac{90.0}{100.0}$

Sugg. how much

to drink

Gift

1

3

14.2

42.9

Other Promos

Total

$\frac{0}{7}$
16.7

1

0

0

0.0

0

0.0

4

$\frac{1}{6}$
66.6

$\frac{16.7}{100.0}$ 
"TECHNIQUES OF PRESENTATION" FOR MALE ONLY ADVERTISEMENTS WITH AND WITHOUT SEXUAL CONNOTATIONS IN NUMBER AND PERCENT

Sexua 1 Connotations Number Percent
Without Sexual Connotations Number Percent

Magazine

Playboy

Cosmopolitan

Newsweek

Tota 1

Brand*

Heuble in

I.W. Haper

Martini \&

Ross $i$

Total
$1 \quad 33.3$

$2 \quad 66.7$

$\overline{3}$

$\overline{100.0}$

33.3

33.3

33.3

$\frac{1}{3}$

Type of Beverage

Vodka
Bourbon
Scotch
Canadian
Other Whisky
Gin
Rum
Brandy
Tequila
Liqueur
Vermouth
Cocktails
Other
$\quad$ Total

0.0

33.3

0.0

0.0

0.0

0.0

0.0

0.0

0.0

0.0

33.3

33.3
0

1

0

0

0

0

0

0

0

0

1

1

$\frac{0}{3}$

Size of Ad

Under half page

Half to less

than full page

Full page

More than full,

less than two

Two or more pgs

Tota 1

$\frac{1}{3}$
101

23

$\frac{44}{168}$

Other

$J \& B$

Seagrams

Other

$99.9 * *$

$\frac{0.0}{99.9 * \%}$

0.0

17

0.0

66.7

32

114

$$
0.0
$$

60.1

13.7

$\frac{26.2}{100.0}$

16.7

14.3

8.3

$\frac{77.4}{100.0}$

* On $1 \mathrm{y}$ the brands which are featured in 5 percent or more of the ads are listed separately.

$* *$ Rounding difference. 
"TECHNIQUES OF PRESENTATION" FOR MALE ONLY ADVERTISEMENTS WITH AND WITHOUT SEXUAL CONNOTATIONS IN NUMBER AND PERCENT

Sexua 1 Connotations Number $\quad$ Percent
Without Sexual Connotations

Number Percent

Color Format

Black \& White

Color

Mixed

Tota 1

Missing Cases
0

3

$\frac{0}{3}$
0.0

100.0

$\frac{0.0}{100.0}$
37

115

$\frac{9}{161}$

(7)
23.0 71.4

$\frac{5.6}{100.0}$

Environment

\section{Tavern,}

restaurant

Indoors, party

Outdoors, party

Outdoors, beach

Fictional/

studio

Tota 1

Missing Cases
0.0

0.0

0.0

0.0

$\frac{100.0}{100.0}$

33.3

33.3

$\frac{33.3}{99.9}$
85

0

$\frac{92}{167}$

(4)
3.0

7.2

0.0

28.9

$\frac{101}{166}$

$\frac{60.9}{100.0}$

Relation to

Product

Drinking

Decorative

Tota 1

Missing Cases

44.3

0.0

$\frac{55.7}{100.0}$

Promotiona 1

Techniques

Recipe offers

0

0.0

12

27.9

Claims product purity

0

0.0

4

9.3

Claims of naturalness

Sugg. how much

to drink

Gift

0

0.0

1

2.3

Other promos

Total

1

0.0

9

20.9

33.3

11

25.6

$\frac{0}{1}$

$\frac{0.0}{100.0}$

$\frac{6}{43}$

$\frac{14.0}{100.0}$

* Rounding difference 
TABLE XV

"TECHNIQUES OF PRESENTATION" FOR MIXED COMPANY ADVERTISEMENTS WITH AND WITHOUT SEXUAL CONNOTATIONS IN NUMBER AND PERCENT

Sexua 1 Connotations Number
Percent
Without Sexual Connotations Number $\quad$ Percent

Magazine

Playboy

Cosmopolitan

55

33

Newsweek

Tota 1

$\frac{12}{100}$

55.0

33.0

91

47

51.7

$\frac{12.0}{100.0}$

$\frac{38}{176}$

26.7

$\frac{21.6}{100.0}$

Brand*

Inver House

8.0

7.0

7.0

Seagrams

24

13.6

Gordons

Canadian Club

7

Martini \&

Rossi

$6 \quad 6.0$

Southern

Comfort

Wolfschmidt

Metaxa

Ronrico

Other

Tota 1

Smirnoff

13.6

Other

72.8

137

$6 \quad 6.0$

$6 \quad 6.0$

$5 \quad 5.0$

$5 \quad 5.0$

$\frac{50}{100} \quad \frac{50.0}{100.0}$

$\overline{176} \quad \overline{100.0}$

Type of

Beverage

Vodka

Bourbon

Scotch

Canadian

other

Whiskey

Gin

Rum

Brandy

Tequila

Liqueur

Vermouth

Cocktails

other

Tota 1

10

4

12

8

12

10

6

6

4

21

6

0

$\frac{1}{100}$
10.0

4.0

12.0

8.0

12.0

10.0

6.0

6.0

4.0

21.0

6.0

0.0

$\frac{1.0}{100.0}$
20

10

36

27

26

11

7

4

2

24

1

3

$\frac{5}{176}$
11.4

5.7

20.5

15.3

14.7

6.3

4. 0

2.3

1.1

13.6

.6

1.7

$\frac{2.8}{00.0}$

* Only the brands which are featured in 5 percent or more of the ads are listed separately. 
TABLE XV (CONTINUED)

"TECHNIQUES OF PRESENTATION" FOR MIXED COMPANY ADVERTISEMENTS WITH AND WITHOUT SEXUAL CONNOTATIONS IN NUMBER AND PERCENT

Sexua 1 Connotations Number
Percent
Without Sexua1 Connotations Number Percent

Size of Ad

Under half page

9

9.0

17

9.7

Half to less

than full

8

8.0

21

133

11.9

Ful1 page

78

78.0

75.6

More than full, less than two

\begin{tabular}{rr}
2 & 2.0 \\
3 & 3.0 \\
\hline 100 & 100.0
\end{tabular}

2
$\frac{3}{176}$

1.1

Two or more $\mathrm{pgs}$ Tota 1

Color Format

Black \& White

Color

8

8.3

82.3

Mixed

Tota 1

Missing Cases

79

$\frac{9}{96}$

(4) $\frac{9.4}{100.0}$

10.0

20.0

1.0

20.0

$\frac{49.0}{100.0}$
24

142

$\frac{3}{169}$

(7) $\frac{1.7}{100.0}$

14.2

84.0

$\frac{1.8}{100.0}$

Envi ronment

Tavern, restaurant

5.1

Indoors, party

20

49

28.0

20

51

1.1

Outdoors, beach

$\frac{49}{100}$

$\frac{64}{175}$

29.2

Fictiona 1/

studio

Tota 1

Missing Cases

(1)

$\frac{36.6}{100.0}$

Relation to Product

Males

Holding Drinks $\quad 56$

Drinking

Decorative

Tota 1

Missing Cases
56
0
47

$\frac{47}{103}$

44

0

$\frac{61}{105}$ $\frac{45.6}{100.0}$

Females

Holding Drinks

Drinking

Decorative

Tota 1

Missing Cases
54.4

0.0

103

50.7

0

$\frac{100}{203}$

(4)

41.9

0.0

$\frac{58.1}{100.0}$
75

0

$\frac{124}{199}$

(4)
0.0

$\frac{49.3}{100.0}$

37.7

0.0

$\frac{62.3}{100.0}$ 
TABLE XV (CONTINUED)

"TECHNIQUES OF PRESENTATION" FOR MIXED COMPANY ADVERTISEMENTS WITH AND WITHOUT SEXUAL CONNOTATIONS IN NUMBER AND PERCENT

Sexual Connotations Without Sexual Connotations Number Percent

Promotiona 1

Techniques

Recipe offers

15

55.6

20

33.9

Claims product purity

Claims of

natura lness

0

0.0

2

3.4

0

0.0

2

3.4

Sugg. how much to drink

Gift

\begin{tabular}{rr}
3 & 11.1 \\
6 & 22.2 \\
3 & 11.1 \\
\hline 27 & 100.0
\end{tabular}

9

15.2

Other promos

Total

$\frac{11.1}{100.0}$

19

32.2

$\frac{7}{59}$

$\frac{11.9}{100.0}$ 
TABLE XVI

"TECHNIQUES OF PRESENTATION" FOR COUPLES ONLY ADVERTISEMENTS WITH AND WITHOUT SEXUAL CONNOTATIONS IN NUMBER AND PERCENT

$\frac{\text { Sexual Connotations }}{\text { Number }}$

Magazine

Playboy

Cosmopolitan

Newsweek

Tota 1

Brand*

Inver House

Canadian Club

Gordons

Wolfschmidt

Ronrico

Southern

Comfort

Metaxa

other

Tota 1

Type of

Beverage

Vodka

Bourbon

Scotch

Canadian

Other

Whiskey

Gin

Rum

Brandy

Tequila

Liqueur

Vermouth

Cocktails

other
45

20

$\frac{10}{75}$

8

6

6

6

5

5

4

$\frac{35}{75}$
60.0

26.7

$\frac{13.3}{100.0}$

10.7

8.0

8.0

8.0

6.7

6.7

5.3

$\frac{46.6}{100.0}$

Without Sexual Connotations Number Percent 
TABLE XVI (CONTINUED)

"TECHNIQUES OF PRESENTATION" FOR COUPLES ONLY ADVERTISEMENTS WITH AND WITHOUT SEXUAL CONNOTATIONS IN NUMBER AND PERCENT

Sexua 1 Connotations Number $\quad$ Percent
Without Sexual Connotations

Number Percent

Size of Ad

Under half page

8

7

than full

Full page

More than full, less than two

Two or more pgs Tota 1
10.7

9.3

74.6

$\begin{array}{r}2.7 \\ 2.7 \\ \hline 100.0\end{array}$

8.3

79.2

$\frac{12.5}{100.0}$
13

13

72

2

$\frac{0}{100}$

13

82

$\frac{2}{97}$

(3)
13.0

13.0

72.0

2.0

$\frac{0.0}{100.0}$

13.4

84.5

$\frac{2.1}{100.0}$

(3)

$\frac{9}{72} \quad \frac{12.5}{100.0}$

Missing Cases

8.0

3.0

17.3

0.0

21.0

2.0

20.0

30.0

Outdoors, beach

15

$\frac{54.7}{100.0}$

$\frac{44}{100}$

$\frac{44.0}{100.0}$

Relation to

Product

\section{Males}

Holding Drinks 41

Drinking

Decorative

Tota 1

$\frac{41}{75}$

41
0

$\frac{34}{75}$
54.7

0.0

$\frac{45.3}{100.0}$

42.7

0.0

$\frac{57.3}{100.0}$
56

0

$\frac{44}{100}$

39

0

$\frac{61}{100}$
56.0

0.0

$\frac{44.0}{100.0}$

\section{Females}

Holding Drinks 32

0

Decorative Total

$\frac{43}{75}$ 
TABLE XVI (CONTINUED)

"TECHNIQUES OF PRESENTATION" FOR COUPLES ONLY ADVERTISEMENTS WITH AND WITHOUT SEXUAL CONNOTATIONS IN NUMBER AND PERCENT

$\begin{array}{lll}\text { Sexual Connotations } & \text { Without Sexual Connotations } \\ \text { Number } & \underline{\text { Percent }}\end{array}$

Promotional

Techniques

Recipe offers

11

57.9

18

47.4

Claims product purity

Claims of naturalness

0

0.0

2

5.3

Sugg. how much

to drink

Gift

Other promos

Tota 1

$\begin{array}{rr}0 & 0.0 \\ 0 & 0.0 \\ 6 & 31.6 \\ \frac{2}{19} & \frac{10.5}{100.0}\end{array}$

2

5.3

4

12

10.5

$\frac{0}{38}$

31.5

$\frac{10.5}{100.0}$

$\frac{0.0}{100.0}$

Brand. Because in the human models sample the brands were more concentrated, those brands which were featured in 5 percent or more of the ads, rather than the previous 3 percent or more, were listed separately.

Aside from the residual "other," a brand which was clearly associated with sexual connotations in advertisements was Martini \& Rossi; 24.5 percent of the female only ads, 33.3 percent of the male only ads, and 6 percent of the mixed company ads were ads presented with the Martini \& Rossi label. Black Velvet and Tequila Sausa (both representing 9.4 percent) were significant for the female only ads that carried sexual connotations. Inver House, Canadian Club, Southern Comfort, Wolfschmidt, Gordons, Metaxa, and Ronrico were as equally significant in that all of these brands were present in at least 5 percent of the mixed company and couples only ads that carried sexua 1 connotations. 
The only brand that stood out for all group ads without sexual connotations was Seagrams: 10 percent in female only ads, 8.3 percent in male only ads, 13.6 percent in mixed company ads and 11 percent in couples only ads. Another significant brand associated with no sexual connotations was Smirnoff, especially for the mixed company group and the couples only group ( 8.5 percent and 5 percent respectively).

Type. Not surprising, given the findings on brand names, vermouth was highly associated with the advertisements in which sexual connotations existed, especially for the female only ads (24.5 percent) and the male only ads ( 33.3 percent). What was surprising was that in many cases the type of liquor was associated with ads carrying sexual connotations and with ads that did not carry sexual connotations. For example, liqueurs were associated with the female only ads ( 17 percent), the mixed company ads (21 percent), and the couple on $1 y$ ads ( 18.7 percent) that carried sexual connotations. Likewise liqueurs were associated with female only ads ( 30 percent), mixed company ads ( 13.6 percent), and couple only ads ( 21 percent) that did not carry sexual connotations.

Size, Color Format. The majority of all the advertisements with and without sexual connotations for all of the subgroups were presented as ful1-page and full-color advertisements.

Environment. Clearly the environment for the female only ads is either the fictional (or studio) setting or indoors, with or without sexual connotations in the ad. Of the female only ads, 90.6 percent of the ads with sexual connotations and 90 percent of the ads without sexual connotations were set in a fictional environment. Of the 
female only ads, 7.5 percent of the ads with sexual connotations and 10 percent without sexual connotations were set indoors. The only exception to this finding was one female only ad, with sexual connotations, that was set outdoors in a place such as the beach/ mountains.

The significance of this finding is revealed in the fact that no other group (with the exception of the three male only ads that carried sexual connotations), with or without sexual connotations, was as limited in environmental settings.

In fact, outside of the three male only ads with sexual connotations that were set in a fictional (or studio) environment, no group was set in the fictional (or studio) environment in more than 60 percent (which was the male on $1 y$ ads without sexual connotations) of the ads. Further, all of these groups were presented in the tavern/ restaurant setting in at least 3 percent of the advertisements. Not one female only ad was placed in such an environment. And in relationship to the outdoors setting, such as the beach, not one of the other groups were set in such an environment in less than 20 percent of the advertisements.

Definitely, the "woman's place" is quite limited. Relation to the Product. In both the mixed company ads and the couples only ads, with and without sexual connotations, males were more often (at least 10 percent more often) portrayed as holding drinks while females were predominantly (again, at least 10 percent more often) in the decorative role (see Tables XV and XVI). 
In the female on $1 y$ ads with sexual connotations, women were again depicted much more often in the decorative role (62.3 percent). Yet, in the female only ads without sexual connotations the majority of the women were depicted as holding drinks (75 percent) rather than decorative (25 percent).

In the male only ads with sexual connotations, the depiction of the men was split; one was holding a drink, one was drinking, and one was decorative. In the male only ads without sexual connotations, more men were presented in the decorative role ( 55.7 percent) than holding drinks ( 44.0 percent).

One conclusion that can be drawn from these findings is that in ads where sexual connotations do not exist, it is possible for the woman's role to become less decorative, where she may in fact proudly hold a drink made with her brand of rum, as Uniker-Sebeok (1981: 248) argues.

Promotional Techniques. The most predominant promotion was the recipe offers for all the groups. With the couples only and mixed group there was no notable difference between the ads containing the sexual connotations and the ads not containing sexual connotations for this promotional technique. The difference lies in the male only ads with sexual connotations and the female only ads with sexual connotations. "Gift" was the only promotional technique in the male only ads. Recipe offers, suggestions on how much to drink and gift giving were included in the female only ads.

Thus, one could conclude that the promotional techniques are used in a way that is consistent with the "proper place" of men 
and women; men are to "buy" and women are to "make recipes, shop, and be careful of how much they drink."

\section{Relevant Characteristics}

Tables XVII, XVIII, XIX, and XX contain the "relevant characteristics" for the different groups, in number and percent.

Presentation. The most outstanding finding in the presentation section of the "relevant characteristics" of the different groups is in the female only ads without sexual connotations. Specifically, as indicated in Table XVII, 55.0 percent of the female only ads without sexual connotations presented females in the partial presentation "hands on $1 y . "$

This finding is quite notable in that it confirms, given the earlier finding that 75 percent of the non-sexual connotation female only ads presented the females holding drinks, that where there are hands, the hands are actively doing something in relationship to the product.

As demonstrated in the same table (Table XVII), where sexual connotations exist, such a presentation drops dramatically (3.8 percent) and is replaced by full figure ( 35.8 percent) and waist-up presentations ( 32.1 percent).

As to the presentation of males, in the ads with sexual connotations, one male was presented in full figure, one male was presented in the "head only" partial presentation, and the other male was presented waist up. In the male only ads without sexual connotations, the most common ( 40.6 percent) presentations of the males 
TABLE XVII

"RELEVANT CHARACTERISTICS" FOR FEMALE ONLY ADVERTISEMENTS WITH AND WITHOUT SEXUAL CONNOTATIONS: PRESENTATION, PHYSICAL PROXIMITY, FOCUS OF ATTENTION, RELATIONAL POSTURES, AND DRESS

Sexual Connotations Number $\quad \underline{\text { Percent }}$
Without Sexual Connotations Number Percent

Presentation

\begin{tabular}{lr}
\hline Full & 19 \\
Partial: & \\
Hands Only & 2 \\
Heads Only & 1 \\
Torso Only & 0 \\
Waist Up & 17 \\
Other & $\frac{14}{53}$ \\
Total &
\end{tabular}

35.8

3

15.0

Partial:

Hands Only
Heads Only
Torso Only
Waist Up
Other
Total

2

3.8

1.9

0.0

11

55.0

0

32.1

$\frac{14}{53}$

$\frac{26.4}{100.0}$

5.0

0.0

0.0

0

$\frac{25.0}{100.0}$

Physical Proximity Low Involvement Medium Involvement High Involvement

0

0

0

Alone

Tota 1
0.0

0.0

0.0

$\frac{100.0}{100.0}$

88.0

0.0

0.0

0.0

8.0

4
$\frac{1}{49}$

(1)

0

0

$\frac{4.0}{100.0}$

Focus of Attention Looking at Product

Looking at

$$
\text { Others in Ad }
$$

Looking at Something/

Not Product

Looking Outside Ad,

Not Audience

Focus Somewhere Else Total

Missing Cases

$\frac{5}{20}$

0.0

0.0

0.0

$\frac{20}{20}$

$\frac{100.0}{100.0}$

Dress

Formal

Professiona 1

Casua 1

Swimsuits

Nightwear/PJs

Other Dress

Total

Missing Cases

13

1

3

$\frac{0}{42}$

(1)

$$
\begin{array}{r}
57.1 \\
2.4 \\
31.0 \\
2.4 \\
7.1 \\
0.0 \\
\hline 100.0
\end{array}
$$

5

55.6

11.1

0.0

11.1

22.2

2
$\frac{0}{9}$

$\frac{0.0}{100.0}$ 
TABLE XVIII

"RELEVANT CHARACTERISTICS" FOR MALE ONLY ADVERTISEMENTS WITH AND WITHOUT SEXUAL CONNOTATIONS: PRESENTATION, PHYSICAL PROXIMITY, FOCUS OF ATTENTION, RELATIONAL POSTURES, AND DRESS

Presentation

Fu11

Partial:

Hands Only

Heads Only

Torso Only

Waist Up

Other

Total

Missing Cases

Physical Proxmity

Low Involvement

Medium Involvement

High Involvement

Alone

Total

Missing (3)

Focus of Attention

Looking at Audience

Looking at Product

Looking at

Others in Ad

Looking at Something/

Not Product

Looking Outside Ad,

Not Audience

Focus Somewhere Else Tota 1

Missing Cases

0

0

0

$\frac{3}{3}$

1

33.3

0.0

33.3

0.0

33.3

$\frac{0.0}{99.9 *}$

0.0

0.0

0.0

$\frac{100.0}{100.0}$

0.0

0.0

0.0

50.0

0.0

$\frac{50.0}{100.0}$

50.0

50.0

0.0

0.0

0.0

$\frac{0.0}{100.0}$

Tota 1

Missing Cases

*Rounding difference

0

$\frac{0}{2}$
Sexual Connotations Number Percent

\section{Without Sexual Connotations Number Percent \\ Nithout sexual c}

Numer

71

40.6

45

25.7

5.1

1

37

$\frac{12}{175}$

(13)

21.1

$\frac{6.9}{100.0}$

8

4.8

19.2

1.8

3

74.2

$\frac{124}{167}$

(1)

47

36.7

3.1

16

12.5

17

13.3

32

$\frac{12}{128}$

(10)

25.0

$\frac{9.4}{100.0}$

10

8.3

22

18.2

47

38.8

0.0

0

0.0

$\frac{42}{121}$

(10)

$\frac{34.7}{100.0}$ 
were in the full-figure presentation followed by the partial presentation "hands only" (25.7 percent) and the waist-up presentation (21.1 percent).

The presentation of males and females in the mixed company ads and the couples only ads with and without sexual connotations were very similar. There were more females in full-figure presentations, more males in "hands only" presentations, and roughly equivalent males and females in the other presentations (see Tables XIX and XX). Physical Proximity. For all the female only ads (100 percent), the females were featured alone, that is, with no other females. For the three male only ads with sexual connotations, they too were featured alone. But while 74.2 percent of the male only ads featured the males "alone," 19.2 percent featured males in medium involvement, 4.8 percent featured males in low involvement, and 1.8 percent featured males in high involvement with other males.

The significance of these findings is that seemingly females have not "come far enough" to share with one another the activity of enjoying a drink together.

That is not to say they do not share this activity, but it would appear this is only so if males are included in the ad.

As Tables XIX and XX indicate, for both mixed company and couples only ads the percentages dropped substantially for low involvement and medium involvement, and increased significantly when sexual connotations were part of the ads, indicating that intimate interaction increases with sexual connotations. 
TABLE XIX

"RELEVANT CHARACTERISTICS" FOR MIXED COMPANY ADVERTISEMENTS WITH AND WITHOUT SEXUAL CONNOTATIONS: PRESENTATION, PHYSICAL PROXIMITY, FOCUS OF ATTENTION, RELATIONAL POSTURES, AND DRESS $\begin{array}{llll}\text { Sexual Connotations } & \text { Without Sexual Connotations } \\ \underline{\text { Number }} \underline{\text { Percent }} & \underline{\text { Number }} \text { Percent }\end{array}$

Presentation

Ful1

Males

50

56

23.5

89

$21 \cdot 3$

Females

26.3

97

23.3

Partial:

Hands On $1 y$

Males

Females

9

2

4. 2

12

2.9

Heads Only

Males

6

.9

5

1.2

Females

5

2.8

16

3.8

2.3

3.8

Torso Only

Males

Females

0

0

0.0

0.0

.5

Waist UP

Males

27

12.7

.2

Females

26

12.2

70

16.8

Other

Males

8.0

65

15.6

Females

Tota 1

$\frac{15}{213}$

$\frac{7.1}{100.0}$

22

5.3

$\frac{22}{417}$

$\frac{5.3}{100.0}$

Physical Proximity

Low Involvement

Medium Involvement

High Involvement

4

18

78

Alone

$$
\text { Tota } 1
$$

$\overline{100}$

Arm Lock:

Females Into Males 0

Males Into Females Tota 1

0

0.0

0.0

4.0

18.0

14

57

104

8.0

78.0

$\overline{100.0}$

$\overline{175}$

32.6

59.4

$\overline{100.0}$

2

100.0

$\frac{0}{2}$

$\frac{0.0}{100.0}$

Shoulder Lock:

Males Around

Females

6

66.7

9

50.0

Females Around

Males

Tota 1

$\frac{3}{9}$

$\frac{33 \cdot 3}{100 \cdot 0}$

$\frac{9}{18}$

$\frac{50.0}{100.0}$ 


\section{TABLE XIX (CONTINUED)}

"RELEVANT CHARACTERISTICS" FOR MIXED COMPANY ADVERTISEMENTS WITH AND WITHOUT SEXUAL CONNOTATIONS: PRESENTATION, PHYSICAL PROXIMITY, FOCUS OF ATTENTION, RELATIONAL POSTURES, AND DRESS

Sexua 1 Connotations Number
Percent

Without Sexual Connotations Number Percent

Focus of Attention

Looking at Audience Males

15

Females

21

Looking at Product

Males

Females

Looking at

others in $\mathrm{Ad}$

Males

Females

57

46

28.0

84

36

39

9.0

10.3

6

12

1.5

2.0

22.7

72

21.0

Looking at

Something/

Not Product

Males

Females

4

12

2.0

41

10.3

5.9

37

9.3

Looking Outside Ad,

Not Audience

Males

Females

5

3.4

18

19

4.5

2.5

4.8

Focus Somewhere

Else

Males
Females
Total
Missing Cases

$\begin{array}{r}6.9 \\ 8.4 \\ \hline 100.0\end{array}$

18

4.5

$\frac{17}{399}$

(8)

$\frac{4.3}{100.0}$

Relational Postures

Positioned Higher

in Ad

Males

Females

Total

33

$\frac{5}{38}$
86.8

$\frac{13.2}{100.0}$
58

$\frac{9}{67}$
86.6

$\frac{13.4}{100.0}$

Laying/Reclining

Position

Males

1

6.3

0

0.0

Females

$\frac{15}{16}$

$\frac{2}{2}$ $\frac{100.0}{100.0}$ 
TABLE XIX (CONTINUED)

"RELEVANT CHARACTERISTICS" FOR MIXED COMPANY ADVERTISEMENTS WITH AND WITHOUT SEXUAL CONNOTATIONS: PRESENTATION, PHYSICAL PROXIMITY, FOCUS OF ATTENTION, RELATIONAL POSTURES, AND DRESS

Sexual Connotations Number
Percent

Without Sexual Connotations Number

Relational

Postures Cont.

Hands Tracing object

Males

Females

Total
0
$\frac{12}{12}$

0.0

$\frac{100.0}{100.0}$
0

$\frac{11}{11}$
0.0

$\frac{100.0}{100.0}$

Hands Grasping

Object

Males

Females

Total

10

$\frac{0}{10}$
100.0

$\frac{0.0}{100.0}$
16

$\frac{0}{16}$
100.0

$\frac{0.0}{100.0}$

Receiving End/

Mock Attack

Males

Females

Tota 1

Dress

Forma 1

Males

Females

Professional

Males

Females

Casua 1

Males

Females

Swimsuits

Males

Females

4

66.7

$\frac{2}{6}$

$\frac{33.3}{100.0}$

$\frac{1}{1}$

100.0

$\frac{0.0}{100.0}$

ightwear/PJs

Males

Females

20

33

10.5

17.4

32

18.6

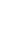

14

4

7.4

2.1

25

4

14.5

2.3

41

21.6

81

89

46.8

37

19.5

51.8

8

9

4.2

4.7

4

2.4

1.8

3

1.5

0.0

4

2.1

0

0.0

Other Dress

Males

Females

Tota 1

10

5.3

$\frac{3.7}{100.0}$

33

19.1

$\frac{7}{190}$

Missing Cases

190 
TABLE XX

"RELEVANT CHARACTERISTICS" FOR COUPLES ONLY ADVERTISEMENTS WITH AND WITHOUT SEXUAL CONNOTATIONS: PRESENTATION, PHYSICAL PROXIMITY, FOCUS OF ATTENTION, RELATIONAL POSTURES, AND DRESS

Presentation

Sexual Connotations Without Sexual Connotations

Ful1

Males

Females

Number

Percent

Number

Percent

Partial:

Hands Only

Males

Females

Heads Only

Males

Females

Torso only

Males

Females

Waist UP

Males

Females

Other

Males

Females

Tota 1

32

35

5

2

5

4

0

0

19

21

14

$\frac{13}{150}$
21.3

23.3

3.3

1.3

3.3

2.7

0.0

0.0

12.7

14.0

9.3

$\frac{8.7}{99.9 *}$
39

49
19.5

24.5

4.0

2.0

1.5

3.0

0.0

0.0

19.5

15.0

30

11

$\begin{array}{r}5.5 \\ 5.5 \\ \hline 100.0\end{array}$

$\frac{11}{200}$

Physical Proximity

\begin{tabular}{lr}
\hline Low Involvement & 4 \\
Medium Involvement & 8 \\
High Involvement & 63 \\
Alone Total & $\frac{0}{75}$ \\
\multicolumn{1}{c}{ Total } &
\end{tabular}

5.3

10.7

84.0

$\frac{0.0}{100.0}$

8

8.0

26

26.0

66

66.0

$\frac{0}{75}$

$\frac{0}{100}$

$\frac{0.0}{100.0}$

Arm Lock:

Females Into Males 0

Males Into Females 0 Total

0.0

0.0

2
$\frac{0}{2}$

100.0

$\frac{0.0}{100.0}$

Shoulder Lock:

Males Around

Females

Females Around

Males

Total

3

75.0

9

56.3

$\frac{1}{4}$

$\frac{25.0}{100.0}$

$\frac{7}{16}$

$\frac{43.7}{100.0}$

* Rounding difference 
TABLE XX (CONTINUED)

"RELEVANT CHARACTERISTICS" FOR COUPLES ONLY ADVERTISEMENTS WITH AND WITHOUT SEXUAL CONNOTATIONS: PRESENTATION, PHYSICAL PROXIMITY, FOCUS OF ATTENTION, RELATIONAL POSTURES, AND DRESS

Sexual Connotations Number
Percent

Without Sexual Connotations

Focus of Attention

Looking at Audience

$$
\text { Males }
$$

Females

Looking at Product

Males

Females

Looking at Others

in Ad

Males

Females

Looking at Something/

Not Product

Males

Females

Looking Outside Ad,

Not Audience

Males
Females

Focus Somewhere Else

Males

Females

Total

Missing Cases

43

35

2

8

4

1

$\begin{array}{r}13 \\ 15 \\ \hline 143\end{array}$

24

$\frac{3}{27}$

Laying/Reclining

Position

Males

Females

Total

8

4

Relational Postures

Males

Tota 1

27

$\frac{4}{5}$
5.6

9.8

0.0

0.0

30.1

24.4

1.4

5.6

34

26

19.4

14.8

2.8

.7

9.1

$\frac{10.4}{100.0}$

88.9

29

$\frac{11.1}{100.0}$

$\frac{6}{35}$

82.9

$\frac{17.1}{100.0}$ $\begin{array}{r}4.5 \\ 4.5 \\ \hline 100.0\end{array}$

(6)
13

13

8

10

4.5

5.7

7.4

7.4

\begin{tabular}{rr}
8 & 4.5 \\
8 & 4.5 \\
\hline 176 & 100.0
\end{tabular}

20.0

0
0
0

0.0

$\frac{80.0}{100.0}$

$\frac{0.0}{0.0}$ 
TABLE XX (CONTINUED)

"RELEVANT CHARACTERISTICS" FOR COUPLES ONLY ADVERTISEMENTS WITH AND WITHOUT SEXUAL CONNOTATIONS: PRESENTATION, PHYSICAL PROXIMITY, FOCUS OF ATTENTION, RELATIONAL POSTURES, AND DRESS

Sexua 1 Connotations Number
Percent
Without Sexual Number

Relationa 1

Postures Cont.

Hands Tracing object

Males

Females

Tota 1 $\begin{array}{lr}0 & 0.0 \\ 7 & \frac{100.0}{7}\end{array}$

0

$\frac{4}{4}$

0.0

$\frac{100.0}{100.0}$

Hands Grasping

Object

Males

Females

Total

Receiving End/

Mock Attack

Males
Females
Total

Dress

Forma1

Males

Females

15

11.2

$\begin{array}{r}100.0 \\ 0.0 \\ \hline 100.0\end{array}$

9

100.0

4
$\frac{0}{4}$

$\frac{0}{9}$

$\frac{0.0}{100.0}$

Percent

Professiona 1

Males

Females

3

60.0

1

100.0

$\frac{2}{5}$

$\frac{40.0}{100.0}$

$\frac{0}{1}$

$\frac{0.0}{100.0}$

Casua 1

Males

Females

24

17.9

16

9.3

21

12.1

11

4

8.2

3.0

13

7.5

0

0.0

25

18.7

40

23.1

22

16.5

46

26.6

Swimsuits

Males

Females

5.2

5.2

1

0

.6

7
7

2.2

2.2

0

0.0

Nightwear/PJs

Males

Females

3

Other Dress

Males

Females

Tota 1

$\frac{6}{7}$

$$
4.5
$$

$\frac{5.2}{100.0}$

17

0.0

$0 \quad 0.0$

Missing Cases

$\frac{19}{173}$

(2)
9.8

$\frac{11.0}{100.0}$ 
Only the ads without sexual connotations presented female arms interlocked in male arms for mixed company and couples only ads.

While male arms around female shoulders and female arms around male shoulders were roughly equivalent in the ads without sexual connotations for both the mixed company ads and the couples only ads, the percentage for the male arms around female shoulders was greater than the female arms around male shoulders for both mixed company ( 66.7 percent compared to 33.3 percent) and couples only (75 percent compared to 25 percent) ads when the ads contained sexual connotations. Focus of Attention. Probably the most notable finding in this area involves a comparison of the male only ads and the female only ads.

As indicated in Tables XVII and XVIII, when no sexual connotations exist in the ads, males are more likely than females to "look at others in the ad" ( 12.5 percent compard to 0 percent) and "focus somewhere else" ( 9.4 percent compared to 0 percent), whereas females are more likely to "look at the audience" ( 55.6 percent compared to 36.7 percent), and "look at the product" ( 11.1 percent compared to 3.1 percent). The focus of attention in these ads (without sexual connotations) is very similar for males and females when "looking at something in the ad, but not the product" and "looking outside the ad, but not at the audience.

When sexual connotations existed in the ads, the differences between males and females were much more pronounced. In the female only ads, the majority of females focused on the audience ( 88 percent). Only a few (4) "looked outside the ad, but not at the 
audience" ( 8 percent) and on 1y one focused "somewhere else" (4 percent). In the male only ads, no males "looked at the audience"; onehalf the time (50 percent) they looked at "something, but not the product" and the other half (50 percent) they were focused "somewhere else."

In the mixed company ads and couples ads, there were more females looking at the audience and looking at the product than males and more males looking at other people than females whether sexual connotations existed in the ad or not (see Tables XIX and XX). Yet, depending on whether or not sexual connotations existed in the ad, the other focuses of attention were not so consistent. For example, more females than males focused on "something, but not the product" and "somewhere else" in ads that contained sexual connotations for both the mixed company ads and couples only ads; in the ads with no sexual connotations this focus was roughly equivalent for males and females. In ads with sexual connotations, more males than females "looked outside the ad but not at the audience" in both mixed company and couples on $1 y$ ads; the opposite was true when the ads did not contain sexual connotations.

Relational Postures. As indicated earlier in the relational postures of the human models sample, males were more likely to be positioned higher in the ad and grasping objects while females were likely to be lying down or in a reclining position and tracing objects in both the mixed company ads and couples only ads with or without sexual connotations ( see Tables XIX and XX). 
One finding did stand out though. Most mock attacks occurred in ads with sexual connotations for both mixed company ads and couples only ads and males were more likely to be on the receiving end of these attacks. At least in the couple only ads, one could argue (see Root, 1984: 63) that maybe a little "aggressiveness does spice things up."

Dress. The most significant finding in the dress section was that there were no models presented in nightwear, such as pajamas, in ads that did not carry sexual connotations. In fact, even in the male only ads with sexual connotations no male was presented in nightwear. In contrast, in the female only ads with sexual connotations, females were presented in nightwear 7.1 percent of the time. This presentation in the female only ads with sexual connotation was followed by formal dress ( 57.1 percent), casual dress ( 31 percent), swimsuit and professional dress (each 2.4 percent). The two male only ads with sexual connotations presented the males in either one of professional dress or formal dress.

In the mixed company ads and couples only ads, more females were presented in formal dress and more males were presented in professional dress whether or not sexual connotations existed in the ad. Men and women were presented in equivalent poses with swimwear and other dress whether sexual connotations existed or not for both the mixed company ads and the couple only ads. And men and women were presented in roughly equivalent poses with nightwear in the ads with sexual connotations for both mixed company ads and couples only ads (see Tables XIX and XX). 
Era

Presented in Table XXI is the variable "era" in number and percent for the different groups. In the female only ads and male only ads without sexual connotations, the percentage of such ads increased from era to era; 15 percent to 30 percent to 55 percent for the female only ads and 15.5 percent to 35.7 percent to 48.8 percent for male only ads. For the mixed company ads and couples only ads without sexual connotations, this pattern did not hold. While there was an increase in ads without sexual connotations from the demure era to the sexy era for both mixed company ads and couples on $1 y$ ads ( 11.9 percent

TABLE XXI

"ERA" IN NUMBER AND PERCENT FOR ALL GROUPS ADVERTISEMENTS WITH AND WITHOUT SEXUAL CONNOTATIONS

Sexual Connotations

Number Percent
Without Sexual Connotations Number Percent

Female Only

Demure

Sexy

Modern

Tota 1

\begin{tabular}{rr}
5 & 9.4 \\
29 & 54.7 \\
19 & 35.8 \\
\hline 53 & 100.0
\end{tabular}

33.3

0.0

$\frac{66.7}{100.0}$

\begin{tabular}{rr}
3 & 15.0 \\
6 & 30.0 \\
$\frac{11}{20}$ & 55.0 \\
\hline & 100.0
\end{tabular}

26

$60 \quad 35.7$

$\frac{82}{168}$

$$
\frac{48.8}{100.0}
$$

Mixed Company

Demure

Sexy

Modern

Tota 1
8

39

$\frac{53}{100}$
8.0

39.0

$\frac{53.0}{100.0}$
21

86

$\frac{69}{176}$
11.9

48.9

$\frac{39.2}{100.0}$

Couples On 1y

Demure

Sexy

Modern

Total

\begin{tabular}{rr}
4 & 5.3 \\
25 & 33.3 \\
46 & 61.3 \\
\hline 75 & 100.0
\end{tabular}

\begin{tabular}{rr}
10 & 10.0 \\
46 & 46.0 \\
44 & 44.0 \\
\hline 100 & 100.0
\end{tabular}


to 48.9 percent and 10 percent to 46 percent respectively), there was a decrease in such ads from the sexy era to the modern era (down to 39.2 percent for mixed company ads and 44 percent for couple only ads). In relationship to these findings, the percentage of ads with sexual connotations rose steadily from era to era for the mixed company ads and the couple only ads. Likewise, for the male only ads, only one appeared in the demure era while the other two appeared in the modern era.

But there did appear to be quite a change in the female only ads with sexual connotations. While it was demonstrated that there was a tremendous increase in such ads from the demure era to the sexy era (from 9.4 percent to 54.7 percent), there was a significant decrease from the sexy era to the modern era (from 54.7 percent to 35.8 percent).

Thus while the majority of the female only ads do in fact carry sexual connotations, as mentioned earlier, there does appear to be a difference in the eras in which they are concentrated.

\section{Target Market}

The "target market" for the distilled beverage advertisements is indicated in Table XXII, which specifies the categories by type of ad. The most outstanding finding in relationship to the target market was in the ads that carried sexual connotations; the majority were targeted for males. All ( 100 percent) of the female only ads with sexual connotations were targeted for males, 66.7 percent of the male only ads were targeted for males, 59 percent of the mixed company ads 
were targeted for males, and 54.7 percent of the couples only ads were targeted for males. Quite insignificant were such ads targeted for females: only 4 percent of the mixed company ads, 5.3 percent of the couples only ads, and only one of the male only ads.

of the female only ads that did not carry sexual connotations, 75 percent were targeted for the general audience and 25 percent were targeted for females.

\section{TABLE XXII}

TARGET MARKET IN NUMBER AND PERCENT FOR ALL GROUPS WITH AND WITHOUT SEXUAL CONNOTATIONS

Sexual Connotations

Number Percent

Without Sexual Connotations Number

Percent

Female On1y

Males Only

Females Only

Genera 1

Aud ience

Tota 1

0

100.0

0.0

$\frac{0}{53}$

$\frac{0.0}{100.0}$

Male On1y

Males Only

Females only

General

Audience

Total

Mixed Company

Males Only

Females only

General

Aud ience

Tota 1

Couples Only

Males Only

Females only

General

Audience

Total
66.7

33.3

$\frac{0}{3}$

59

4

59.0

4.0

$\frac{37.0}{100.0}$

$\frac{166}{176}$

54.7

5.3

4

$\frac{30}{75}$

$\frac{0.0}{100.0}$

$\frac{123}{168}$

41

$\frac{40.0}{100.0}$

$\frac{95}{100}$ $\frac{37}{100}$ $\frac{15}{20}$

$\frac{75.0}{100.0}$

45

0

26.8

0.0

$\frac{73.2}{100.0}$

0.0

25.0

8

4.6

1.1

$\frac{94.3}{100.0}$

\section{4}

4.0

1.0

1

$\frac{95.0}{100.0}$ 
Likewise, of the male only ads that did not carry sexual connotations, 73.2 percent were targeted for the general audience and 26.8 percent were targeted for males.

Both mixed company ads and couples only ads that did not carry sexual connotations were predominately targeted for the general audience ( 94.3 percent and 95 percent respectively), followed by males ( 4.5 percent and 4.0 percent respectively), and finally by females (1.1 percent and 1 percent respectively).

Outside the 25 percent of the female only ads without sexual connotations, the resounding message is clear: women are definitely not a targeted market for distilled beverage advertisements.

\section{Themes and Appeals: Separate}

Tables XXIII and XXIV contain the sixteen separate thematic categories as defined in Appendix A.

As indicated in Table XXIII, the separate categories for the female only ads and male only ads with sexual connotations were very consistent with the information theme $(35.8$ percent and 33.3 percent respectively), ranking second to the sexual connotations theme. This was followed by the special occasion theme, the general success theme, and finally the quality theme. Likewise, for the mixed company ads and couples only ads with sexual connotations, the same four themes occurred most often followed by the tradition theme, the achievement theme, and the host and hostess themes.

For all the categories without sexual connotations (with the exception of couples, which will be explained), the most dominant 
three themes were information, special occasion, and quality. Following these, different themes were more or less prevalent depending on the category.

For the female only ads what followed the top three themes were hostess (10 percent), general success (10 percent), individuality (10 percent), and tradition ( 5 percent). For the male only ads, it was individuality ( 13.1 percent), tradition ( 8.3 percent), host (3.6 percent), and self-reward, (close) friends, and relaxation (each at 1.8 percent). In the mixed company ads, the love and romance theme actually tied the quality theme for third highest percent ( 30.7 percent).

\section{TABLE XXIII}

THEMES AND APPEALS: SEPARATE, IN FEMALE ONLY AND MALE ONLY ADVERTISEMENTS WITH AND WITHOUT SEXUAL CONNOTATIONS, IN NUMBER AND PERCENT

Sexual Connotations

$\begin{gathered}\text { Female Only } \\ (\mathrm{N}=53)\end{gathered}$
Per-

Themes and Appea $1 s^{*}$ Number cent Number cent
No Sexua 1 Connotations Female Only Male Only $\frac{(N=20)}{\text { Per- }} \frac{(N=168)}{\text { Per- }}$ Number cent Number cent

$\begin{array}{lrrrrrrrr}\text { Achievement/Success } & 0 & 0.0 & 0 & 0.0 & 0 & 0.0 & 1 & .6 \\ \text { Self Reward } & 0 & 0.0 & 0 & 0.0 & 0 & 0.0 & 3 & 1.8 \\ \text { Host } & 0 & 0.0 & 0 & 0.0 & 0 & 0.0 & 6 & 3.6 \\ \text { Hostess } & 0 & 0.0 & 0 & 0.0 & 2 & 10.0 & 3 & 1.8 \\ \text { Information } & 19 & 35.8 & 1 & 33.3 & 10 & 50.0 & 98 & 58.3 \\ \text { (Close) Friends } & 0 & 0.0 & 0 & 0.0 & 0 & 0.0 & 3 & 1.8 \\ \text { Relaxation } & 0 & 0.0 & 0 & 0.0 & 0 & 0.0 & 3 & 1.8 \\ \text { Camaraderie } & 0 & 0.0 & 0 & 0.0 & 0 & 0.0 & 0 & 0.0 \\ \text { Love/Romance } & 0 & 0.0 & 0 & 0.0 & 3 & 15.0 & 0 & 0.0 \\ \text { Special Occasions } & 15 & 28.3 & 1 & 33.3 & 10 & 50.0 & 66 & 39.3 \\ \text { "General" Success } & 2 & 3.8 & 1 & 33.3 & 2 & 10.0 & 20 & 11.9 \\ \text { Sexual Connotations } & 53 & 100.0 & 3 & 100.0 & 0 & 0.0 & 0 & 0.0 \\ \text { Individuality } & 0 & 0.0 & 0 & 0.0 & 2 & 10.0 & 22 & 13.1 \\ \text { Physical Activity } & 0 & 0.0 & 0 & 0.0 & 0 & 0.0 & 2 & 1.2 \\ \text { Quality } & 5 & 9.4 & 1 & 33.3 & 4 & 20.0 & 46 & 27.4 \\ \text { Tradition/Heritage } & 2 & 3.8 & 0 & 0.0 & 1 & 5.0 & 14 & 8.3\end{array}$

* Not mutually exclusive 
Following this theme was (close) friends ( 13.6 percent), general success ( 8 percent), and physical $(6.3$ percent) as the more dominant themes.

As mentioned, the couple only ads differed somewhat from the other groups in regard to the top three themes. This was actually because the love and romance theme ranked second ( 48 percent) for this group when sexual connotations were not present. Following these (much like the mixed company group), the close friends, general success, and physical themes were more prevalent.

\section{TABLE XXIV}

THEMES AND APPEALS: SEPARATE, IN MIXED COMPANY AND COUPLES ONLY ADVERTISEMENTS WITH AND WITHOUT SEXUAL CONNOTATIONS, IN NUMBER AND PERCENT

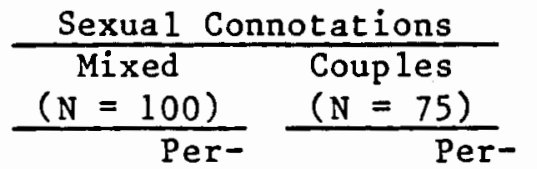

Themes and Appeals* Number cent Number cent
No Sexual Connotations

$\begin{array}{cc}\text { Mixed } & \begin{array}{c}\text { Couples } \\ (\mathrm{N}=176)\end{array} \\ \text { Per- } & \frac{N=100)}{\text { Per- }}\end{array}$

Number cent Number cent

$\begin{array}{lrrrrrrrr}\text { Achievement/Success } & 2 & 2.0 & 2 & 2.7 & 0 & 0.0 & 0 & 0.0 \\ \text { Self Reward } & 0 & 0.0 & 0 & 0.0 & 4 & 2.3 & 4 & 4.0 \\ \text { Host } & 1 & 1.0 & 1 & 1.3 & 5 & 2.8 & 1 & 1.0 \\ \text { Hostess } & 3 & 3.0 & 1 & 1.3 & 7 & 4.0 & 2 & 2.0 \\ \text { Information } & 53 & 53.0 & 41 & 54.7 & 103 & 58.5 & 62 & 62.0 \\ \text { (Close) Friends } & 1 & 1.0 & 1 & 1.3 & 24 & 13.6 & 15 & 15.0 \\ \text { Relaxation } & 1 & 1.0 & 0 & 0.0 & 2 & 1.1 & 2 & 2.0 \\ \text { Camaraderie } & 2 & 2.0 & 0 & 0.0 & 22 & 12.5 & 0 & 0.0 \\ \text { Love/Romance } & 0 & 0.0 & 0 & 0.0 & 54 & 30.7 & 48 & 48.0 \\ \text { Special Occasions } & 12 & 12.0 & 7 & 9.3 & 56 & 31.8 & 38 & 38.0 \\ \text { "Genera1" Success } & 10 & 10.0 & 6 & 8.0 & 14 & 8.0 & 9 & 9.0 \\ \text { Sexual Connotations } & 100 & 100.0 & 75 & 100.0 & 0 & 0.0 & 0 & 0.0 \\ \text { Individuality } & 0 & 0.0 & 0 & 0.0 & 6 & 3.4 & 5 & 5.0 \\ \text { Physical Activity } & 2 & 2.0 & 1 & 1.3 & 11 & 6.3 & 5 & 5.0 \\ \text { Quality } & 20 & 20.0 & 16 & 21.3 & 54 & 30.7 & 26 & 26.0 \\ \text { Tradition/Heritage } & 8 & 8.0 & 6 & 8.0 & 9 & 5.1 & 5 & 5.0\end{array}$

*Not mutually exclusive 
Two points can be made from these findings: (1) when sexual connotations do not exist, love and romance is quite notable, at least for the mixed groups (note, though, that three ads contained the love and romance theme for the female only ads without sexual connotations) and (2) females do not have close friends, not unless there is a male present.

To get a better understanding of the themes and appeals used in the ads for the different groups, Tables XXV and XXVI contain the themes and appeals recoded, as mentioned in Chapter IV to address the dominant regroupings of product-related and humans-models-related

\section{TABLE XXV}

THEMES AND APPEALS: RECODED, IN FEMALE ONLY AND MALE ONLY ADVERTISEMENTS WITH AND WITHOUT SEXUAT CONNOTATIONS AND NUMBER OF THEMES PER AD, IN NUMBER AND PERCENT

Sexual Connotations
$\begin{aligned} & \text { Female Only } \\ & (\mathrm{N}=53)\end{aligned} \frac{(\mathrm{N}=3)}{\text { Per }-} \quad \frac{\text { Per }}{}$

Themes and Appea $1 s^{*}$

Lifesty le

Psychologica 1

Serving Others

Sociabilityt:

Sports

Sexuality

Product Related

Number of Themes

in Ad

One

Two

Three

Four

\begin{abstract}
Number cent
Number cent
\end{abstract}

$$
2 \quad 3.8
$$

No Sexua 1 Connotations

$\begin{array}{ll}\begin{array}{l}\text { Female Only } \\ (\mathrm{N}=20)\end{array} & \begin{array}{l}\text { Male Only } \\ \text { Per- }\end{array}\end{array}$

Number cent Number cent

$\begin{array}{llll}2 & 3.8 & 1 & 33.3\end{array}$

$0 \quad 0.0$

0.0

$0 \quad 0.0$

1528.3

$0 \quad 0.0$

$53 \quad 100.0$

$20 \quad 37.7$

$$
0
$$

0

0.0

133.3

0.0

3100.0

266.7

2

210.0

21

12.5

210.0

10

10.0

25

14.9

10

50.0

0.0

9

5.4

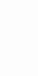

315.0

1470.0

2

41.1

21.2

$117 \quad 69.6$

* Not mutually exclusive

$\stackrel{\star}{*}$ Special Occasion/Holiday theme included. 
themes. Further, Tables XXV and XXVI contain the number and percent of the number of themes (recoded as such) per ad.

TABLE XXVI

THEME AND APPEALS: RECODED IN MIXED COMPANY AND COUPLES ONLY ADVERTISEMENTS WITH AND WITHOUT SEXUAL CONNOTATIONS AND NUMBER OF THEMES PER AD, IN NUMBER AND PERCENT

$\frac{\text { Sexua } 1 \text { Connotations }}{\text { Mixed }}$
$\frac{(N=100)}{\text { Per }-} \frac{(N=75)}{\text { Per- }}$

Themes and Appeals*

Lifestyle

Psychological

Serving Others

Sociability*

Sports

Sexuality

Product Related
Number cent
No Sexual Connotations

\begin{tabular}{cc}
$\begin{array}{c}\text { Mixed } \\
(\mathrm{N}=176)\end{array}$ & $\begin{array}{c}\text { Couples } \\
(\mathrm{N}=100)\end{array}$ \\
\cline { 1 - 2 } & Per-
\end{tabular}

Number cent Number cent

Number of Themes

and Appeals in Ad

\begin{tabular}{lrrrrrrrr}
\cline { 1 - 2 } & 26 & 26.0 & 21 & 28.0 & 64 & 36.4 & 29 & 29.0 \\
Two & 58 & 58.0 & 45 & 60.0 & 90 & 51.1 & 51 & 51.0 \\
Three & 14 & 14.0 & 7 & 9.3 & 17 & 9.7 & 16 & 16.0 \\
Four & 2 & 2.0 & 2 & 2.7 & 5 & 2.8 & 4 & 4.0
\end{tabular}

* Special Occasion/Holiday theme included.

Themes and Appeals: Recoded

For the female only ads and the male only ads with sexual connotations, the following themes were quite evident: product-related, sociability, and lifestyle. Likewise, for the mixed company and couples only ads with sexual connotations, these same themes were the most prevalent (see Table XXVII). One notable finding was that in all groups with sexual connotations no psychological themes were present. 
For the female on $1 y$ ads without sexual connotations, the three most dominant themes were product-related ( 70 precent), sociability (50 percent), and sexuality ( 15 percent). The love and romance theme was significant here.

TABLE XXVII

THEMES AND APPEALS PORTRAYED FOR EACH GENDER TYPE IN PERCENTAGES

Themes and

Appea ls*

Lifestyle

Psychological

Serving Others

Sociability

Sports

Sexuality

Product-Related
Female

Only

5.5

2.7

2.7

34.2

0.0

76.7

46.6

73
Male

Only

12.9

14.6

5.3

40.9

1.1

1.8

69.6
Mixed***

Company

$$
9.4
$$

3.6

5.4

38.0

4.7

55.8

66.7

276
Tota 1

Ads

10.0

7.1

5.0

38.5

2.9

41.0

64.8

Number of Ads

171

520

*Not mutual1y exclusive.

$*$ Couples included in mixed company.

For the male only ads without sexual connotations, the three most dominant themes were product-related (69.6 percent), sociability (41.1), and psychological (14.9).

And for both the mixed corapany and couples only, the dominant themes were product-related ( 71 percent and 73 percent respectively), sociability (51 percent and 48 percent respectively), and sexuality, the love and romance theme ( 30.7 and 48 percent).

Thus, much like Strickland et al. (1982: 666) concluded, most of the themes and appeals were product-related. But unlike Strickland 
et al., these data indicate that which themes and appeals are significant depends on the composition of different groups within the ad. And indeed, when looking at the number of themes per ad, this conclusion is intensified. As indicated in Table XXV, 43.4 percent of the female only ads with sexual connotations carried only that theme. In no male only ads with sexual connotations was this so; in other words, all the male on $1 y$ ads contained more than just the sexual connotations theme.

Composition does make a difference. This fact becomes even clearer when all the ads are combined (520) and the dominant themes are listed for the different groups, as Table XXVII indicates.

Sexuality is the most dominant theme $(76.7$ percent) for the female only ads, whereas it is only evident in the male only ads 1.8 percent of the time.

Given these findings, the following section addresses the evaluation of the two hypotheses and discusses the variables associated with each.

EVALUATION OF THE HYPOTHESES

Hypothesis 1: The portrayal of women in distilled beverage advertising emphasizes the sexual persuader role over the consumer role.

Evaluation of this hypothesis can be greatly simplified by drawing on the findings indicated in Tables XII and XXII. Of the female only ads (in which, only one female was present per ad), 76.2 percent contained the thematic code sexual connotations. All of these ads (100 percent) were targeted for "males on $1 y . "$ 
In the mixed company ads and couples only ads, 36.2 percent and 42.9 percent respectively contained the thematic code sexual connotations. Of these, the majority ( 59 percent and 54.7 percent respectively) were once again targeted for "males only."

In contrast, only 1.8 percent of the male only ads (totaling three in number) contained the thematic code sexual connotations and of these, only one was targeted for females.

These findings coupled with the observation that within the human models group, females were rarely targeted as a separate market (2.3 percent), especially when compared to males (who were targeted 32.1 percent of the time; see Table VI), clearly demonstrate that the portrayal of women is distilled beverage advertisement is not as coequa 1 consumer.

In fact, given the findings that in most ads females are portrayed more often in decorative poses (59.2 percent; see Table III), focusing on the spectator of the ad (see Table IX and more specifically, Table VII), and in relational postures clearly subservient to males (see Tables $X, X I X, X X$ ) along with the fact that the majority contain sexual connotations, the only conclusion that can be drawn is that the proper place of women in distilled beverage advertisements is that of sexual persuader over that of co-equal consumer.

In other words, women continue to be used in a sexual1y exploitative way.

Hypothes is 2: Laws, rules and regulations addressing the issue of women in distilled beverage advertising have had little impact over time in the portrayal of women in such advertising. 
As indicated in Table XXI, for all the eras the number of ads that contained the sexual connotations theme in the female on ly ads outweighed the number that did not.

Yet, when just focusing on the ads that contained sexual connotations, there does seem to be a decrease in the number and percent of such ads in the modern era for the female only ads, 54.7 percent in the sexy era to 35.8 percent. Likewise, when focusing only on the female only ads that did not contain sexual connotations, the number and percent increased from one era to the next (15 percent to 30 percent to 55 percent).

Given these findings, one could conclude that the laws, rules and regulations applying to the woman's place are indeed having an impact on the reduction of women being portrayed as sexual persuaders, and thus that this second hypothesis is not supported.

But, as also indicated in Table XXI, this pattern does not hold when mixed company and couples only ads (of which females are a part) are analyzed. In fact, the findings for these groups are just the opposite; "sexual connotations" continued to increase from era to era. For example, in the couples only ads, the percent of the ads that contained the thematic code sexual connotations increased from 5.3 percent in the demure era to 33.3 percent in the sexy era, and then rose to 66.3 percent in the modern era (see Table XXI). This pattern was also true for the mixed company ads, as Table XXI indicates. Interpreting this particular finding, one could argue that in a response to criticisms of sexism in distilled beverage advertisements (see Chapter III, especially Marsteller and Karnchanapee, 1980), the 
advertisers of such products shifted the emphasis of sexual connotations from female on $1 y$ ads to mixed group ads, yet did not decrease the ads "which emphasize sex in such a way as to utilize sensualism and suggestiveness to encourage the purchase and/or consumption of any type or brand of distilled spirits" (DISCUS 1975 resolution quoted in Marsteller and Karchanapee, 1980: 10).

As such, support for the second hypothesis is indicated; women continue to be used as sexual persuaders over time but even more so now in ads in which males are included.

In summary, it appears that with the inclusion of women in advertisements traditionally associated with the masculine role, such as distilled beverages, there is little to support the argument that the image of females is "upgraded." In fact, women continue to be exploited in such advertising. Thus such advertising cannot be considered a vanguard for social change in the "woman's place."

In other words, it appears that rather than challenging the socially constructed world of maleness and femaleness, the inclusion of women in distilled beverage advertisements continues to reinforce and maintain the view that the proper "place" for women is successfully occupying a social position subservient to men. That is the only "real" way to be. 


\section{CHAPTER VI}

\section{SUMMARY AND DISCUSSIONS}

This concluding chapter addresses some of the issues raised by the theoretical framework of this study, comments on selected findings from the content analysis, and offers some suggestions for future research.

The central focus of this research effort has been an attempt to investigate whether or not distilled beverage advertising, in which women have only recently been included, could be perceived as representing a new format or context for secondary socialization whereby a constructed reality different than the traditional roles of women could be created. Specifically, could women be perceived more as coequal consumers rather than subservient to men by their inclusion in advertisements traditionally associated with the masculine role.

Analyzing such advertising using the semiological approach (see Chapter III, especially Leiss et a1., 1986), which suggests the meaning of the ad is built up out of the ways that different signs are organized and related to each other, and as concluded in Chapter v, the nearly equal participation of women in the use of distilled beverages did not mean that women's drinking was more accepted nor that women should be treated as more equal consumers, at least not as evident by their portrayal in the distilled beverage advertisements analyzed in this study. 
Specifically in that 76.2 percent of the female only ads contained sexual connotations (see Chapter $V$ ), the only conclusion that could be drawn was that such advertising only reinforced and maintained the view that the proper place of women was as traditional instruments of persuasion in traditionally decorative, sexually exploitative roles.

In other words, rather than creating the reality of "more powerful female gender displays, where a young woman may be shown . . proudly holding up a drink made with 'her' brand of rum" as some have argued (Umiker-Sebeok, 1981: 248), the findings within this study supported the notion that under the guise of sexual liberation (the inclusion of women in advertising traditionally associated with "the most macho male images"), the advertisers of this particular product capitalized on women's new self-image and turned to manipulating one aspect of the new woman, i.e., her sexuality, and continued to exploit the traditional image of woman as sex object (see Chapter III, particularly Ceulemans, 1979).

In considering this finding, one could argue that the media (via distilled beverage advertising) is distorting the real position of women, especially in light of the evidence, as previously discussed (see Chapter III), that more women are drinking today than a generation ago, and that women are drinking more. This, in fact, is the new woman.

Yet, as Gaye Tuchman (1979: 537) points out, "the cult of the New Woman subverts the tenet that sexism is an institutionalized 
phenomenon. . ." The importance of this cannot be understated when addressing the portrayal of women in any form of advertising.

The fact that advertisers rely on what is believed to exists in imaginations of the target audience, that gender roles have been unequivocally differentiated, and that the "ideal" of the woman's place has traditionally been that "ladies don't drink," the reliance on traditional images of women in distilled beverage advertising rather than that of co-equal consumers, which would challenge these images, can only be understood if one acknowledges the institutionalization of sexism.

Further, recognizing that the social worlds of "maleness" and "femaleness" are worlds that are reified, that is, whereby "the dialectic between man, the producer, and his products is lost to consciousness" (Berger and Luckmann, 1967: 89; original gender), one could argue that such advertising may in fact symbolically be capturing the real position of women in American society--"their real 1ack of power" (Tuchman, 1979: 533).

This would appear so given the findings of this study. Specifically, even in the female only ads that did not contain sexual connotations, the portrayal of women still represented more of the ideal of the women's place than any alteration of the existing cultural context that defines appropriate gender role images. For instance, while it was found in the techniques of presentation section of the female only ads without sexual connotations that in 75 percent of the cases women were holding drinks and thus having some relation to the product, rather than being presented in the decorative pose, 
this presentation was accompanied by the "hands only" presentation as the most dominant depiction ( 55 percent) of these women; on $1 y$ three women were presented in full figure presentations (40.6 percent). By contrast, men in the male only ads without sexual connotations were predominantly featured in full figure presentations (40.6 percent).

Likewise, in the relevant characteristics section of these same advertisements, women were predominantly featured in fictional (90 percent) or indoor ( 10 pecent) settings, in poses focusing on the audience ( 55.6 percent), in formal ( 16.7 percent) or casual (66.6 percent) dress, and most indicative of a lack of change in the women's place, in the ads alone (see Table XVII). Men, on the other hand, were featured in various settings, including taverns and restaurants ( 3 percent) and outdoors, such as the beach ( 28.9 percent), in not on 1y casual and formal dress, but "professional" dress (18.2 percent), and in ads with other males; 25.8 percent of such ads featured males interacting with other males to some degree.

Further, the most dominant theme and appeal used in the female only ads without sexual connotations (after the emphasis on the product-related themes and the special occasion theme) was love and romance ( 15.0 percent); for men, the emphasis was on individuality (13.1 percent). In fact, several themes included in the male only ads never appeared in the female only ads, such as relaxation, (close) friends, self-reward, physical, and achievement and success; one theme that did not appear in the male only ads was love and romance (see Table XXIII). 
Thus, even while it was found that one female in the female only ads without sexual connotations was presented in professional dress and that 25 percent of such ads ( 5 in tota1) were targeted for females (see Table XXII), it was quite obvious that such advertisements reinforced and maintained the objective reality of the worlds of maleness and femaleness rather than creating a new reality.

A second focus of this research effort was to ascertain if the laws, rules, and regulations addressing the issue of women in distilled beverage advertising have had any impact over time in the portrayal of women in such advertising.

As concluded in Chapter $\mathrm{V}$, while it might appear this was the case if one only concentrated on female only ads, the fact the mixed company and couples only ads (which contained the thematic code sexual connotations) increased in number and percent, lends support to the hypothesis (that the laws, rules and regulations had little impact) was indicated. Again this hypothesis is greatly dependent on the socially constructed worlds of maleness and femaleness. For example, what constitutes "dignified" and "in good taste" for roles that have been delegated as subservient?

According to Berger and Luckmann (1967: 115) any threat to the existing social definitions of reality, e.g., "That is not very dignified to present females lying down as if sexually available" is "nihilated"; that is, "neutralized by assigning an inferior ontological status, and thereby a not-to-be-taken-seriously cognitive status, to all definitions existing outside the symbolic universe." 
This is quite evident, as pointed out in Chapter III (see Komisar, 1971), in some of the males' reactions to the charges of sexism in advertising, e.g., "We didn't think that was degrading" (1971: 212).

Yet, because any "reality . . gains in massivity in the course of its transmission" (Berger and Luckmann, 1967: 61), the fact that distilled beverage advertising, much like all advertising (see Chapter III), continues to objectify the unequal social worlds of maleness and femaleness points to some serious questions about the supposed social equality of men and women given the inclusion of women in such advertising.

Indeed, given the findings in this study, conclusions drawn such as "relatively infrequent were such controversial themes as sexual connotation" (Strickland et al., 1982: 679) negates the fact that it al1 depends on the composition of the ad--no human models, only male models, or only female models.

If "rigorous analysis of the content [distilled] beverage alcohol advertising per se is necessary to inform the present regulatory debates and public policy considerations," (Strickland et al., 1982: 680-81), it would appear that an analysis of men and women's roles in such advertising is a ncessary first step, for as this study concludes, males and females are not presented equally, at least not in this type of alcohol advertising. This is not to suggest that it might not be possible for a different construction of reality to exist in other forms of alcohol advertising such as beer or wine. 
Because, as mentioned in Chapter II, women have been included in the brewers' and vinters' advertisements for many years, and there appears to be a growing emphasis on such products as wine coolers and light beers, it could be that women are considered to be more co-equal consumers than this study would indicate. More research in this area would seem pertinent.

Further, the findings in the present study do not exclude the possibility that some form of equality exists in the distilled beverage advertisements.

As indicated earlier, one area in which sexual connotations appeared to be increasing was in the mixed company, specifically couples only, advertisements. Further, of the three male only ads that contained sexual connotations, two of these were presented in the modern era.

"Since the most central media goal is economic profit, [and] sex - . is functional in the sense that even though it may be of low taste, it maximizes the size of the audience exposed to advertisements" (Defleur and Ball-Rokeach, 1982: 178) it could be possible that males, as we 11 as females, will be delegated to the inferior status of sex object: after all, "it sells, doesn't it?" 
REFERENCES

Aaker, D. and J. Myers 1975. Advertising Management. Englewood Cliffs, N.J.: Prentice-Hall, in Leiss et al. 1986. Social Communication in Advertising, p. 41.

Argyle, M., V. Salter, H. Nicholson, M. Williams, and P. Burgess 1970. "The Communication of Inferior and Superior Attitudes by Verbal and Nonverbal Signals." British Journal of Social and Clinical Psychology, 9, pp. 222-231.

Atkin, C. and M. Block 1981. "Content and Effects of Alcohol Advertising." Report submitted to the Bureau of Alcohol, Tobacco and Firearms, the Federal Trade Commission, the National Institute on Alcohol Abuse and Alcoholism, and the Department of Transportation (Nat. Tech. Inform. Serv., Pub. No. 82-123142). Springfield, Va., cited in Strickland et a1. 1982. "A Content Analysis of Beverage Alcohol Advertising: I. Magazine Advertising," pp. 655-682.

1984. "A Reply to Strickland." Journal of Studies on Alcohol, 45 (1), pp. 93-100.

Atkin, C., J. Hocking, and M. Block 1984. "Teenage Drinking: Does Advertising Make a Difference?" Journal of Communication, 34 (2), Spring, pp. 157-167.

Bandura, A., E. Blanchard, and B. Ritter 1969. "Relative Efficacy of Desensitization and Modeling Approaches for Inducing Behavioral, Affective, and Attitudinal Changes." Journal of Personality and Social Psychology, 13 (3), pp. 173-199.

Beckman, L. 1975. "Women Alcoholics: A Review of Social and Psychological Studies." Journal of Studies on Alcohol, 36, pp. 797-824.

Belfer, M., R. Schader, M. Carroll and J. Harmatz 1971. "Alcoholism in Women." Archives of General Psychiatry, 25, pp. 540-544 cited in Rat Iiff and Burkhart 1984. "Sex Differences in Motivations for and Effects of Drinking Among College Students," pp. 26-32.

Benet, J. 1978. "Conclusion: Will Media Treatment of Women Improve," in Tuchman et al. (Eds.) 1978. Hearth and Home, pp. 266-271. 
Berger, J. 1979. Ways of Seeing. British Broadcasting System and London: Penguin Books.

Berger, P. and T. Luckmann 1967. The Social Construction of Reality. Garden City, N.Y.: Anchor Books, Doubleday and Company, Inc.

Bord in, R. 1981. Woman and Temperance: The Quest for Power and Liberty, 1873-1900. Philadelphia: Temple University Press.

Breed, W. and J. DeFoe 1979. "Themes in Magazine Alcohol

Advertisements: A Critique." Journal of Drug Issues, 9, pp. 511-522.

1980. "Mass Media, Alcohol and Drugs: A New Trend." Journal of Drug Education, 10 (2) pp. 135-43.

1981. "Risk and Alcohol Lifestyle Advertising." Abstract and Review, Alcohol and Driving, 2 (9), pp. 5-10, cited in

Strickland et a1. 1982. "A Content Analysis of Beverage Alcohol Advertising: I. Magazine Advertising," pp. 655-682.

Broverman, I., S. Voge1, D. Broverman, F. Clarkson, and P. Rosenkratz 1972. "Sex-Role Stereotypes: A Current Appraisal." Journal of Social Issues, 28 (2), pp. 59-78.

Busby, L. 1975. "Sex Role Research on the Mass Media." Journal of Communication, 25 (4), Autumn, pp. 107-131.

Butcher, H. et a1. 1981. "Images of Women in the Media," in Cohen and Young (Eds.), The Manufacture of News, pp. 317-326.

Cadwe11, F. 1971. Statement quoted in Komisar. The Image of Women in Advertising, p. 231 .

Cahalan D., I. Cisin, H. Crossley 1969. American Drinking Practices: A National Study of Drinking Behavior and Attitudes. New Brunswick, N.J.: Rutgers Center of Alcohol Studies, cited in Whitehead and Ferrence 1976. "Women and Children Last," in Greenblatt and Schuckit (Eds.), Alcoholism Problems in Women and Children, pp. 163-192.

Ceulemans, M. 1977. "Het Vrouwbeeld in de Reclame," Communicatie, 7 (3) Autumn, pp. 1-8, in Ceulemans 1979. Mass Media, p. 11. 1979. Mass Media: The Image, Role, and Social Conditions of Women. New York: United Nations Educational Scientific and Cultural Organization (UNESCO).

Chafe, W. 1979. Women and Equality: Changing Patterns in American Culture. New York: Oxford University Press. 
Chafetz, J. 1974. Masculine/Feminine or Human? An Overview of the Sociology of Sex Roles. Itasca, I1 I.: F.E. Peacock Publishers, Inc.

Chilcote, S. Jr. 1976. "Media Images of Alcohol: The Effects of Advertising and Other Media on Alcohol Abuse." Statement at Subcommittee on Alcoholism and Narcotics Hearings, March 11, pp. 210-219.

Cisin, I. 1982. "Formal and Informal Social Controls Over Drinking," pp. 145-158 in Ewing and Rouse (Eds). Drinking: Alcohol in American Society--Issues and Current Research.

Cohen, S. and J. Young (Eds.) 1981. The Manufacture of News. Beverly Hills: Sage Publications.

Courtney, A. and S. Lockeretz 1971. "A Woman's Place: An Analysis of the Roles Portrayed by Women in Magazine Advertisements." Journal of Marketing Research, VIII, February, pp. 92-95.

Courtney, A. and T. Whipple 1974. "Women in T.V. Commercials." Journal of Communication, 24 (2), Spring, pp. 110-118.

Crick, R. 1984. "Sweeping Changes in Liquor Advertising Suggested," The Oregonian, March 27, p. B1.

Cu11, J. and R. Hardy 1973. "Language Meaning (Gender Shaping) Among Blind and Sighted Students." The Journal of Psychology, 83, p. 334.

Culley, J. and R. Bennett 1976. "Selling Women, Selling Blacks." Journal of Communication, 26 (4), Autumn, pp. 160-174.

Deckard, B. 1975. The Women's Movement: Political, Socio-Economic, and Psychological Issues. New York: Harper and Row, in Ceulemans 1979. Mass Media, p. 7.

Defleur, M. and S. Ball-Rokeach 1982. Theories of Mass Communication, 4th Edition. New York: Longman.

Demone, H. Jr. and H. Weschsler 1976. "Changing Drinking Patterns of Adolescents During the Last Decade," in Greenblatt and Schuckit (Eds.). Alcoholism Problems in Women and Children, pp. 195-210.

DeSaussure, F. 1966. Course in General Linguistics. New York: McGraw Hill, in Leiss et a1. 1986. Cormunication in Advertising, Pp. 150 .

Dispenza, J. 1975. Advertising the American Women. Dayton, Ohio: Pflaum Publishing, in Ceulemans 1979. Mass Media, p. 9. 
Distilled Spirits Council of the United States (DISCUS) 1975. Code of Good Practice. Washington, D.C.: DISCUS, in Marsteller and Karnchanapee 1980. "The Use of Women in the Advertising of Distilled Spirits: 1956-1979," pp. 1-12, and U.S. Congress, 1976 , p. 213.

1977. Summary of State Laws and Regulations Relating to Distilled Spirits, 22nd Edition. Washington, D.C.: Government Printing office.

Dominick, J. and G. Ranch 1972. "The Image of Women in Network TV Commercials." Journal of Broadcasting, 16 (3), pp. 259-265, cited in Busby 1975. "Sex Role Research on the Mass Media," pp. 107-131.

Eveslage, T., R. Ostman and R. Trager 1978. "Liquor Advertisements: A Peek into the Black Box of Strategy." Presented at the Eighth Annual Popular Culture Association Convention, Cincinnati, in Strickland et a1. 1982. "A Content Analysis of Beverage Alcohol Advertising: I. Magazine Advertising," pp. 655-682.

Ewing, J. and B. Rouse (Eds.) 1982. Drinking. Alcohol in American Society: Issues and Current Research. Chicago: Nelson-Hall.

Finn, T. and D. Strickland 1982. "A Content Analys is of Beverage Alcohol Advertising: II. Television Advertising." Journal of Studies on Alcohol, 43 (9), September, pp. 964-989.

Friedan, B. 1963. The Feminine Mystique. New York: N.W. Norton and $\mathrm{Co}$.

Gerbner, G. 1972. "Communication and Social Environment." Scientific American, September, pp. 153-160.

1978. "The Dynamics of Cultural Resistance," in Tuchman et al. (Eds.) 1978. Hearth and Home, pp. 46-47.

Gill, K. and D. Boyden (Eds.) 1988. Gale Directory of Publications Volume I: Catalog of Publications. Detroit: Gale Research

Glazer, N. 1980. "Overworking the Working Woman: The Double Day in a Mass Magazine." Women's Studies International Quarterly, 3, pp. 79-93.

Goffman, E. 1976. Gender Advertisements. San Francisco: Harper Colophon Books (Harper and Row, Publishers).

Gordon, E. 1943. The Wrecking of the Eighteenth Amendment. Francestown, N.H.: The Alcohol Information Press. 
Gornick, V. and B. Moran (Eds.) 1971. Women in Sexist Society. New York: Basic Books.

Gravesteyn, M. 1975. "Rolverandering Voor Vrouw in Autoreclame." Ariadne, 2, October, pp. 26-27, in Ceulemans 1979. Mass Media, p. 11 .

Green, R. and J. Money (Eds.) 1969. Transsexualism and Sex Reassignment. Baltimore, Md.: The John Hopkins University Press.

Greenblatt, M. and M. Schuckit (Eds.) 1976. Alcoholism Problems in Women and Children. San Francisco: Grune and Stratton.

Gusfield, J. 1955. "Social Structure and Moral Reform: A Study of the Woman's Christian Temperance Union." The American Journal of Sociology, LXI (3), November, pp. 221-232.

1963. Symbolic Crusade. Urbana, I11.: University of Illinois Press.

Hammond, R. 1976. Statement at U.S. Congress, Senate Committee on Labor and Public Welfare, Subcommittee on Alcoholism and Narcotics, pp. 196-202.

Hanson, D. 1974. "Drinking Attitudes and Behaviors Among College Students." Journal of Alcohol and Drug Education, 19, pp. 6-14, cited in Demone and Wechsler 1976. "Changing Drinking Patterns of Adolescents During the Last Decade," in Greenblatt and Schuckit (Eds.). Alcoholism Problems in Women and Children, p. 198.

Harpers Magazine 1936 (April). Cited in E. Gordon 1943. The Wrecking of the Eighteenth Amendment. Francestown, N.H.: The Alcohol Information Press, p. 225.

Harris, R. and A. Shelton 1962. Advertising and the Public. London: Andre Deutsch, in Vestergaard and Schroder 1985. The Language of Advertising, p. 2 .

Haug, W. 1971. "Kritik der Warenasthetik." Frankfurt am Main: Suhrkamp, in Vestergaard and Schroder 1985. The Language of Advertising, p. 9.

Heilbronn, L. 1987. "The Semiotics of Alcohol: A Consideration of Alcohol Consumption on Television in the Context of Current Communications Research." Unpublished paper, Department of Sociology, University of California, Berkeley, CA 94720. 
Henley, N. and B. Thorne 1975. She Said/He Said: An Annotated Bibliography of Sex Differences in Language, Speech, and Nonverbal Communication. Pittsburgh: KNOW, Inc.

1977. "womanspeak and manspeak: sex differences and sexism in communication, verbal and nonverbal," in Sargent 1977. Beyond Sex Roles.

Henstra, P. and L. Pinckaers 1976. "Het Beeld Van d Vrouw in de Reclame: 1965-1975." Paper presented at the Conference on Advertising and Women, Erasmus University, Rotterdam, February, in Ceulemans 1979. Mass Media, p. 11 .

Higgins, P. 1980. Outsiders in a Hearing World: A Sociology of Deafness. Beverly Hills: Sage Publications.

Holahan, C. and C. Stephan 1981. "When Beauty Isn't Talent. The Influence of Physical Attractiveness, Atitudes Toward Women, and Competence on Impression Formation." Sex Roles, 7, pp. 867-876.

Holsti, 0. 1969. Content Analysis for the Social Sciences and Humanities. Reading, Mass.: Addison-Wesley in Ogilvie et a1., 1982. "Computer-Aided Content Analysis," p. 221.

Hope, E. 1972. "Knowledge of Smoking and Drinking." Journal of American College Health Association, 20, PP. 219-229, cited in Demone and Wechsler 1976, "Changing Drinking Patterns of Adolescents During the Last Decade," p. 198.

Hornik, E. 1977. The Drinking Woman. New York: Association Press.

Howland, R. and J. Howland 1982. "200 Years of Drinking in the United States: Evolution of the Disease Concept," pp. 39-60 in Ewing and Rouse (Eds.). Drinking: Alcohol in American Society.

Janus, N. 1977. "Research on Sex-Roles in the Mass Media: Toward a Critical Approach." Insurgent Sociologist, 7, Summer, pp. $19-31$.

Keller, G. 1980. Statement quoted in Marsteller and Karnchanapee 1980. "The Use of Women in the Advertising of Distilled Spirits: 1956-1979," p. 5.

Key, W. 1972. Subliminal Seduction. New York: Signet.

1976. Media Sexploitation. New York: Signet.

1976. Statement at U.S. Congress, Senate Committee on Labor and Public Welfare, Subcomittee on Alcoholism and Narcotics, pp. 173-187. 
Kleinke, C. and C. Hinrichs 1983. "College Adjustment Problems and Attitudes Toward Drinking Reported by Feminine, Androgynous, and Masculine College Women." Psychology of Women Quarter1y, 7 (4), Summer, pp. 373-382.

Kohn, P. and R. Smart 1987. "Wine, Women, Suspiciousness and Advertising." Journal of Studies on Alcohol, 48 (2), pp. 161-166.

Komisar, L. 1971. "The Image of Women in Advertising," in Gornick and Moran (Eds.) 1971. Women in Sexist Society.

Krippendorff, K. 1980. Content Analysis: An Introduction to its Methodology. Beverly Hills, Calif.: Sage Publications.

Lasswel1, H. 1948. "The Structure and Function of Communication in Society," in Bryson (Ed.). The Communication of Ideas, pp. 37-51, cited in Tuchman et a1. (1978). Hearth and Home, p. 3.

Leech, G. 1966. English in Advertising: A Linguistic Study of Advertising in Great Britain. London: Longmans.

Leiss, W., S. Kline, and S. Jhally 1986. Social Communication in Advertising. New York: Metheun, Inc.

LeMoncheck, L. 1985. Dehumanizing Women. Totowa, NJ: Rowman and Allanheld.

Lender, M. and K. Karnchanapee 1977. "Temperance Tales: Antiliquor Fiction and American Attitudes Toward Alcoholics in the Late 19 th and Early 20th Centuries." Journal of Studies on Alcohol, 38 (7), pp. 1347-1370.

Lender, M. and J. Martin 1982. Drinking in America. New York: The Free Press.

Levitt, T. 1970. "The Morality (?) of Advertising." Harvard Business Review, 48, in Leiss et al., 1986. Social Communication in Advertising, p. 41 .

Linder, S. 1970. The Harried Leisure Class. New York: Columbia University Press, in Leiss et al., 1986. Social Communication in Advertising, p. 140 .

Lisansky, E. 1958. "The Woman Alcoholic." Annals of the American Academy of Politica 1 and Social Science, 315, pp. 73-81, cited in Ratliff and Burkhart 1984 . "Sex Differences in Motivations for and Effects of Drinking Among College Students," pp. 26-32. 
Linsky, A. 1970-71. "Theories of Behavior and the Image of the Alcoholic in Popular Magazines 1900-1966." Public Opinion Quarter1y, 34, Winter, pp. 573-581.

Lipman-Blumen, J. 1984. Gender Roles and Power. Englewood Cliffs, N.J.: Prentice-Hall, Inc.

Long, M. and R. Simon 1974. "The Roles and Statuses of Women on Children and Family TV Programs." Journalism Quarterly, 51

(1), Spring, pp. 107-160.

Looney, M. 1976. Statement at U.S. Congress, Senate Committee on Labor and Public Welfare, Subcommittee on Alcoholism and Narcotics.

Loree, M. 1977. L'image de 1a Femme Dans la Publicite Nord-Americaine et Francaise, in Michel (Ed.). Femmes, Sexisme et Societes, pP. 133-145, cited in Ceulemans 1979. Mass Media, Pp. 11-12.

Maccoby, E. and C. Jack1in 1974. The Psychology of Sex Differences. Stanford, Calif.: Stanford University Press, in Lipman-Blumen, Gender Roles and Power, p. 56.

MacKay, D. 1983. "Prescriptive Grammar and the Pronoun Problem," in Thorne et a1. Language Gender and Society, pp. 38-53.

Manley, P. 1984. "Ban on Alcohol Ads Urged," The Oregonian, May 25, p. D8.

Marryat, F. 1968. Statement quoted in Winkler 1968. "Drinking on the American Frontier," p. 419.

Marsteller, P. and K. Karnchanapee 1980. "The Use of Women in the Advertising of Distilled Spirits: 1956-1979." Journal of Psychedelic Drugs, 12 (1), January-March, Pp. 1-12.

Mayo, C. and N. Henley (Eds.) 1981. Gender and Nonverbal Behavior. New York: Springer-Verlag.

McLachlan, J. 1977. "A Scale for the Evaluation of Psychological Distress." Journal of Clinical Psychology, 33, Pp. 159-161, cited in Ratiff and Burkhart 1984. "Sex Differences in Motivations for and Effects of Drinking Among College Students," pp. 26-32.

McLachlan, J., R. Walderman, D. Birchmore and L. Marsden 1979. "Self-Evaluation, Role Satisfaction, and Anxiety in the Woman Alcoholic." International Journal of Addiction, 14, pp. 809-832, cited in Ratliff and Burkhart 1984. "Sex Differences in Motivations for and Effects of Drinking Among College Students," Pp. 26-32. 
Miles, B. 1975. Channeling Children. Sex Stereotyping in Prime Time TV, in Ceulemans (1979). Mass Media, p. 8 .

Miller, S. 1975. "The Content of News Photos: Women's and Men's Roles." Journalism Quarterly, 52 (1), Spring, pp. 70-75.

Millett, K. 1970. Sexual Politics. Garden City, NY: Doubleday and Company, Inc.

Millum, T. 1975. Images of Woman: Advertising in Women's Magazines. London: Chatto and Windus, in Ceulemans 1979. Mass Media.

Milman, D. and W. Su 1973. "Patterns of Drug Usage Among University Students: Very Heavy Use of Marihuana and Alcohol by Undergraduates." Journal of American College Health Association, 21, pp. 181-187, cited in Demone and Wechsler 1976. "Changing Drinking Patterns of Adolescents During the Last Decade," p. 198.

Moore, T. 1984. "Broadcasters Oppose Shift in OLCC and Rules," The Oregonian, May 19, p. D4.

National Advertising Review Board 1975. Advertising and Women: A Report on Advertising Portraying or Directed to Women. New York: National Advertising Review Board, in Ceulemans 1979. Mass Media, and in Marsteller and Karnchanapee 1980. "The Use of Wornen in Advertising of Distilled Spirits: 1956-1979," pp. $1-12$.

National Institute on Alcohol Abuse and Alcoholism 1978. Third Special Report to the U.S. Congress on Alcohol and Hea1th From the Secretary of Health, Education, and Welfare, June. Washington, D.C.: U.S. Department of Health, Education, and Welfare.

New York Times Magazine 1972. A letter on June 18 cited in Busby 1975. "Sex Role Research on the Mass Media," p. 110.

O'Donne11, W. and K. O'Donnell 1978. "Update: Sex Role Messages in T.V. Commercials." Journal of Communication, 28, Winter, pp. 156-158.

Ogilvie, D., P. Stone and E. Kelly 1982. "Computer-Aided Content Analysis," in Smith and Manning, 1982. Qualitative Methods, pp. 219-246.

01iver, R. 1981. "Advertising and Society" in Advertising in Canada: Its Theory and Practice. P. Zarry and R. Wilson (Eds.). Toronto: McGraw-Hill Ryerson, cited in Leiss et a1. 1986. Social Communication in Advertising, p. 40. 
Packard, V. 1957. The Hidden Persuaders. New York: D. McKay.

Pfautz, H. 1962. "Image of Alcohol in Popular Fiction: 1900-1904 and 1946-1950." Quarterly Journal of Studies on Alcohol, 23 (1) pp. $131-146$.

Pingree, S., R. Hawkins, M. Butler, and W. Paisley 1976. "A Scale for Sexism." Journal of Communication, 26 (4), Autumn, pp. 193-201.

Pittman, D. and M. Lambert 1978. Alcohol, Alcoholism, and Advertising: A Preliminary Investigation of Asserted Associations. St. Louis: Washington University Social Science Institute, in Strickland et al. 1982. "A Content Analysis of Beverage Alcohol Advertising: I. Magazine Advertising," pp. 655-682.

Plumer, R. 1975. Sexual Stigma: An Interactionist Account. Boston: Rout ledge and Kegan Paul.

Poe, A. 1976. "Active Women in Ads." Journal of Communication, 26 (4) Autumn, Pp. 185-192.

Pope, D. 1983. The Making of Modern Advertising. New York: Basic Books, in Leiss et al. 1986 . Social Communication in Advertising, p. 40 .

Ratliff, K. and B. Burkhart 1984. "Sex Differences in Motivations for and Effects of Drinking Among College Students." Journal of Studies on Alcohol, 45 (1), pp. 26-32.

Reekie, W. 1974. Advertising: Its place in Political and Managerial Economics. London: Macmilitan, in Vestergaard and Schroder 1985. The Language of Advertising, pp. 6-7.

Ritzer, G. 1980. Sociology: A Multiple Paradigm Science, Revised Edition. Rockleigh, N.J.: Al1yn and Bacon, Inc.

Robertson, I. 1987. Sociology, 3rd Edition. New York: Worth Publishers.

Rocard, G. and Gutman C. 1968. Sois Belle et Achete: La Publicite et les Femmes. Paris: Ed. Gonthier, in Ceulemans $1 \overline{979}$. Mass Media, P. 11 .

Root, J. 1984. Pictures of Women: Sexuality. Boston: Pandora Press.

Rotzo11, K., J. Haefner, and C. Sandage 1976. Advertising and Society: Perspectives Toward Understanding: Columbus, Ohio: Copywright Grid, in Leiss et a1. 1986. Social Communication in Advertising, p. 40. 
Rouse, E. 1984. "Ethnic Image in Ads Transformed," The Oregonian, May 20, P. D5.

Rubin, J., F. Provenzano, and Z. Luria 1974. "The Eye of the Beholder: Parents' Views on Sex of Newborns." American Journal of Orthopsychiatry, 44 (4), pp. 512-19, cited in Lipman-Blumen 1984. Gender Roles and Power, pp. 54-55.

Sandage, C. and V. Fryburger (Eds.) 1960. The Role of Advertising. Homewood, Ill.: Richard Irwin, in Leiss et al. 1986. Social Communication in Advertising, p. 40 .

Sargent, A. 1977. Beyond Sex Roles. San Francisco: West Publishing Company.

Schutz, A. 1962. Collected Papers, Vol. I. The Hague: Nijhoff, in Berger and Luckmann 1967. Social Construction of Reality, p. 16.

Scott, W. 1955. "Reliability of Content Analysis: The Case of Nominal Scale Coding," Public Opinion Quarterly, 17, pp. $281-287$.

Screen Actors Guild 1974. "The Relative Roles of Men and Women in Television Commercials." A survey conducted by the SAG-New York Branch Women's Conference Committee, November 13, in Ceulemans 1979. Mass Media, p. 8.

Serbin, L., K. O'Leary, R. Kent, and I. Tonick 1973. "A Comparison of Teacher Response to the Pre-Academic and Problem Behavior of Boys and Girls." Child Development, 44, pp. 796-804, cited in Lipman-B lumen 1984 . Gender Roles and Power, p. 56

Sexton, D. and P. Haberman 1974. "Women in Magazine Advertisements." Journal of Advertising Research, 14 (4), August, pp. 41-46.

Shapiro, M. 1984. "Metaphor in the Philosophy of the Social Sciences." Language and Politics, pp. 195-214.

Shultz, M. 1975. "The Semantic Derogation of Women," in Thorne and Henley (Eds.) 1975. Language and Sex, pp. 64-75.

Smith, R. and P. Manning 1982. Qualitative Methods, Vo1. II: A Handbook of Social Science Methods. Cambridge, Mass.: Ballinger.

Sternglanz, S. and L. Serbin 1974. "An Analysis of the Sex Roles Presented on Children's Television Programs." Developmental Psychology, 10 (5), in Janus 1977. "Research on Sex-Roles in the Mass Media," pp. 19-31. 
Stoller, R. 1968. Sex and Gender: On the Development of Masculinity and Feminity. New York: Science House.

Stone, P., D Dunphy, M. Smith, and D. Ogilvie 1966. The General Inquirer: A Computer Approach to Content Analysis. Cambridge: M.I.T. Press, in Ogilvie et a1., "Computer-Aided Content Analysis," p. 221 .

Strickland, D., T. Finn and M. Lambert 1982. "A Content Analysis of Beverage Alcohol Advertising: I. Magazine Advertising." Journal of Studies on Alcohol, 43 (7), pp. 655-682.

Thaxton, L. and C. Jaret 1985. "Singers and Stereotypes: The Image of Female Recording Artists." Sociological Inquiry, 55 (3), Summer, pp. 239-263.

Thorne, B. and N. Henley (Eds.) 1975. Language and Sex: Difference and Dominance. Rowley, Mass.: Newberry House.

Thorne, B., C. Kramarae and N. Henley (Eds.) 1983. Language, Gender, and Society. Rowley, Mass.: Newberry House.

Tuchman, G. 1978. "Introduction: The Symbolic Annihilation of Women by the Mass Media," in Tuchman et a1. 1978. Hearth and Home, pp. 3-38.

1979. "Women's Depiction by the Mass Media." Signs: Journal of Women in Culture and Society, 4 (31), pp. 528-542.

Tuchman, G., A. Daniels, and J. Benet (Eds.) 1978. Hearth and Home: Images of Women in the Mass Media. New York: Oxford University Press.

Umiker-Sebeok, J. 1981. "A View From American Magazine Advertisements," in Mayo and Henley. Gender and Nonverbal Behavior, pp. 209-252.

U.S. Congress 1976. Senate Committee on Labor and Public Welfare, Subcommittee on Alcoholism and Narcotics. Media Images of Alcohol; the Effects of Advertising and other Media on Alcohol Abuse, Hearings 94th Congress, 2d Session, March 8. Washington, D.C.: U.S. Government Printing Office.

U.S. Department of Health, Education, and Welfare 1971. First Special Report to the U.S. Congress on Alcohol and Health, from the Secretary of Health, Education, and Welfare, December. Washington, D.C.: U.S. Government Printing Office.

1974. Second Special Report to the U.S. Congress on Alcohol and Health: New Knowledge. Washington, D.C.: U.S. Government Printing $\overline{\text { Office. }}$ 
Van De Maele, B. 1978. Het Beeld Van de Vrouw in de Reclame Van de Nederlandstalige Vrouwenbladen: Een Inhoudsanalyse, Catholic University of Leuven, in Ceulemans 1979. Mass Media, p. 11.

Venkatesan, M. and J. Losco 1975. "Women in Magazine Ads: 1959-71." Journa1 of Advertising Research, 15 (5), October, pp. 49-54.

Verna, M. 1975. "The Female Image in Children's TV Commercials." Journal of Broadcasting, 19 (3), Summer, pp. 301-308.

Vestergaard, Torben and Kim Schroder 1985. The Language of Advertising. United Kingdom: Basil Blackwell Publisher, Ltd.

Viewpoint 1975. "Liquor Industry Should Clean Up Ads or Face New Regulations." Article submitted at U.S. Congress, Senate Conmittee on Labor and Public Welfare, Subcommittee on Alcoholism and Narcotics.

Wagner, L. and J. Bano 1973. "A Woman's Place: A Follow-Up Analysis of the Roles Portrayed by Women in Magazine Advertisements." Journal of Marketing Research, X, May, pp. 213-214.

Walum, L. 1977. The Dynamics of Sex and Gender: A Sociological

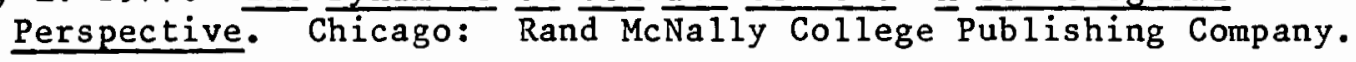

Ward, D. and J. Balswick 1978. "Strong Men and Virtuous Women." Pacific Sociological Review, 21 (1), January, pp. 45-53.

Warren, D. 1978. "Commercial Liberation." Journal of Communication, 28, (1), winter, pp. 169-173.

Weibel, K. 1977. Mirror, Mirror. Garden City, NY: Anchor Press.

Weitzman, L. 1979. Sex Role Socialization: A Focus on Women. Palo Alto, Calif.: Mayfield Publishing Co.

Whitehead, P. and R. Ferrence 1976. "Women and Children Last: Implications of Trends in Consumption for Women and Young People," in Greenblatt and Schuckit (Eds.). Alcoholism Problems in Women and Children, pp. 163-192.

Whiting, B. and C. Pope 1974. "A Cross-Cultural Analysis of Sex Differences in the Behavior of Children Aged Three to Eleven." Journa 1 of Social Psychology, 92, in Lipman-Blumen 1984. Gender Roles and Power, pp. 54-55.

Williamson, J., D. Karp, J. Dalphin, and P. Gray 1982. The Research Craft: An Introduction to Social Research Methods, Second

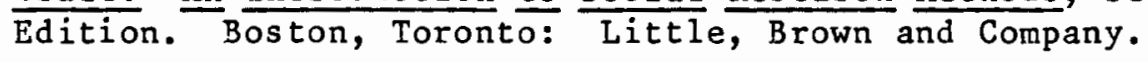


Williamson, J. 1978. Decoding Advertisements. Boston: Marion Boyars Publishers, Ltd.

Wilsnack, S. 1976. "The Impact of Sex Roles and Women's Alcohol Use and Abuse," in Greenblatt and Schuckit (Eds.). Alcoholism Problems in Women and Children, Pp. 37-63.

Winkler, A. 1968. "Drinking on the American Frontier." Quarterly Journal of Studies on Alcohol, 29 (2), June, Pp. 413-445.

Winokur, G. and P. Clayton 1968. "Family History Studies: IV. Comparison of Male and Female Alcoholics." Quarterly Journal on Studies of Alcohol, 29, pp. 885-891.

Worth, S. and L. Gross 1974. "Symbolic Strategies." Journal of Communication, 24, Autumn, pp. 27-39.

Zito, G. 1975. Methodology and Meaning. New York: Praeger Publishers. 
APPENDIX A

IN-DEPTH CODING SHEET

No.

\section{Structural Characteristics}

1. Magazine Name:

a. Playboy

b. Cosmopolitan

c. Newsweek

2. Year of Issue Number of Pages

3. Brand of Beverage

Type of Beverage:
a. vodka
b. bourbon
c. $s \cot c h$
d. canadian
e. other whiskey
g. rum
h. brandy
f. gin
j. 1iqueur
k. other
i. tequila

4. Size of Ad:

a. under half page

b. from half page to less than full page

c. full page

d. more than full page to less than full page

e. two or more pages

5. Color Format:
a. black or white
b. color
c. mixed

6. Human Mode1(s) (Full or Partial)
a. yes
b. no

\section{Content Categories}

I. Techniques of Presentation

1. "Caption of the Ad": 
2. Environment:
a. tavern, lounge, restaurant
b. indoors - party, get-together, etc.
c. outdoors - party, get-together, etc.
d. outdoors - beach, mountains, etc.
e. fictional setting, no background, other

3. Display of Product:

a. number of beverage containers

b. number of drinks portrayed

* If 非Males, 非Females: a. none $b$. one c. two d. three or more

*4. Relation to Product:

a. holding drinks

b. drinking

c. decorative (i.e., no functional relationship to product

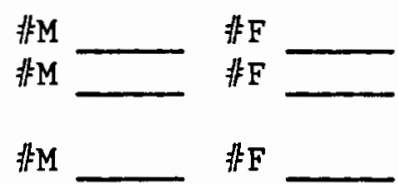

5. Promotional Techniques:
a. recipe offers
b. claims of product purity
c. claims of naturalness
d. claims of caloric content
e. suggestions of how much to drink (i.e., heavy, in moderation, etc.
f. other suggested uses of the product:

II. Relevant Characteristics of Human Models

*A. Presentation:

1. Full Presentation of Mode1(s)

HN

非

2. Partial Presentation of Mode1(s)
a. hand (s) only
b. head (s) only
c. torso
d. other :

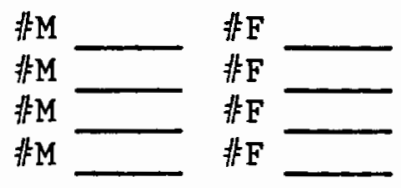

3. Dress Style:
a. formal
b. executive, professional
c. casual
d. swimwear
e. nightwear (p.j.'s, etc.)
f. other:

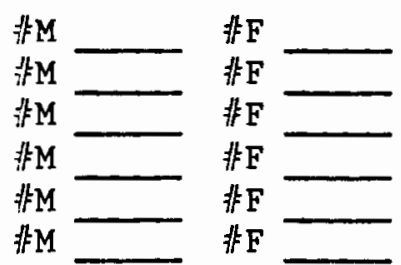


B. Physical Proximity to Others:

a. Low involvement

b. medium involvement

c. high involvement

d. "arm lock": females into males males into females

e. "shoulder lock": male's arm around female , female's arm around male

f. no other in ad

*C. Focus of Attention:

a. looking at the "audience" (spectator of the ad)

b. looking at the product

c. looking at others in the ad

d. looking at something in the ad, not the product or others

e. other:

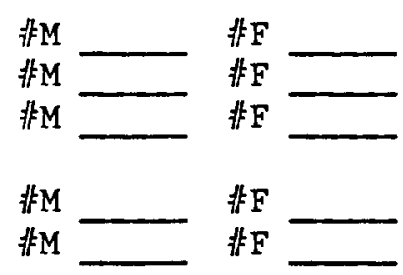

D. Relationa1 Posture (put an X beside $M$ applicable, if at a11 applicable):

a. greater girth/height

b. placed physically higher in ad

c. reclining position (lying on floors, beds, sofas, etc.)

d. head lowered relative to others, including viewer of the ad

e. covering self/face with hands

f. sucking/biting fingers

g. finger to finger position

h. more expansive expression ("flooding out of happiness")

i. hands tracing out 1 ines of an object, cradling it, caressing it, "just barely touching it"

j. hands grasping, manipulating, or holding object

k. mode 1 being shielded behind objects (wa11s, counters, others, etc.)

1. mode1(s) initiating "mock assaults" (throwing pillows, water, etc.)

m. mode1(s) on the receiving end of mock assaults (grabbed, pushed, etc.)

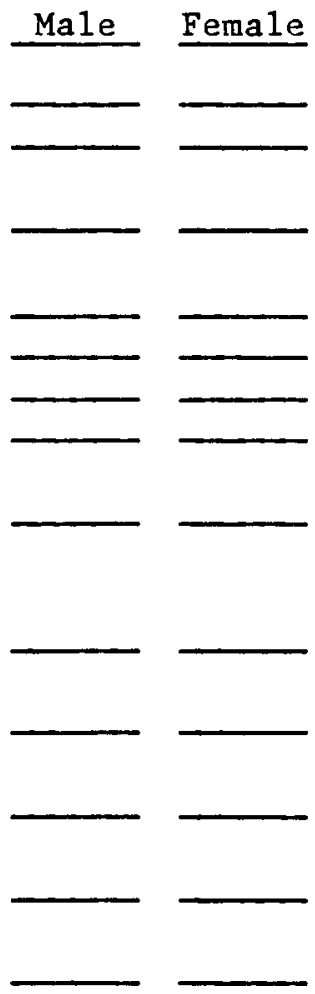

III. Themes and Appeals

1. Achievement and success

--Must refer to a specific event of some kind

- A particular success in work or competition of some kind --Awards, graduations, etc. 
Do not code this theme "present" for such things as:

--Completion of ordinary, everyday tasks (end of a hard day's work, etc.)

--Simple handshakes that are greetings rather than congratulations

--Success in general (social or economic status; see theme 11)

--Celebrations of events where congratulations are not earned (birthdays, anniversaries, holidays, etc.; see theme 10)

2. Self-reward (due to self-esteem)

--Reward yourself because you are worth it, you deserve it

--You deserve the best (our product)

--High self-esteem; you're number 1 , treat yourself to

Do not code this theme "present" for such things as:

--Gifts from or to others

--Buying a product without some implication that "you deserve it"

--Buying a round of drinks, without the suggestion that it is done because "you deserve it"

--Buying the product as a reward for some achievement (see theme 1)

3. Host (implication of MALES serving others)

4. Hostess (implications of FEMALES serving others)

- "Serve only the best; serve

--"A good host/hostess knows what to serve;

--Clear signs of serving others

Do not code this theme "present" for such things as:

-Get-togethers where "serving others" is not implied

5. Infornation (product-related)

--Specific references to calories, price

--Specific information about the process of ingredients

- How the process or ingredients differ from similar products

--Note: Frequently you see ads that give the appearance of presenting information but don't actually say much at all. These too will be for this category, since these ads are in fact informational appeals, code it as such

Do not code this theme "present" for such things as:

--Simple claims about the purity of the water used, the excellence of the grains used, etc.

6. (Close) Friendship

--Sincere portrayals of friendship

--Scenes showing close friends together

--Suggestions that you "share" the product, whether or not there is an explicit suggestion to share it with friends or someone close 
Do not code this theme "present" for such things as:

--Get-togethers that are simply a gathering of people who know each other (see theme 8)

--A male-female pair of "close friends" where love or sex might be more appropriate themes (see themes 9 and 12)

7. (Change-of-state) Relaxation

--Any change of state, drinking after (implied) work or play, etc.

- A suggestion of mood-alteration

- The suggestion that this product will help you unwind

Do not code this theme "present" for such things as:

--Picnics, parties, or other forms of recreation that do not represent change of pace or environment from the activity portrayed immediately beforehand

--Normal bar scenes or get-togethers that do not imply a change of state

8. Camaraderie

--Partying with friends; a get-together (this can be a bar scene)

--Picnics, outings, etc.; a shared experience; a social occasion

--Alcohol as a group-bonding; social lubricant

Do not code this theme "present" for such things as:

--A male-female pair where themes of love or sex may be more appropriate (see themes 9 and 12)

--A group where "close friendshp" may be more appropriate (see theme 6)

--A scene with fewer than three people

9. Love and Romance

- The words love, amore, etc.; a drawing of a heart, etc.

--Long-term relationship; romance, caring

- When it appears that romance is a more important ingredient in a relationship than sex

--Note: Frequently the relationship between a man and a woman in an ad is ambiguous (friendship, love, sex?). Consult the text for references to the relationship, or references that fall under one of these themes. If no such references exist, obviously the picture itself must suffice. Finally, just because you have a couple in the ad does not mean that you must code friendship, love, sex. Do so only if the "gestalt" of the ad leads you to such a decision.

Do not code this theme "present" for such things as:

--Close friendship or sex (see themes 6 and 12)

--Where brand name has the words love, amore, etc.

10. Special Occasions and Holiday Celebrations

- Birthdays, anniversaries, weddings, holidays, and banquets

- Celebration of events where congratulations are not earned

--Also, gifts from others (housewarmings, etc.) 
Do not code this theme "present" for such things as: --Graduations or other milestones that are earned (see theme 1)

11. "Genera1" Success

- An appeal to success or achievement as a general goal

--General references to success in terms of high social or economic status

--Attempts to associate the product with success

--Use of the word success in phrases such as "the road to success," the ladder of success, etc.

--Note: To the extent that this category is designed to pick up references to success not covered by theme 1 , the two types of success themes will usually be mutually exclusive.

Do not code this theme "present" for such things as:

--References to specific successes that more naturally fit under theme 1 (Success and Achievement)

12. Sexual Connotations

--References suggesting sexual encounter

- This can include references in the text of the ad such as naughty, discreet, tempting, kisses but never tells, etc.

--(Provocative) poses of models suggesting sexual availability or sexual encounter

--Puns such as "sip into something comfortable," "Get into shorts," etc.

- References not only to product but to model also; "I never say no to

--Provocative dress styles (low cut dresses, unbuttoned blouses, etc.)

Do not code this theme "present" for such things as:

--Where it appears love and romance is a more important ingredient in a relationship (see theme 9 and note) or close friendship (see theme 6)

--Get-togethers where no sexual connotations exist (see theme 8)

- Where model(s) are attractive yet not implying any sexual reference

13. Individuality

--Be unique; be a leader

- Be your own person; nonconformity appeals

- The individuality must be connected somehow with the product

--Reverse appeals such as "it's not for everybody"

- The appeal could be implicit by describing the unique characteristics of a model who uses the product

Do not code this theme "present" for such things as:

--Portrayals of attributes that are rare or scarce but not necessarily appeals to individuality

- Individuality that is not tied to the product somehow

--Appeals that claim that the product is unique without trying this uniqueness to the drinker (at least implicitly) 
14. Physica1 Activity

--Portrayal of the model(s) in moderately strenuous activity or sports

--The implication of some form of nonpaid work or physical exertion

- The presence of sports equipment, impllying that the model(s) in the ad have participated or willparticipate in that sport

--or (nonwork) activity where one goal is to keep in shape

Do not code this theme "present" for such things as:

- Scenes where the human model(s) are spectators at a sporting event

--Ads portraying models in some form of work (even if it is strenuous)

15. Quality

--The best money can buy

--Quality of the product, process, or ingredients

--Any use of complimentary adjectives

Do not code this theme "present" for such things as:

--Nonspecific descriptors such as "smooth"

- References to taste of product, with no specific quality claim

16. Tradition or Heritage

--Mention of the history or long-standing use of the product

--Reference to traditional or family formula or method

--Association with earlier era

--Quotes like "since 1893" in relatively large print

Do not code this theme "present" for such things as:

--Products that are imported but make no mention of an age-old tradition

--Simply the year the company began (in small print)

IV. Target Market

Most ads are "targeted" to a specific audience (consumer). Which audience do you think this ad is specifically "targeting"?

a. Males

b. Females

c. Both 
APPENDIX B

ABBREVIATED FORM OF CODING SHEET

No.

Structura1 Characteristics

1. Mag.

2. Yr.

; 非pg

3. Brand

; Type

4. Size

5. Color

6. Human Mode 1s

\section{Content Categories}

I. Techniques of Presentation

1. Caption:

2. Environment

3. Display: \#Cont. ; 非Drinks

4. Relationship to product:

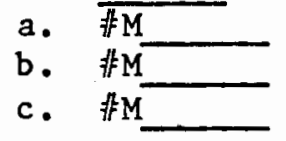

非

非

5. Promotional Tech.

\#F

II. Relevant Characteristics of Human Models

A. Presentation:

1. full presentation of mode1(s):

2. partial presentation of model(s):

a. hand (s) only

b. head (s) only

c. torso

d. other:

3. dress style:

a. formal

b. executive, professional

c. casua 1

d. swimwear

e. nightwear (P.J.'s, etc.)

f. other:

非M

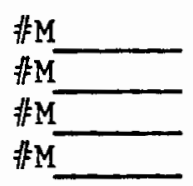

急F

非

非

\#F

\#F

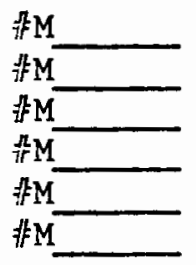

\# $\mathrm{F}$ \#F 作 \#F \#F 非 
B. Physical Proximity: ; ;

c. Focus of Attention:

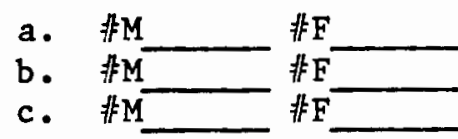

d. $\# M$ \#F

e. FM 非

D. Relational Posture:

Male Female

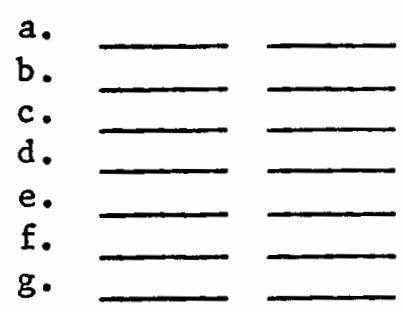

Male Female

h.

i.

j.

k.

1.

II.

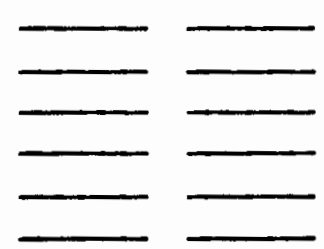

III. Themes and Appeals:

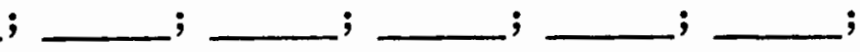

IV. Target Market:

Additional Comments: 


\section{APPENDIX C}

COMPUTER CODING OUTLINE

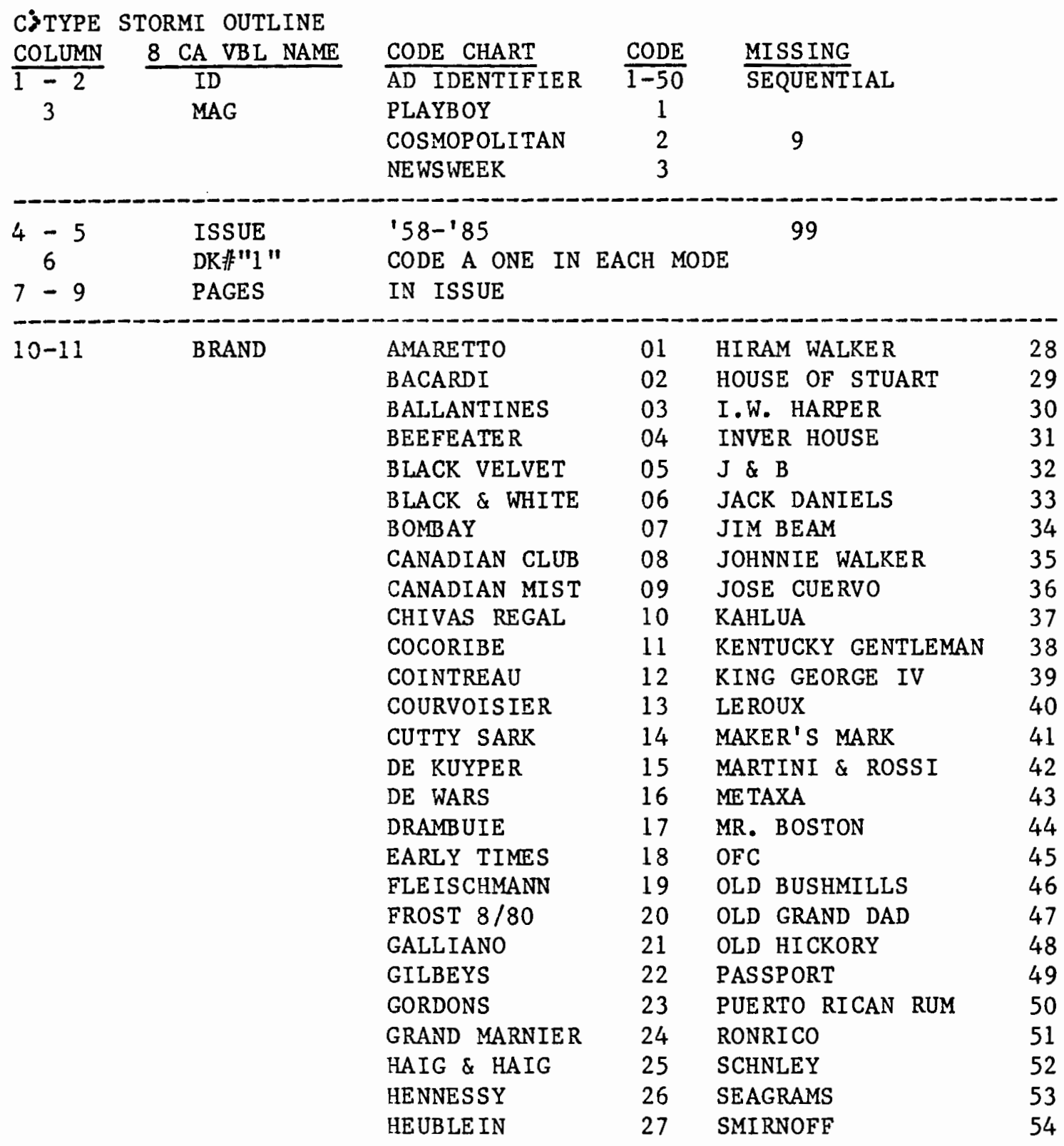




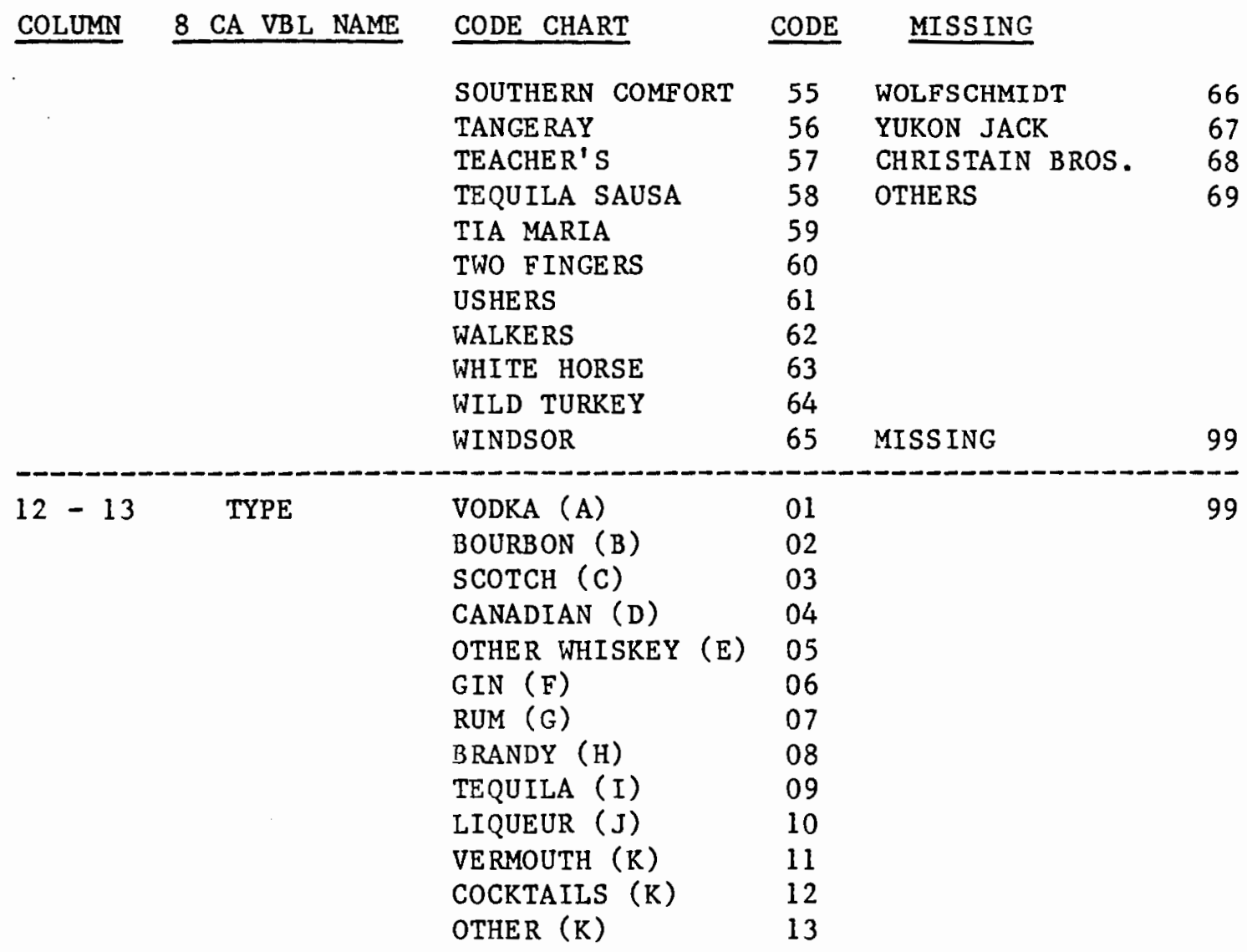

\begin{tabular}{|c|c|c|c|c|}
\hline 14 & SIZE & $\begin{array}{l}\text { UNDER } 1 / 2 \text { PG. (A) } \\
1 / 2-<\text { FULL PG. (B) } \\
\text { FULL PG. (C) } \\
\text { >FULL- } 2 \text { 2 FULL (D) } \\
2 \text { OR MORE PGS. (E) }\end{array}$ & $\begin{array}{l}1 \\
2 \\
3 \\
4 \\
5\end{array}$ & 9 \\
\hline 15 & COLOR & $\begin{array}{l}\text { BLACK \& WHITE (A) } \\
\text { COLOR (B) } \\
\text { MIXED (C) }\end{array}$ & $\begin{array}{l}1 \\
2 \\
3\end{array}$ & 9 \\
\hline 16 & HUMAN & $\begin{array}{l}\text { YES (A) } \\
\text { NO (B) }\end{array}$ & $\begin{array}{l}1 \\
2\end{array}$ & 9 \\
\hline 17 & ENVIR & $\begin{array}{l}\text { TAVERN, REST. (A) } \\
\text { INDOORS (B) } \\
\text { OUTDOORS PARTY (C) } \\
\text { OUTDOORS BEACH (D) } \\
\text { FICTIONAL (E) }\end{array}$ & $\begin{array}{l}1 \\
2 \\
3 \\
4 \\
5\end{array}$ & 9 \\
\hline $18-19$ & CONTNER & $\#$ OF CONTAINERS & _ & 99 \\
\hline $20-21$ & DRINKS & \# OF DRINKS & 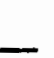 & 99 \\
\hline
\end{tabular}




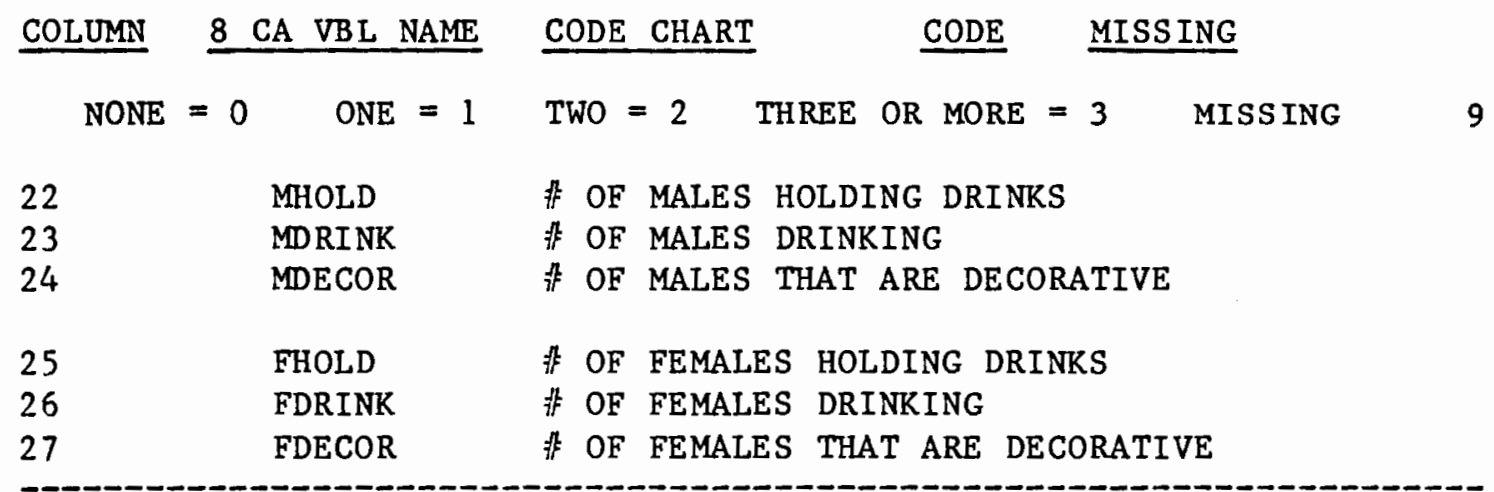

$\begin{array}{llllll}28 & \text { RECIPE } & 0 & \text { IF NOT PRESENT, } 1 \text { IF PRESENT (A) } \\ 29 & \text { PURITY } & 0 & \text { IF NOT PRESENT, } 1 \text { IF PRESENT (B) } \\ 30 & \text { NATURAL } & \text { O IF NOT PRESENT, I IF PRESENT (C) } \\ 31 & \text { CALORIC } & \text { O IF NOT PRESENT, I IF PRESENT (D) } \\ 32 & \text { SUGG DR } & 0 \text { IF NOT PRESENT, I IF PRESENT (E) } \\ 33 & \text { GIFT } & 0 \text { IF NOT PRESENT, I IF PRESENT (F) } \\ 34 & \text { OTHER } & 0 & \text { IF NOT PRESENT, I IF PRESENT (F) }\end{array}$

\begin{tabular}{|c|c|c|}
\hline $\mathrm{NONE}=0$ & $\mathrm{ONE}=1$ & THREE OR MORE $=3$ \\
\hline 35 & FULL $M$ & FULL PRESENTATION OF MALES \\
\hline 36 & FULL $F$ & FULL PRESENTATION OF FEMALES \\
\hline 37 & MHANDS & MALES HANDS ONLY \\
\hline 38 & MHEADS & MALES HEADS ONLY \\
\hline 39 & MTORSO & MALES TORSO ONLY \\
\hline 40 & MWAIST & MALES WAIST AND UP \\
\hline 41 & MaOTHER & MALES IN OTHER PRESENTATIONS (PARTIAL) \\
\hline 42 & FHANDS & FEMALES HANDS ONLY \\
\hline 43 & FHEADS & FEMALES HEADS ONLY \\
\hline 44 & FTORSO & FEMALES TORSO ONLY \\
\hline 45 & FWAIST & FEMALES WAIST AND UP \\
\hline 46 & FeOTHER & FEMALES IN OTHER PRESENTATIONS (PARTIAL) \\
\hline 47 & MFORMAL & MALES IN FORMAL DRESS \\
\hline 48 & MPROF & MALES IN EXECUTIVE, PROFESSIONAL DRESS \\
\hline 49 & MCASUAL & MALES IN CASUAL WEAR \\
\hline 50 & MSWIM & MALES IN SWIMWEAR \\
\hline 51 & MaP.J. & MALES IN NIGHTWEAR \\
\hline 52 & MaDRESS & MALES IN OTHER TYPES OF DRESS \\
\hline
\end{tabular}




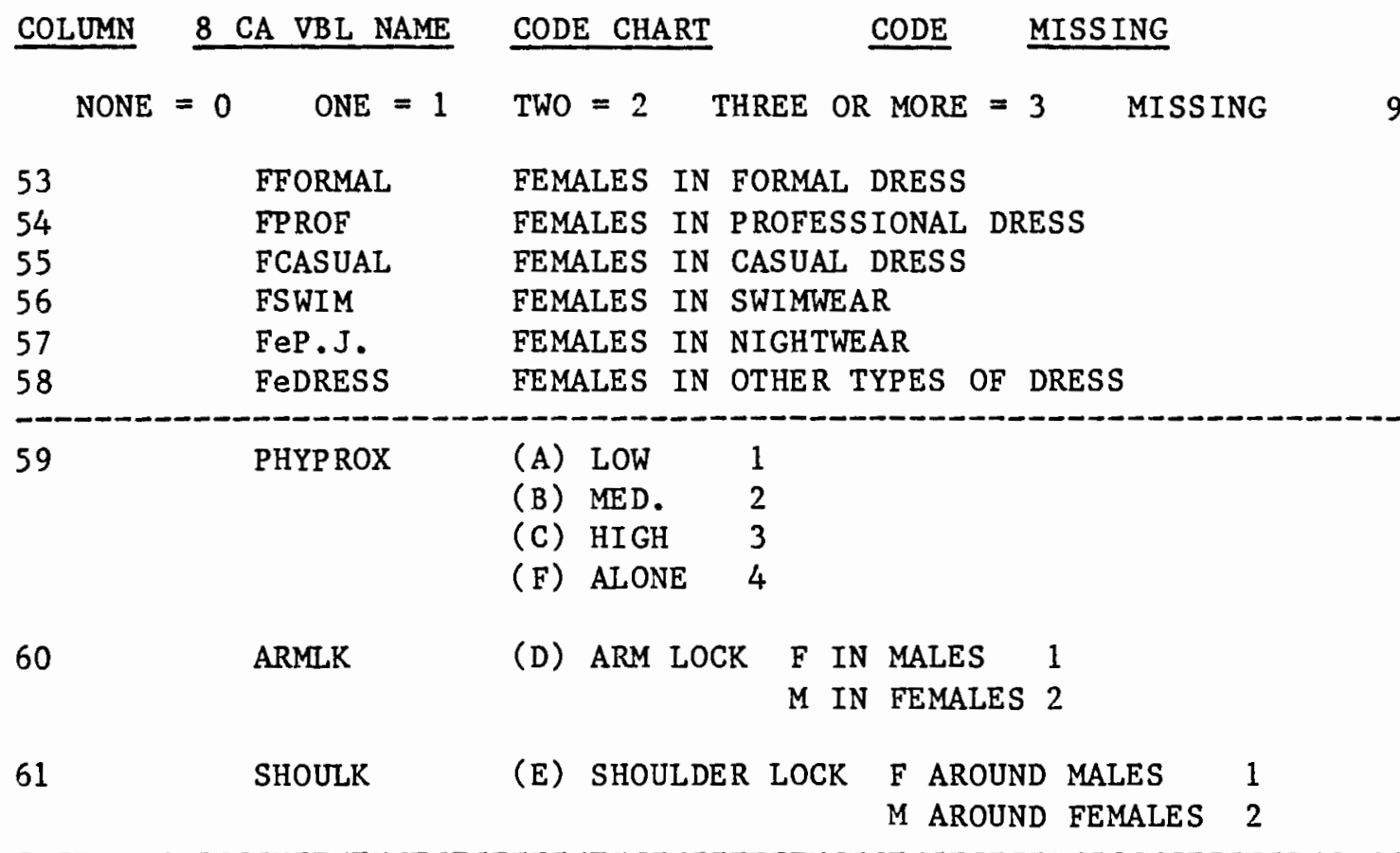

NONE $=0 \quad$ ONE $=1 \quad$ TWO $=2 \quad$ THREE OR MORE $=3 \quad$ MISSING

$\begin{array}{lll}62 & \text { AUDM } & \text { MALES LOOKING AT THE AUDIENCE (A) } \\ 63 & \text { PRODM } & \text { MALES LOOKING AT THE PRODUCT (B) } \\ 64 & \text { PEOPLEM } & \text { MALES LOOKING AT OTHERS IN AD (C) } \\ 65 & \text { SOMEM } & \text { MALES LOOKING AT SOMETHING IN THE AD (D) } \\ 66 & \text { OUTS IDEM } & \text { MALES LOOKING OUTSIDE AD, NOT AT AUD (E) } \\ 67 & \text { FOCUSM } & \text { MALES LOOKING AT SOMETHING, OTHER (E) } \\ 68 & \text { AUDF } & \text { FEMALES LOOKING AT THE AUDIENCE (A) } \\ 69 & \text { PRODF } & \text { FEMALES LOOKING AT THE PRODUCT (B) } \\ 70 & \text { PEOPLEF } & \text { FEMALES LOOKING AT OTHERS IN AD (C) } \\ 71 & \text { SOMEF } & \text { FEMALES LOOKING AT SOMETHING IN THE AD (D) } \\ 72 & \text { OUTSIDEF } & \text { FEMALES LOOKING OUTSIDE AD, NOT AT AUD (E) } \\ 73 & \text { FOCUSF } & \text { FEMALES LOOKING AT SOMETHING, OTHER (E) }\end{array}$

1 IF MALES 2 IF FEMALES 9 IF NEITHER OR MISSING

$\begin{array}{lll}74 & \text { HEIGHT } & \text { (A) GREATER GIRTH/HEIGHT } \\ 75 & \text { RECLINE } & \text { (C) RECLINING POSITION } \\ 76 & \text { HDSTRACE } & \text { (I) HANDS BARELY TRACING OBJECTS } \\ 77 & \text { HDSGRASP } & \text { (J) HANDS GRASPING OBJECTS } \\ 78 & \text { RECMOCK } & \text { (M) MODELS ON RECEIVING END OF MOCK ASSAULTS }\end{array}$




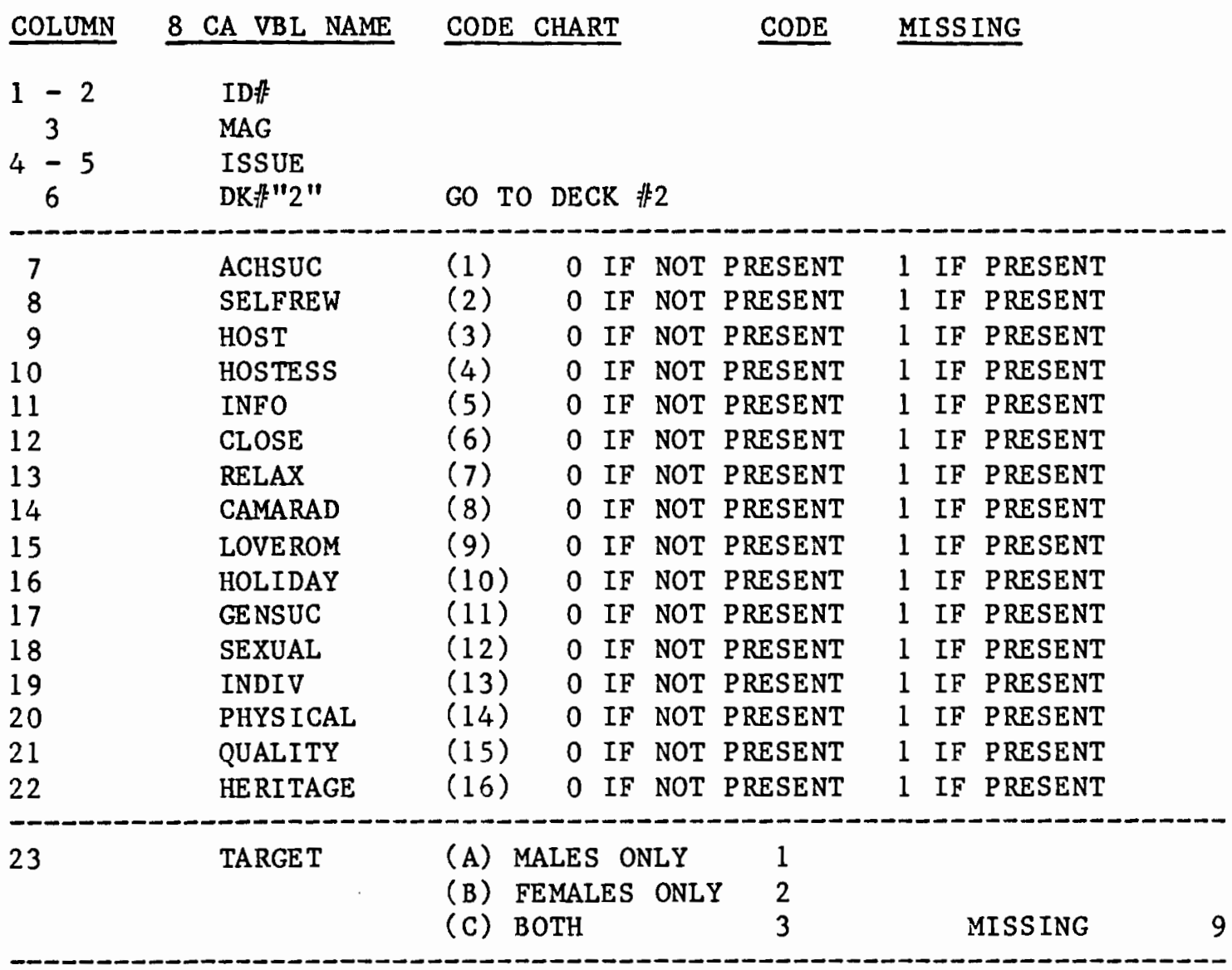

